University of Louisville

ThinkIR: The University of Louisville's Institutional Repository

Electronic Theses and Dissertations

$12-2014$

\title{
A magical country : stories from Appalachia.
}

James Eric Leary 1977-

University of Louisville

Follow this and additional works at: https://ir.library.louisville.edu/etd

Part of the Appalachian Studies Commons, Folklore Commons, and the Modern Literature Commons

\section{Recommended Citation}

Leary, James Eric 1977-, "A magical country : stories from Appalachia." (2014). Electronic Theses and Dissertations. Paper 1754.

https://doi.org/10.18297/etd/1754

This Doctoral Dissertation is brought to you for free and open access by ThinkIR: The University of Louisville's Institutional Repository. It has been accepted for inclusion in Electronic Theses and Dissertations by an authorized administrator of ThinkIR: The University of Louisville's Institutional Repository. This title appears here courtesy of the author, who has retained all other copyrights. For more information, please contact thinkir@louisville.edu. 


\title{
A MAGICAL COUNTRY: STORIES FROM APPALACHIA
}

By

James Eric Leary

B.A. Eastern Kentucky University, 2001

M.A. University of Louisville, 2005

\begin{abstract}
A Dissertation
Submitted to the Faculty of the

College of Arts and Sciences of the University of Louisville in Partial Fulfillment of the Requirements

for the Degree of
\end{abstract}

Doctor of Philosophy

Department of Humanities

University of Louisville

Louisville, Kentucky

December 2014 
Copyright 2014 by James Leary

All rights reserved 



\title{
A MAGICAL COUNTRY: STORIES FROM APPALACHIA
}

\author{
By \\ James Leary \\ B.A., Eastern Kentucky University, 2001 \\ M.A., University of Louisville, 2005
}

A Dissertation Approved on

November 24, 2014

by the following Dissertation Committee:

Dissertation Director

Dr. Annette Allen

Paul Griner

Dr. Selene Phillips

Dr. Michael Williams 


\section{ACKNOWLEDGMENTS}

From the University of Louisville, I would like to thank Professors Paul Griner, Michael Williams, Selene Phillips, and Alan Leidner for graciously agreeing to serve on my dissertation committee and guiding me through my scholarly and creative work.

I am also indebted to the love, friendship, and guidance of Jessica Maupin, Dan Maupin, Dr. Amy Tudor, Dr. Elijah Pritchett, Revely Culver, Dr. Julie Wade, Catherine Leary, Stacy Taylor, Bryan Scichilone, Betty Wilson, Julian Wilson, and Kathryn Leary. All of them have had a hand in this work and its completion.

Lastly, the work would not have been possible or fruitful without the advocacy and guidance of Professor Annette Allen, and I will always consider her a mentor and friend. 


\section{ABSTRACT \\ A MAGICAL COUNTRY: STORIES FROM APPALACHIA \\ James Leary}

November 24, 2014

Fairy tales and other forms of fantastic literature have fascinated children and adults for generations. The scholarship on these types of works indicate that many find their folkloric origins in oral storytelling, and those roots may be quite ancient. However, some of the earliest examples of recorded literature capture stories of magic and fantasy. The interplay between the oral and literary form remains a significant area of study and development for folk literature, and new artistic productions, termed variants in the scholarship, continue to appear frequently in contemporary American culture. The criticism and creative work presented here add to the outpouring of fairy tale variants and southern literature that have been so prevalent in the United States in the late twentieth and early twenty-first centuries.

The dissertation is divided into two main sections. Section I provides scholarly discussion on the history of fantastic literature, the history of scholarship on fairy tales, the value of production of fairy tale and related films in contemporary society, and indepths critical discussions of the sources and variants used to develop the body of fiction that follows.

Section II includes the collection of short fiction titled A Magical Country: Stories from Appalachia. This collection follows several traditions of the literary collection of 
oral stories, including a frame tale and rotating narrators. Five different storytellers share oral stories with each other and an extended audience in a rural Appalachian general store. The store serves as a focal point for the community where information, rumors, and successes are disseminated. Each of the five stories in the collection blends elements from fairy tales and Appalachian oral stories currently in circulation. All together, the collection of stories illustrate the concerns and perspectives of rural, southern Appalachia and the encroachment of contemporary life and problems from what is perceived as the outside world which is urban life and city dwellers. 


\section{TABLE OF CONTENTS}

PAGE

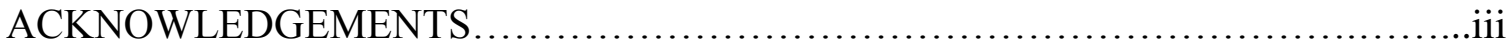

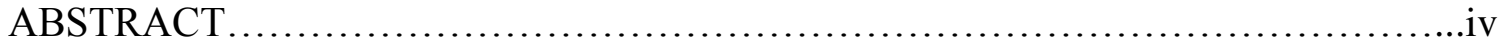

INTRODUCTION

SECTION I: Rural Conditions, Fairy Tales, and the Fantastic.........................................

CHAPTER I: Definitions of the Fairy Tales and the Fantastic...........................................

CHAPTER II: What Good Is a Magical Castle?: The Value of Fairy Tales and the Fantastic ............................................................... 16

CHAPTER III: Origin and Genesis of the Creative Work................................................26

CHAPTER IV: Structure: Frames and Short Fiction.......................................................34

CHAPTER V: Critical and Artistic Discussion of the Creative Work................................40

Roses and the Magic of Transformation in: The Consequences of Beastly Behavior"

"Shift the Clever Foal": In Kentucky, a Horse Will Go Farther Than a Cat"

"The Boy Who Went Forth to Learn What Fear Was": From Fish to Opossums

"Hank and Ginger Go Snipe Hunting": "Hansel and Gretel" in New

Country .58

From "Little Red Cap" to "Big Red Cap": Urban Wilderness..................................67

SECTION II: A Magical Country: Stories from Appalachia..............................................77

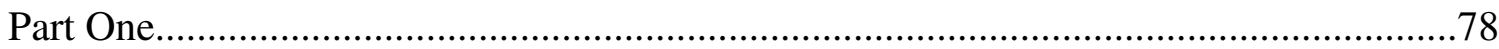


Part Two.

Ray Workman's Animal Tale: Shifty the Clever Foal....................................112

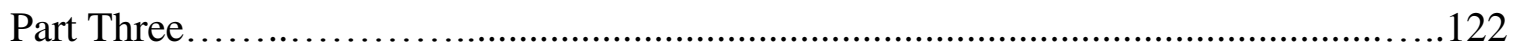

Julian Bowles' Magical Tale of Victory: Playing the Opossum Harmonica.......127

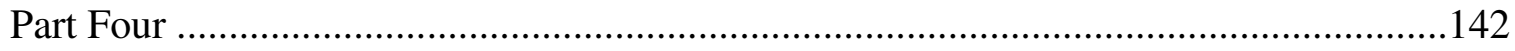

Shirley Bishop's Tale of Magic Pies and Witches: Hank and Ginger Go Snipe

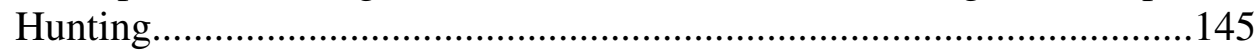

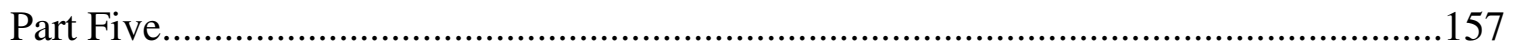

Russel Bishop's Warning Tale: Big Red Cap...............................................161

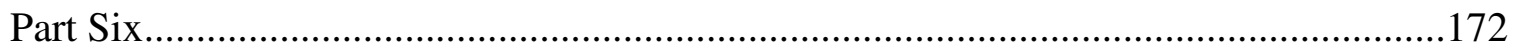

REFERENCES......................................................... 178

APPENDICES

Appendix A: Photographs of Levy and Surrounding Areas..............................187

Appendix B: Bibliography of Films and Television Series with Magical Content.. 


\section{INTRODUCTION}

My creative project, submitted in completion of my doctoral work at the University of Louisville, is a collection of short fiction entitled A Magical Country: Stories from Appalachia. The collection will offer contemporary variants of traditional fairy tales in a localized, rural, and protected world that faces influence from outside forces.

To connect the traditions of fantastic literature to contemporary fiction, readers must clearly see the links between contemporary production of fantastic stories and previous variants of fairy tales and magical works. Contemporary variants offer new cultural contexts for audiences, as it offers them a view into the life and conditions of current American audiences. That fairy tales offer a useful vehicle for culture and storytelling is not unusual in some respects; scholars have claimed throughout the twentieth century that children benefit from the magical world of fairy tales in fundamental ways. ${ }^{1}$ However, many of the new works are clearly not intended for child audiences; adults are benefitting now, and the reasons for this are as old as the stories

\footnotetext{
${ }^{1}$ Bruno Bettelheim refers to this benefit in The Uses of Enchantment. Specifically, he writes that a story, to enrich a child's life, must stimulate his imagination; help him to develop his intellect and to clarify his emotions; be attuned to his anxieties and aspirations; give full recognition to his difficulties, while at the same time suggesting solutions to the problems which perturb him" (5). Maria Tatar, in Off with their Heads!: Fairy Tales and the Culture of Childhood, is critical of Bettelheim's insistence that that tales themselves hold messages for children, instead asserting that each generation and culture of adults imbues them with their own meaning to raise children effectively (20). Either way, it is clear that readers and scholars agree in how the stories are perceived, even if they disagree in how they are infused with meaning.
} 
themselves. The alterations to these traditional stories demonstrate some of the fundamental building blocks of how people see themselves and their next generation(s).

The stories presented in the following collection do the same; they offer insight into contemporary contexts for American life. However, the work here focuses on a particular region and its people: the borderlands of Southern Appalachia, and the people who live there. The dissertation includes an accompanying discussion of the fiction, the traditions from which my work derives, the relevance of these traditions to the current cultural context in the United States, the process of writing and creating the fictional pieces, and intersections with contemporary scholarship on fairy tales that influence and inhabit the fiction, and the oral transmission of stories.

The dissertation is divided into two main sections. Section I provides scholarly discussion on the history of fantastic literature, the history of scholarship on fairy tales, the value of production of fairy tale and related films in contemporary society, and indepths critical discussions of the sources and variants used to develop the body of fiction that follows.

Section II includes the collection of short fiction titled A Magical Country: Stories from Appalachia. This collection follows several traditions of the literary collection of oral stories, including a frame tale and rotating narrators. Five different storytellers share oral stories with each other and an extended audience in a rural Appalachian general store. ${ }^{2}$ The store serves as a focal point for the community where information, rumors, and successes are disseminated. Each of the five stories in the collection blends elements from fairy tales and Appalachian oral stories currently in circulation. All together, the collection of stories illustrate the concerns and perspectives of rural, southern Appalachia

\footnotetext{
${ }^{2}$ See Appendix A: Photographs of Levy and Surrounding Areas for images of the store.
} 
and the encroachment of contemporary life and problems from what is perceived as the outside world which is urban life and city dwellers. 
SECTION I: RURAL CONDITIONS, FAIRY TALES, AND THE FANTASTIC 


\section{CHAPTER I}

\section{DEFINITIONS OF THE FAIRY TALE AND THE FANTASTIC}

While A Magical Country: Stories from Appalachia contains a collection of short fiction that includes themes and motifs from life in Appalachia, one of the central components of each tale is an example of fantastic literature, the fairy tale. Chapters IV and $\mathrm{V}$ provide an overview of specific fairy tales that influenced the collection as well as the oral stories, geography, and historical conditions of the area of Appalachia that the stories inhabit. This collection is most related, despite the setting and Appalachian elements, to the fairy tale, and this type of magical story is currently one of the most popular approaches to storytelling in the United States. Therefore, the background of the characteristics and use of these stories, including their place in fantastic literature, is vital to understanding their role in my collection.

Contemporary film and literary production certainly offer a wide variety of stories utilizing the fantastic or magic as part of the narrative. Intended generally for popular audience, these productions primarily arrive in the form of film, ${ }^{3}$ but the genres are also being used in marketing and video games, as well as small pockets of production in nearly every form of artistic expression.

A great number of these productions offer new variants of fairy tales, but other stories that include supernatural elements are on the rise as well. Yet before

\footnotetext{
${ }^{3}$ See Appendix B: Bibliography of Films and Television Series with Magical Content for a list of many of these films.
} 
demonstrating what these newer productions offer, previous studies of the fantastic and the magical offer some historical context. This must begin with the fantastic, as the term points to the larger genre considerations of works that can include examples from fairy tales to super heroes to mythical stories. The brief history of the fantastic and fairy tales presented here serves as the background and illumination for the included body of work. It is by no means exhaustive, but it does provide the contexts for periods of activity in fairy tale production leading up to the present.

Defining the fantastic in literature must begin with Tzvetan Todorov's excellent genre analysis. Todorov's theory of the fantastic describes three different states that a reader may encounter. The first and primary state is simply called the fantastic. He writes about such an encounter:

In a world which is indeed our world, the one we know, a world without devils, sylphides, or vampires, there occurs an event which cannot be explained by the laws of this same familiar world... . The fantastic is the hesitation experienced by a person who knows only the laws of nature, confronting an apparently supernatural event. (25)

The person who experiences such a phenomenon then has two choices; he or she may come to the realization that the experience is the result of an illusion or deception of the senses, or the person comes to understand that the event is in fact an integral part of reality, even if the laws are unknown to the victim.

Thus Todorov outlines his three possible states. The two states that exhibit some finality also have specific terms. Understanding that one is within an illusory state or experiencing some mental phenomenon is considered the fantastic uncanny. Arriving at 
the conclusion that the experience is real and subject to some unknown set of laws is the fantastic marvelous. However, the fantastic does not always lead to one of these two conclusions. In addition to the two progressions, a third state is possible:

The fantastic occupies the duration of this uncertainty. Once we choose one answer or the other, we leave the fantastic for a neighboring genre, the uncanny or the marvelous. The fantastic is that hesitation experienced by a person who knows only the laws of nature, confronting an apparently supernatural event. (25)

Yet Todorov does not limit this condition to simply the characters in a work. The reader must also participate or identify with the character. Todorov sees this as a necessary condition: "The reader's hesitation is therefore the first condition of the fantastic" (31). Such a text would have the reader experience much of the same confusion as the character in the story.

One of the primary sources in human history for the supernatural, and the fantastic, has always been folklore. Myths are examined, in terms of lineage, as historical practices of worship. Legends inspire investigation of historical records to tie legendary figures from this genre of folklore to at least some historical fact or context. However, the fairy tale has often defied scholarly attempts to define the genre because of its close relationship with oral traditions. One thing that seems certain is that fairies are certainly no requirement, despite the application of the term to these types of stories. The complicated and difficult history of these types of stories perhaps makes them ripe for reuse in contemporary life. In a nation obsessed with ownership and intellectual property, they hold no masters. Folklore is entirely out of copyright. Recent artists have 
taken advantage of this fact in particular with the fairy tale. The body of scholarship addressing fairy tales tends to focus on three main areas of interpretation: source, definition, and meaning.

Discovering the source of these stories has been especially difficult for scholars due to the nature of the oral transmission of tales. On one hand, most of the records are in collections of literary variants, and scholars usually can only trust authorial assertions of origin and historical records for accuracy. According to Jones in The Fairy Tale: The Magic Mirror of the Imagination, the tradition of fairy tales that precedes the Renaissance in the West comes in a wide variety of texts: "various collections appeared in manuscript form during the Middle Ages in India, the Middle East, the Mediterranean area, and Europe, and they included fairy tales as part of their recording and reworking of the oral traditions of those cultures" (xv). Jones implies here that these texts included either simply fragments of fairy tales or full stories in addition to other types of stories. ${ }^{4}$ Beginning with the Renaissance and in the years following, scholars had a much clearer picture of fairy tale lineage and important variant collections (see Fig. 1.)

\begin{tabular}{|ll|}
\hline $14^{\text {th }}$ century & Boccaccio, Decameron \\
$16^{\text {th }}$ century & Straparola, The Pleasant Nights \\
1634 & Basile, Pentameron \\
1697 & Perrault, Contes du Ma Mère L'Oye \\
1729 & Perrault, Tales of Mother Goose (first English translation) \\
1744 & Newberry, A Little Pretty Pocketbook \\
1782 & Musäus, Volksmärchen der Deutschen \\
$1785-1789$ & Le Cabinet des Fees (42 vols.), in which appeared Mme de Villeneuve's \\
& version of Beauty and the Beast, among other fairy tales \\
$1812-1815$ & Grimm, Kinder- und Hausmärchen
\end{tabular}

Fig. 1. A list of important dates and works provided by Jones, xvi.

After the Grimm Brothers, the record becomes much more substantial. The genre continues to evolve chronologically through Hans Christian Anderson, John Jacobs,

${ }^{4}$ These may be other types of oral literature or other genres entirely. 
Lang's translations of new works into English (such as The Arabian Nights

Entertainments), Yeats, and even beyond if one includes the connected genre of fantasy writers such as Tolkien, ${ }^{5}$ Seuss, ${ }^{6}$ and Sendak. ${ }^{7}$

The Finnish School attempted to discover and record geographic locations and dates for original variants of tales with little clear success, but the school also focused on defining the fairy tale via motifs. This group of scholars not only includes Julius Krohn, founder of the historic-geographic method for studying folklore, but also his student Antti Aarne. Stith Thompson continued the work of Aarne by translating, editing, and enlarging the classification system he developed. More recent scholars like Ashliman and Uther have continued to work with motifs and themes to build on the work of the Finnish School to publish new volumes of classification that show thematic links between variants. Mircea Eliade claims folk tales were originally based on ancient initiatory rights: "We could almost say that the tale repeats, on another plane and by other means, the exemplary initiation scenario. The tale takes up and continues 'initiation' on the level of the imaginary" (201-2). However, most scholars claim that fairy tales or at least oral variants and some literary variants, did not originate as stories for children but rather moved into that realm only with the rise of children's literature beginning in the eighteenth century. ${ }^{8}$ Although observers may note that many contemporary variations often appear designed exclusively for children, Jack Zipes indicates in Breaking the Magic Spell that adults are also heavily invested in the stories through politics, mass

${ }^{5}$ The Hobbit, 1937

${ }^{6}$ The Cat in the Hat, 1957

${ }^{7}$ Where the Wild Things Are, 1963

${ }^{8}$ A great number of fairy tale scholars address this, but Tatar, Zipes, Haase, and Shavit all discuss this transition. The shift is also related to the class difference between the nurses who raised the children of elevated social status, as the lower status nurses often reworked their own knowledge of oral stories to make them more suitable for children. 
media, and the culture industry. ${ }^{9}$ Graham Anderson finds themes and motifs of earlier tales in ancient storytelling. ${ }^{10}$

Meaning and definition for the fairy tale are linked, as the definition of a tale is classed by its motifs, which are used to construct their meaning and classify their similarities. However, different disciplines have offered their own approaches to the relationship between meaning and definition. Authors like Bottigheimer define the fairy tale as more of a literary production or recorded texts rather than focusing on the oral tradition (1-3, 6-8). ${ }^{11}$ Psychoanalytic interpretations, like Jungian and Freudian, attempt to find other avenues for meaning in the stories. ${ }^{12}$ Chiriac, from a Freudian perspective, argues that a "Definition of the fairy-tale should include the idea of artistic creation and also the one of aspiration of the human soul." While transformation and magic are the two characteristics of fairy tales most suited to my project and research, the stories follow Chiriac's model as well; they are also examples of artistic creation that address the aspirations of the protagonists.

Tolkien also offers his own interpretation of the nature of fairy tales and the magic they hold at their center in his essay "On Fairy Stories." Magic has a particular set of characteristics. He describes a fairy tale as a story:

which touches on or uses Faerie, whatever its own main purpose may be: satire, adventure, morality, fantasy. Faerie itself may perhaps most nearly be translated by Magic--but it is magic of a peculiar mood and power, at

\footnotetext{
${ }^{9}$ In particular, Zipes explores the career of Walt Disney, the development of his corporation, and the influences of capital on artistic production. Furthermore, Zipes considers the relationships between an industry that produces cultural artifacts that are used to educate and inform American audiences and their effects on child development, political positions, and ownership of oral tales.

${ }^{10}$ Anderson explores the links between myth and oral storytelling, drawing board links from early human ritual and spirituality to the content of contemporary fairy tale themes and motifs.

${ }^{11}$ Bottigheimer sees Straparola's work as the basic model for later collections (24-25).

${ }^{12}$ Furthermore, meaning is the approach of most literary critics.
} 
the furthest pole from the vulgar devices of the laborious, scientific, magician. There is one provisio: if there is any satire present in the tale, one thing must not be made fun of, the magic itself. (3)

Tolkien describes here one of the central characteristics for classification of the fairy tale: magic that is part of the fabric of the word and treated with a certain respect of reverence.

The work of the Aarne and Thompson in their index, as well as Uther's continued revisions, and Jones provide a means of framing the concepts of magic and transformation. Jones, like previous scholars, adopts Aarne's classification of "Tales of Magic" as indicative of a fairy tale (8). In fact, his analysis provides scholars with a clear method of placing folk narratives into manageable categories defined by specific, common characteristics. For Jones, folk narratives are understood according to the following outline he constructs from the work of previous scholars: ${ }^{13}$

Folk Narratives

I. Myths--etiological narratives employing immortal protagonists

II. Legends--quasi-historical narratives employing extraordinary protagonists

III. Folktales--quotidian narratives employing ordinary protagonists

A. Fables--didactic or moralistic tales (ATU 1-299, Animal Tales)

B. Jokes--humorous tales (ATU 1200-1999, Anecdotes and Jokes)

C. Novellas--romantic tales (ATU 850-799, Realistic Tales)

D. Fairy Tales--magical tales (ATU 300-749, Tales of Magic)

\footnotetext{
${ }^{13}$ Added here are the relevant ATU index categories for each.
} 
However, for the purposes of this discussion, Jones' treatment of the last category, fairy tales, is most significant. Jones provides scholars with a definition of the fairy tale that includes five main components. Of these five, four address form or style: an unpretentious protagonist, utilization of fantasy, an adventure or quest, and a happy ending (18). ${ }^{14}$ The fifth, theme, is significant enough that Jones dedicates his entire next chapter to it. For Jones, specific themes serve as markers of the fairy tale, and he suggests three major variations; fairy tales are themed according to "three major categories of human experience: the psychology of the individual, the sociology of the community, and the cosmology of the universe" (19). ${ }^{15}$ As a result, many of these stories focus on youthful protagonists who are trying to understand and find paths to success in their own communities.

In addition, the navigation between oral and literary variants of these tales is significant, even in contemporary American society. Oral variants are performed to a live audience whose members then have the opportunity to re-perform and reinvent the stories again. Literary variants are the written work of an individual writer. However, storytellers offer interaction and play between both of these approaches; in other words, they overlap. This borrowing or exchange is particularly prevalent in today's fairy tale related productions. ${ }^{16}$ The fiction presented here incorporates those same patterns of oral to written and vice versa to weave a new set of stories. Fairy tales have a long tradition

\footnotetext{
${ }^{14}$ Tolkien also address the happy ending component in "On Fairy Stories."

${ }^{15}$ These themes are not necessarily unique to fairy tales, but Jones asserts that they are particularly relevant to the problems that young people face. Therefore, they are significant because fairy tales are often perceived as lessons on how to navigate those themes as one progresses into adulthood (19).

${ }^{16}$ See list of recent fairy tale productions for a collection of many of these.
} 
of this oral and literary interplay. In fact, the oral collections complied by modern folklorists were all likely influenced by literary culture preceding their collection. ${ }^{17}$

Franklin Edgerton and Steven Swann Jones reveal that some of the earliest roots of fairy tales can be found in The Panchatantra, an Indian text with fairy tale motifs dating back to 200 BCE. Jones also traces the lineage through The Arabian Nights Entertainment, or A Thousand and One Nights, a text with origins at least as early as the tenth century. All of these demonstrate clear literary styling, but individual authors, no longer anonymous because of historical obscurity, become part of the scholarship in the fourteenth century, when Giovanni Boccaccio develops his stories by moving away from formulaic medieval structures into the Florentine vernacular. This marks one flurry of activity in the history of fairy tale production, as writers sought to retell popular stories in a common language. Giovanni Francesco Straparola serves as the commonly perceived origin of many of the traditional fairy tales western culture adopts today and is likely one of the sources that Perrault uses. Basile is also a likely source for Perrault; his work, The Tale of Tales, or Entertainment for Little Ones, later becomes an inspiration the work of the Grimm brothers. Steven Swann Jones marks these three writers and their periods as significant because they all demonstrate the reworkings of stories that the authors had undoubtedly heard as oral variants (38). The resurgence during the Victorian period saw an early transformation of folk stories into entertainment for higher social classes.

Writers like Perrault and Villeneuve took stories supposedly from the simple folk, though they had also been reworked by literary and oral interchange, and recreated the tales for a new audience, a literary and erudite one. The revival during the nineteenth century has

\footnotetext{
${ }^{17}$ This is also one of the justifications Bottigheimer focuses on for her emphasis on the literary tale as the root of the genre $(1-3,6-8)$.
} 
had one of the most lasting impacts for American audiences, as they are intimately familiar with the work of Jacob and Wilhelm Grimm. Their project was primarily one of linguistic nationalism, they created a series of editions that would be second only to the Bible in popularity in Germany and later the Western world (Zipes, The Golden Age of Fairy Tales xviii). Walt Disney offers up another upswing in fairy tale production in the early twentieth century with Ub Iwerks (The Four Musicians of Bremen, Little Red Riding Hood, Puss in Boots, Jack and the Beanstalk, Goldie Locks and the Three Bears, and Cinderella) before he began major productions with the company that was his namesake in 1937 with Snow White and the Seven Dwarfs (Zipes, "Breaking the Disney Spell' 339). Once again, in the 1970's, something new was afoot; in 1979, German critic Horst Künnemann reported that fairy tales were back in vogue (Zipes, Breaking the Magic Spell 1). Contemporary studies on the use and purpose of fairy tales, including works by Bruno Bettelheim and Marie-Louise von Franz, offer interpretations of their psychological underpinnings. Scholarly work continues to develop on the current status of fairy tales and intersects with my own work here. Cristina Bacchilega writes about the intersections of technology, contemporary fairy tale production, and politics. She writes: I argue that we should consider the gender politics of fairy-tale adaptations in relation to other dynamics of power and experiences of disjunction. I also argue that we should reexamine the relationship of the fairy tale with other genres, including the folktale, as constitutive of hybridity, in order to become better attuned to competing uses of magic, enchantment, and wonder across cultures and media platforms. (ix)

She makes this claim in the context of the rise of current fairy tale activity, and my work 
here speaks to her assertion about hybridity: A Magical Country: Stories from Appalachia is in itself a hybrid. Its creation utilizes traditional literature, contemporary oral storytelling, contemporary themes in rural Appalachia, elements from stories that have been digitally dispersed, and historical examination of place via genealogical discovery. The brief history of fairy tales presented here serves as the background and illumination for the body of work that follows. It is by no means exhaustive, but it does provide the contexts for periods of activity in fairy tale production leading up to the present. Even though these tales exist as hybrids of many forms and parts, a fairy tale is centered at the heart of each one, and the hope is that the stories are written in a way to capture a wide audience. Fairy tales are often seen popularly as literature primarily for children, but as the above discussion reveals, there is a long history of interplay between adult and child storytelling. As it turns out, both audiences tend to engage with fantastic literature. 


\section{CHAPTER II}

\section{WHAT GOOD IS A MAGICAL CASTLE?: THE VALUE OF FAIRY TALES AND THE FANTASTIC}

To understand why this resurgence of fantastic stories, in print and film, captivates audiences, previous studies on the value of these stories for children, and adults, offer insight. Clearly in the twentieth century, the Walt Disney Corporation successfully enchanted generations of children with their vivid animated depictions of fairy tale rooted stories. Both Charles Perrault and the Grimm Brothers offered up their works specifically for reasons other than simply the education or entertainment of young children--the Grimms for nationalistic pride and Perrault for adult audiences as well. Fairy tales seem to have split into two major commercial areas: stories designed specifically for children and stories for adults that reinvent the tales they remember from their youth. The variants designed primarily for child audiences have content that will particularly attract a child's attention, but adults will still be reviewing, reading, and performing them with them. Both branches of the fairy tale industry produce works for public consumption, and the effects these stories have, and in turn their purpose, may reveal more of the context for contemporary variants.

Psychoanalytic scholars are most prominent in their analysis of the uses and psychological interaction with fairy tales. While other areas of scholarship might approach the economic structure of fairy tale production, the comparison of societal 
norms to learning lessons from the tales, or the cultural transmission from one culture to another, psychoanalytic scholars work to pair the stages of brain development to the messages incorporated into fairy tales. Books for children do not necessarily require the use of magic or the fantastic; many are on the market that provide lessons for children in a more direct and practical way. However, from the psychoanalytic standpoint, such an approach would not be as suited to the subconscious struggles that children face. Perhaps the most prominent of these scholars is Bruno Bettelheim. According to Bettelheim, Charles Dickens knew that fairy tales help children through an important task, "achieving a more mature consciousness to civilize the chaotic pressure of their unconscious" (23). Therefore, Bettelheim focuses mainly on the use of magical stories and fairy tales to educate children to maintain a sort of emotional intelligence; the reason he proposes for his view is quite compelling:

For a story truly to hold the child's attention, it must entertain him and arouse his curiosity. But to enrich his life, it must stimulate his imagination; help him to develop his intellect and to clarify his emotions; be attuned to his anxieties and aspirations; give full recognition to his difficulties, while at the same time suggesting solutions to the problems which perturb him. In short, it must at one and the same time relate to all aspects of his personality--and this without ever belittling but, on the contrary, giving full credence to the seriousness of the child's predicaments, while simultaneously promoting confidence in himself and in his future. [emphasis added] (5, The Uses of Enchantment: The Meaning and Importance of Fairy Tales.) 
While Bettelheim is mainly concerned with children as the central point of this thesis, in particular their stages of psychological development, adults also find mirrors of their own predicaments reflected in fairy tales. In fact, early collections of tales, such as the Grimm brothers' collection, needed to go through many editions to make the stories more palatable for children, thus indicating adults might have been the primary audience for the oral tales they collected. Besides, adults who were raised in a fairy tale culture much like that of the twentieth century in the United States have already learned to incorporate these types of magical stories into the world view and understanding of human nature. If they were raised in a culture with a tradition rich in fairy tales, like the twentieth century United States, they already understand, on a subconscious level, how to make use of them. In other words, they can already decode the language. ${ }^{18}$

This link between childhood fantasy as a mode of thinking and adult life is not as disconnected as they may seem. Children are able to distinguish between reality and fantasy at a young age, yet they still engage with it. According to Carey:

Children exhibit a form of magical thinking by about 18 months, when they begin to create imaginary worlds while playing. By age 3, most know the difference between fantasy and reality, though they usually still believe (with adult encouragement) in Santa Claus and the Tooth Fairy. By age 8 , and sometimes earlier, they have mostly pruned away these beliefs, and the line between magic and reality is about as clear to them as

\footnotetext{
${ }^{18}$ There are numerous studies and scientific perspectives that address this. Wax and Wax explore the idea that there is value in what adults perceive as magic: "It illuminates or symbolizes a significant concern of Western peoples" (502). Felson and Gmelch's study draws this conclusion: "Put simply, tribal man has faith that his magic works; modern man lacks faith, but he is not taking any chances" (589). LeGuin asserts that fantasy is true, in some sense. It may not be factual, but there is truth embedded in it (44). Sutherland writes that fantasy, "can teach us about the dark interior of our minds, as humans, as individuals, as the writers of our own destinies." That Americans have such easy and frequent access to magical stories and pass them from generation to generation reveals these assertions to be true in American culture.
} 
it is for adults.

If the dividing line is already clear by that point, perhaps there is quite a bit of overlap in the ability of a child and adult to engage with magical ideas. According to Jacqueline Woolly, psychology professor at University of Texas, "Children believe wishing to be a magical process; they understand that simply thinking about something cannot cause it to happen, but claim that magic can make it possible" (998). Woolly goes on to imply that her distinction is significant; it indicates that children engage in magical thinking because of a lack of knowledge or understanding, and that adults do the same. Adults also engage with magical thinking when they lack the knowledge to understand as situation. This does not necessarily indicate that the rest of a child's brain has the capacity and complexity of an adult's. Nor does it mean that adults and older children will not return to these ways of thinking if under duress; they in fact will. Children must still progress through the social development stages of childhood, even if the brain has the mechanical capacity to separate reality from fiction. However, children, as they develop, still regularly engage in fantasy and play. "If the tendency to think magically were no more than self-defeating superstition, then over the pitiless history of human evolution it should have all but disappeared in intellectually mature adults" (Carey). The continued engagement of adults with these types of stories, even ones that are adult-rated or kept beyond the reach of young children, demonstrates that magical perspectives remain valuable and useful to adults. This perspective can easily be obscured in an American culture with a substantial fairy tale industry oriented toward children.

Magic and the fantastic remain useful for the very reasons they are powerful for children; they help to understand and move through the more trying stages of life. For 
children, those stages are much smaller in scope, as they are beginning to understand the world in their immediate contexts. For adults, stages of life involve the development of long term relationships, economic stability and growth, and home acquisition and identity. Developmental stages are often times when people feel a lack of control. For Carey, "Magical thinking is most evident precisely when people feel most helpless." People begin to start thinking of their individual actions in magical terms, like believing that always playing the same set of "my numbers" in the lottery will guarantee eventual victory, and they turn that magical thinking outward and consume media that offers it.

One area of contemporary life in which these psychological effects are utilized is in current therapeutic environments. It was well understood even in the early twentieth century that "folk tales deal primarily with the problems of adults" ("Fairy Tales Told Children"). Verena Kast describes their utility in a two-fold fashion; tales serve to either represent models of adult experiences with anxiety or of living in concert with other human beings in what she terms symbiosis (85). Further studies indicate that there are actual clinical uses for fairy tales or stories about magic for adults. Hans Dieckmann writes:

This graphic mythological experiencing of the world always remains a foundation beneath our rational thought processes and has a by no means only regressive-negative character that finds expression in superstition and neuroses. On the contrary, this layer of emotionally, highly charged images and fantasies is also the foundation for the new emotional acquisitions as well as for the processes of change and maturation in the psyche of adults. (29) 
In other words, the use of magic and mythological themes or archetypes is not just a manifestation of a type of regression or retreat from the world, but instead these stories serve as a strong base for the positive development of the adult psyche. One set of examples comes from Julius E. Heuscher, who describes five case studies where fairy tales are used to effectively treat patients:

The rationale for this procedure evolved largely from a more comprehensive study of the origins and meanings of myths and fairy tales. These narratives portray at different stages of human development the various predicaments and goals, as well as possible solutions and failures. They convey their messages in rich images rather than abstract formulations. (664)

One case involves a young man who dreams about leading others to a fairy tale-like castle who later comes to understand his avoidance of authenticity in his adult life through the narrative of the tale. Another includes a woman who dreams of a golden ball and learned great insight about her children by studying variants of "Jack and the Beanstalk." A third focuses on a Protestant minister plagued with guilt and depression whose story paralleled the Russian fairy tale, "I Know Not What from I Know Not Where." While some of these cases involved the study of dreams, owing some credit to Freudian strategies of interpretation, not all of them did. In particular, the Protestant minister dealt with waking emotions and behavioral patterns. Stasz, Milch, and Simpson offer the use of mythology and fairy tales in two contexts: a way to reach the emotional creativity for beginning writers and as a therapeutic tool for inmates to work through the problems that led to their incarceration. The task involved steps similar to that of fairy 
tale remakes made for a larger audience. Inmates studied the components and themes of mythical and magical stories. They were then asked to create their own stories based on the familiar structures they uncovered. Inmates developed fable and fairy-tale like stories that demonstrated their own paths in life that led them to incarceration. Much like the lessons embedded in other tales in this genre, their own stories had important resolutions for would-be audiences. They served as tales of warning to educate the audience on a successful way to succeed in life and avoid trouble. The implications are that the experience of the creation and consumption of these stories allowed adults to develop strategies for dealing with the world beyond the prison walls (131-7). ${ }^{19}$ In the same way, fairy tale and fantasy productions in contemporary life allow adults to find strategies for dealing with life beyond the walls of their own personal patterns and general anxieties.

Whether adults and children are consuming these stories to satisfy the need for enjoyment and entertainment or for more complex psychological needs, the offerings in film, print, and gaming are plentiful. Their value can be demonstrated by the overwhelming options for consuming magical content or themes. For example, Alice from Alice in Wonderland is now featured in a new recent feature film, a video game for high definition platforms, and dozens of phone apps. Rafferty asserts, “There's no doubt that fairy tales have for the past couple of years — and into the foreseeable future been coming pretty regularly to screens both big and small." Perhaps the popularity of these types of stories reveals their true value for the American culture.

The films by Walt Disney may offer some insight, since Disney is generally

\footnotetext{
${ }^{19}$ Winters addresses the reason why these stories might be useful for inmates. He argues that that are particularly effective for "explore[ing] the depths of their own values and lives in their writings" (58). He goes on to say that this primarily addresses the inmates' lack of social cognitive skills (58). This serves to reinforce some of the cultural normative value of fairy tales and at least, in part, they are effective for children as they also develop social cognitive skills.
} 
credited with bringing fairy tales to the wider American audience and keeping the popularity of previous collections from the brothers Grimm, Perrault, and others alive. Criticized in later scholarship for the traditionalism of race, gender, and social roles, Disney began working with fairy tales to demonstrate his technological mastery of film and animation. Snow White and the Seven Dwarves, widely released in 1937, still offers clear, modern-looking presentation, nearly eighty years later. Disney's reinforcement of the cultural norms and the impressive technique drew large audiences for decades. The world of Disney, the world of the Grimms, and certainly the world of Charles Perrault have long passed. New variants of these stories have changed some of the old themes and motifs to better suit contemporary audiences:

The world from which fairy tales and folk tales emerged has largely vanished, and although it pleases us to think of these stark, simple, fantastic narratives as timeless, they aren't. Thanks to video games, computer graphics and the general awfulness of everyday life, fantasies of all kinds have had a resurgence in the past few years. But the social realities on which the original fairy tales depend are almost incomprehensibly alien to 21 st-century sensibilities. (Rafferty)

Since most young Americans when asked about fairy tales will immediately offer Disney as their maker, these same viewers will realize that the world they knew when they consumed those works has disappeared and transformed. These tales, in turn, will also be transformed. David Christopher Bell sees four critical similarities among contemporary fairy tale variants: heroes have become action heroes; films frequently present birds, forests, and castles that all look similar; evil female characters are played by famous 
beautiful film stars; and they all appear to be dark-reimaginings of previous works. Bell also confesses that part of this may be due to a Disneyfication of the stories in the twentieth century that is only now finally being dispelled. ${ }^{20}$ His concession does not really seem all that necessary in light of the current American condition; the messages that fairy tale narratives present would have been destined to change anyway, such as the American Dream, racial composition, and moral values, all embedded in the works of Disney, have evolved. Disney remains relevant, not just because his fairy tale works are frequently rereleased to new young audiences, but also because the studio that is his legacy continues to create new variants, often trying to meet the moral and cultural expectations of an audience in a new century.

The influx of fairy tale related works grows larger every day in the current consumer context. Amazon lists nearly 5,000 new releases of fairy tale related books within the last ninety days. ${ }^{21}$ Almost 3,000 of those selections are works presented in their Kindle digital format. Many of them are new publications, with new illustrations, of classic collections, but hundreds offer new variants. Clearly the digital world is becoming awash with fairy tales and fantastic literature. Even personal hygiene products are falling into the craze. Children can prepare themselves for the world daily with a

\footnotetext{
${ }^{20}$ Disneyfication is a broad term used by many fairy tale scholars to address Disney's affect on American culture through the vehicle of fairy tales. Baudrillard addresses it as a function of Disneyland: "Disneyland is there to conceal the fact that it is the 'real' country, all of real America, which is Disneyland (just as prison are there to conceal the fact that it is the social in its entirety, in its banal omnipresence, which is carceral). Disneyland is presented as imaginary to make us believe that the rest is real, when in fact all of Los Angeles and the American surrounding it are no longer real but of the order of the hyperreal and of simulation" (25). Giroux provides specific examples of what he calls Disneyfication: "For instance, [the] Houston airport models it[s] monorail after the one at Disneyland. Small towns throughout America appropriate a piece of nostalgia by imitating the Victorian architecture of Disneyland's Main Street U.S.A." (67). More recent and social aspects of it include the princess phenomenon affecting young girls in the United States.

${ }^{21}$ This figure correct on 21 October 2014.
} 
whole host of products labeled Fairy Tales. ${ }^{22}$ Another corporation markets food products, specifically sweets, under the name Fairy Tale Brownies. Consumers can buy wall-sized inspirational quotes for their living rooms based on fairy tales, ${ }^{23}$ a complete LEGO fairy tale figurine set, ${ }^{24}$ and even several varieties of vegetable cultivars that profess to be of fairy tale quality. ${ }^{25}$ Countless areas of the consumer market have some, even if minor, connection to fairy tales, illustrating how prevalent they are in American culture. Such a pervasiveness can only come from the culture's love and admiration for the stories, and it serves to show how significant the cultural marker these types of fantastic stories are in contemporary life. Furthermore, it reveals how much value the culture places on the stories for honoring the traditions of the tales and transmuting them into new forms.

\footnotetext{
${ }^{22}$ The business offers shampoos, lice treatments, bed bug prevention, and sun care all under the name Fairy Tales; and the logo includes a castle in the style of the Disney classic happily-ever-after goal.

${ }^{23}$ This is a vinyl wall covering made by Design with Vinyl that reads, "Life Itself Is a Most Wonderful Fairy Tale."

${ }^{24}$ This contains over 200 pieces, 22 figures, Little Mermaid, and an evil witch.

${ }^{25}$ There are many of these in production, likely to emphasize their impressive, almost magical, growth patterns. "Fairy Tale F1" in the Works Cited is a place one can order an impressive eggplant variety.
} 


\section{CHAPTER III \\ ORIGIN AND GENESIS OF THE CREATIVE WORK}

The artistic purpose of this collection is to develop a literary work that serves as descriptor and metaphor for the conditions of living in and leaving a rural area in contemporary Appalachia in the United States. In particular, the work embodies the contemporary fascination in American culture with the fantastic and magic; furthermore, the American love for the unreal will mingle with the old traditions of the rural storyteller, offering interpretations in short fiction that demonstrate rural minds, too, journey through a world in the throes of rapid information, media, and cultural upheavals. People in these cultures often turn inward as a defense against the intrusion of the outside world. The stories themselves have a thesis: these rural people have rich, complicated cultural experiences with as much depth and quality as those found in some of the greatest urban centers; however, they also experience doubt, anxiety, curiosity, and suspicion when looking outward from their small communities as those from urban areas feel when looking into the rural.

Though many of the motifs and themes embedded in the work may apply to the rural condition in many areas of the United States, this work is particularly balanced on the boundaries most intensely recognized in central and Eastern Kentucky: urban and rural, hill people and mountain people, wealth and poverty, faith and education, loyalty to family and loyalty to state or country, and survival against excess. The passages in this 
work illustrate the primary anxieties of people living in a region that has been exploited heavily for its natural resources while remaining steeped in poverty. The people living there today are one of the few groups in America that are still on the list for acceptable social comedy and derision; few other people are as stereotyped and mocked as the uneducated hill folk farmer, the hollerin' redneck, or the banjo-playing hillbilly. That American culture still finds these caricatures amusing is not lost on the people of the region, and it adds fuel to the fire of their suspicion of the outside world and the trappings of a more modernized life.

Despite the production and consumption of many of these contemporary works of literature, film, and art taking place in large urban areas, magical content in American storytelling as a vehicle for dealing with the hardships and worries of cultural and social upheaval continues to find the same purpose in the work from rural environments. Both types of fictional creation, the mass market film, book, or video game and the traditionally isolated oral storytelling in Appalachia, demonstrate a proclivity for magical content.

The process that led to these works began before I ever started to work with fiction. For many years of my own life, I have felt a pull to the rural in my personal life as well as my creative writing endeavors. Fiction writers know that the truth of their past often ends up inhabiting the present of their work, and I am certainly no exception; my own childhood developed in three separate locations surrounding Appalachia, and thus it often appears in my own creative work. My primary residence as a child was in the southeastern portion of central Kentucky. Richmond, Kentucky, where I was born and lived until my mid-twenties, exists as one of the town seats of Madison County. The 
county is one of the larger ones in the state, with the northern and western portions resembling the Bluegrass region and connected by interstate highway to Lexington, Kentucky. The southern and eastern portions of Madison County are home to the town of Berea, now well known for a vibrant liberal college, Berea College, and a healthy admiration for the arts and crafts of the southern Appalachian region. The entire county serves as a seam between the two cultures: in the Bluegrass region, bourbon, and horse racing are the long-respected industries; and to the east, livestock and crops are grown in the rolling hills leading up to the Appalachians and farther east, where the hills are too forested and steep to support livestock, coal, and cleverness are the main vehicles of the economy.

The second dominant area of my childhood was in those rolling Kentucky hills dotted with livestock and tobacco on the county line between Bourbon and Montgomery Counties. This area is one of the political and geographic boundaries between the Appalachian and Bluegrass regions, and much of my family lives astride this boundary. ${ }^{26}$ All of them grow tobacco, raise cattle, raise chickens, and spend a great deal of time cutting and preparing hay. None of the farms in the area are flat; they all feature undulating lands with cresting hills and deep valleys, generally called hollers to the locals. I spent my summer weeks of each year in this area. When I was a young child, I mostly wandered through haphazard orchards, racing twigs down slow creeks, and chasing dogs around the farm my grandfather worked his entire life. Once I reached the age of seven or eight, I was old enough to begin learning and participated in as many of the tasks the adults did. I pulled tobacco seedlings in preparation for row planting, helped gather tobacco sticks from various barns and sheds, cleaned up discarded leaves

\footnotetext{
${ }^{26}$ See Appendix A: Photographs of Levy and Surrounding Areas for images of related sites in the area.
} 
during the tobacco stripping seasons, and watched in awe of the height and strength and dexterity required for hanging tobacco. As I grew into a teenager and my interests were drawn more and more to education and the technologies available to the more urban populations of Richmond and Lexington, I worked on the farm less often, visited the farm less often, and began to think of it as quaint and old fashioned. Though I was not born there, I experienced the same feelings of many who were: When could I get out, and how? What could this backward, rustic place offer me that more exciting and more populated ones could not? I determined the answer was little and kept my distance.

The third location of my childhood rested on the other side of the Appalachian Mountain range near Greenville, South Carolina. Greenville remains a significant urban area on the southeast side of the Appalachians, and as a teenager, I spent several weeks there every summer visiting family. To reach it, my parents and I traveled by car through the Smoky Mountains, passing through Southeastern Kentucky, Eastern Tennessee, and a small portion of North Carolina. Most of the route was via interstate highway, but the last portion in South Carolina required we leave the highway and travel on a state road. I always found it odd to arrive in Greenville by state road rather than the highway, and my father always explained that no interstate connected the city from the direction we travelled. Since it was the largest urban area I had ever seen up until my fifteen birthday, Greenville seemed large, urban, and chaotic. Even now, thirty years later, the city proper barely has a population over 60,000 . On the route into the city, dozens of farmers would set up stands or simply open the tailgate of their pickup to sell fruits and vegetables; and for the tourists, there would always be stands of baskets full of peaches. Those of us who thought ourselves locals never bought peaches at the stands; instead we traveled to places 
where you could pick your own for a cheaper price. Just as in eastern Kentucky, it was common during those travels to see hundreds of tiny houses and shacks dotting the hillsides as we drove through. Many were accessible only by a small footbridge over a creek or via a dirt road through a nest of trees. Even today, passersby can note many of these roads and tracks looping through the hillsides, and there are just as likely to be hidden driveways as paths for dirt bikes and four-wheelers.

These three primary areas introduced me to rural life in Appalachia, and they began a lifelong struggle for me that pitted the way the people who lived there were depicted by outsiders against the rich experiences I encountered. Less reliant on technology and electricity for entertainment, I grew up in a rich world of books, storytelling, small gatherings, simple foods, and hard manual labor. As a teenager I rebelled against these things, seeing them only as somehow lesser and shameful; I nodded sagely against the closed-minded and insular nature of those rural communities and their intolerances. As an adult, I have come to learn the truth is somewhere in the middle. All of my nostalgia cannot undo the racism, bigotry, and suspicion I have found in Appalachia, yet all those evils do not destroy the rich appreciation for language, creativity, stewardship, hardship, and family that Appalachia has also shown me.

The final component that informs this work is my continued exploration of the fairy tale from a genre standpoint and using these types of oral stories to introduce composition students to the principles of analysis and research. Appalachia is no stranger to the fairy tale. Even according to Ann Troy, as early as 1977, the hill folk began: emerging slowly in children's and adolescents' literature, and the number of books on this group of people remains few in comparison to other 
minority groups. ... For the most part, the books emphasize the dark and dreary picture of a proud people's desire to retain the good life of their mountain ancestors, but as they attempt to do this, they are trapped by economics and twentieth century miseries. (56)

There are numerous collections of folk and fairy tales for children, many of them borrowing from earlier published works, such as those of Perrault or the Grimm brothers. Perhaps one of the most famous collections is Grandfather Tales by Richard Chase, which contains twenty-five tales with a frame story and weight given to both male and female storytellers. Tom Davenport and Gary Carden offer a book or ten tales from the Grimm brothers titled From the Brothers Grimm: A contemporary Retelling of American Folktales and Classic Stories. In this text, similar in composition to my own, the authors rework "Cinderella," "King Thrushbeard," "The Frog King," "Rapunzel," "Snow White," and others into Appalachian variants. ${ }^{27}$ In her collection The Adventures of Molly Whuppie and Other Appalachian Folktales, Anne Shelby offers up new variants using "Molly Whuppie” from Joseph Jacobs’ British collection of tales (2007). Other collections of tales incorporate other rural cultural groups working with variants of tales from European backgrounds. Peggy Ann Griffin's Taking Treasures offers AfricanAmerican folktale variants from Virginia (1995). Another common set of stories interwoven with the European tales are Native American tales, specifically Cherokee in the south. One of the best repositories of these variants, European folktales connected with rural white, African-American, and Native American traditions, can be found on an extensive website hosted by Ferrum College in southwest Virginia compiled by Tina L. Hanlon. Clearly there are far more of these types of stories in print and on the web than

\footnotetext{
${ }^{27}$ The book also accompanies a set of short films that Davenport makes available on his website.
} 
forty years ago, as the appreciation of Appalachian storytelling in literary circles began in earnest in the second half of the twentieth century. However, the production in contemporary culture is high, and I have written my collection of stories to join this growing group. The addition here, though, are contemporary themes that continue to affect the region.

The early part of the twenty-first century is currently experiencing an artistic explosion of general fairy tale and other magic related stories. They appear in films; video games, not a small market, as it includes computer, console, and phone operating system development; novels; and children's books. As consumers, the abundance of magic-related stories seems normal and expected. Perhaps part of this increase in production is the end of Disney's dominance in the fairy tale media market; however, The Walt Disney Corporation remains strong and competitive in the market, offering new, yearly releases that are either contemporary re-imaginings of traditional fairy tales or entirely new intellectual properties that will continue to offer artistic opportunities for Disney in the future. These films are being made by recent generations of producers, writers, and artists who are attempting to capture their own interpretation of American culture. They have been alive to see attacks on domestic soil and major shifts in foreign policy; they have lived through the celebration of prosperity and wealth that the 1990's offered in the United States, and they have felt that financial security fracture in the first decade of the 2000's; they have born witness to our transition from confidence to cultural worry and preoccupation over information, money, and safety. These artists and producers have reacted by retreating from depicting the hardships of reality, which are all available to most citizens in every moment of their daily lives, to engaging audiences on 
the grounds of the fantastic and magical.

This work, while exploring the specific themes and concerns of rural life for an audience in the new millennium, finds itself related to these same projects from others within my generation. Through magic and play, the stories introduce a metaphor to the reality, but the fabrications can often demonstrate a truth greater than the sum of their parts. The final two chapters of the academic discussion will look closely at these parts and how they are used to craft each individual story in the collection. 


\section{CHAPTER IV}

\section{STRUCTURE: FRAMES AND SHORT FICTION}

A Magical Country: Stories from Appalachia offers examples of the transmission of oral tales and their interplay with literary variants in the rural South and Appalachia as well as illustrate some of the social, political, and cultural characteristics of both regions. Many portions of fairy tales have already ended up as viable portions of jokes, lore, and conversation in central Kentucky, a region with which I am intensely familiar. One example of the permeation of oral literature into rural southern culture is captured in the story, "Big Red Cap." This story finds its origins in the copious variants of "Little Red Riding Hood, ${ }^{, 28}$ in one rural and oral variant that persists; the protagonist may be a young boy or young girl and the antagonist may be a wolf, a coyote, or some other danger present to a child. Other Appalachian writers have noticed its prevalence as an oral story as well. Marilyn Thornton Schraff notes its use in children's play, in particular around seeing pigs and other livestock (150). Becky Mushko uses the tale, with childhood memories of it, to construct a new variant for children (1-22). Perhaps there are even echoes of Tex Avery's “Little Rural Riding Hood” in many of the contemporary variants. $^{29}$ "Big Red Cap" uses these variations as a model for a new literary variant of the AT 333 tale type. While still maintaining a structure of an innocent facing an

\footnotetext{
${ }^{28}$ Or "Little Red Cap" for some variants, such as that of the Brothers Grimm

${ }^{29}$ This 1949 short cartoon portrays LRRH in a way that reveals many stereotypes about country people visiting the city.
} 
unfamiliar danger in unfamiliar territory, the tale flips the old one on its head in several ways. The protagonist is a male pursued by a female protagonist. The female is predatory in a sexual manner that highlights the moral consequences of sexual behavior found in rural attitudes, and the journey taken is from the rural into the urban rather than deeper into the forest. Each one of the stories in this collection does similar work to develop the themes addressed above.

The stories are built from a large collection of parts: stories currently in oral transmission that are not necessarily recognizable folk tales, stories that have literary origins but have re-entered the oral tradition, actual geographical features and oral stories from the area of Peyton's Lick in Kentucky, ${ }^{30}$ and portions of traditional European folk tales from some of the most popular collections in the United States. Many fairy tales and other oral stories have become integrated into the practical day-to-day existence of many people in the area. Stories find audiences at dinner tables, family get-togethers, at country stores, and at church. They also occur while feeding livestock, shopping, or driving to town.

To capture this integration of storytelling into everyday tasks and fellowship, the work pursues a track of realist writing that allows for the intrusion or blend of fairy tale themes and structures much like tales from oral traditions. This will include some elements of fairy tales that have entered my own tradition in central Kentucky, an area of the United States that experiences a unique blend of the south and Appalachia. The resultant text is a combination of everyday reality, the comedic, the magical, and the supernatural.

The realism allows for the introduction of serious social and political problems

\footnotetext{
${ }^{30}$ See Appendix A: Photographs of Levy and Surrounding Areas for images of related sites in the area.
} 
affecting the region without moving into the realm of pure fantasy or allegory. This connection to reality serves to ground readers in the knowledge that the narratives reflect real conditions in contemporary society. The magical components will link these stories to larger contemporary American anxieties and tensions between the rural and urban. Characters and objects featured in the stories fit well with the fairy tales traditions, but the traditions are reworked to include new themes and settings.

The overall structure includes a frame tale with an omniscient narrator to assist in guiding readers through the various subjects that the individual stories will address. These types of frame stories have been used before to provide readers with some sort of anchor for delivery; these frames are found in works such as the Decameron, which employs a group of ten storytellers seeking diversion and relief from the plague in Florence; The Canterbury Tales, which employs the pilgrimage as the method for grouping and inspiring storytellers; and One Thousand and One Nights, which provides a frame that reveals storytelling to be a restorative and healing act for a kingdom ravaged by a king's cruelty. These types of frame tale were also the convention for volumes of fairy tales referenced earlier, including The Merry Nights of Straparola with a group of storytellers on the island of Murano and The Pentamerone or The Tale of Tales, or Entertainment for Little Ones with stories told to amuse a cursed princess. ${ }^{31}$

The frame of my own work will also, like the others, provide access to an environment that may not be familiar to many of my readers. This frame, of course, will be characteristic of the culture of the south and Appalachia. Such a centerpiece in both regions can be found in the country store. Rural members of both sides of my family find

\footnotetext{
${ }^{31}$ Sarnelli and D'Aulnoy can be added to the list of fairy tale authors who have employed the technique. Furthermore, Marguerite de Navarre's The Heptameron also uses a frame tale, in her case a flood like in the collection presented here.
} 
themselves, even in contemporary times, drawn to the small, rural store as a meeting place and a location to swap stories. ${ }^{32}$ For the collection, the country store will serve as a place of verbal exchange, for encounters with outsiders passing through the area, and for commerce, though limited. The country store itself serves as a unique and interesting entity on its own merits, as it must serve the diverse needs of a rural population. As a result, what might be a simple convenience store in an urban area, selling refreshments and gasoline, finds a much broader set of customer needs in a rural area. Stores might need to stock a variety of small tools and farm implements; feed and medicines for livestock; a broad range of edible perishables as well as preserved foods; some medicines for human consumption; multiple types of fuel, including kerosene, gasoline, diesel; machinery and equipment for repairing metals and woods; and the usual small trinkets and toys that tease shoppers all over the United States as they enter small stores.

As a result, the central figures present in the frame tale include the store owner and operator, who supplements his income with a small farm; a number of farmers; and the rural folk who often accompany the farmer to the store, including companions or work animals. Specifically, the frame story currently offers five adult, male storytellers; the store owner's wife, Louella, who spends some time revealing her thoughts to the reader through an omniscient narrator; and two young children, a girl in elementary school and a teenage boy. They find themselves passing the time in the country store as recent rain has kept them from furthering their work in the early autumn fields. Hay cannot be bailed wet and must wait for drier weather. Tobacco cannot be cut and cured

\footnotetext{
${ }^{32}$ In some areas, the rural church congregation plays a similar role. In country churches, a certain reverence or protocol permeates the atmosphere; stories not related to the Biblical text in such a place tend to be exchanged only on the periphery of the actual church service, such as before or after. In addition, many of these stories are more personal and may relate to family illness or problems.
} 
as easily in the rainy weather. Heavier rain arrives unexpectedly, and meteorologists indicate that the rain could last some time, leading to worries of flooding. Meanwhile, the rain serves as a signal to readers that just as the land is in some sense cleansed by a heavy rainfall, and even revitalized, the unusually heavy and unexpected rainfall indicates a break from the normal and reliable weather patterns, introducing a kind of stasis. This whisper of change will be echoed in the lives and stories of the farmers, as the reader comes to realize that their way of life exists in sharp contrast to the contemporary worlds of technology, development, urbanization, and industrialization. As the rains threaten crops, livestock, and structure, all elements tied intricately to the economic future of the region, readers also begin to understand the exterior forces that place mutative or destructive pressures on the lives of rural families in the South and Appalachia.

In addition and perhaps as a significant focus, the frame narrative orients readers to the manifestations of contemporary political discourse in rural Kentucky. The frame, as well as the content of many of the stories, addresses the political and social realities that inhabit the daily concerns of rural populations. How much power do rural values and origins have in contemporary society? How and when should one become worried about food and water? How does faith work in a world that seems faithless? How do rural communities reconcile their rugged individualistic nature with the need for outside support? How does generational change affect the sustainability of rural life? What does it mean to be an "other" or an outsider? Should outsiders be treated with suspicion or acceptance? Though these contemporary issues may at first seem distant from the oft perceived magical world of fairy tales, fairy tale scholarship has revealed that such stories 
are often rich with the influence of the culture that records them as literary variants.

Therefore, the repurposing of the tales allows me to investigate and illustrate rural cultural identity. As such, the borrowed stories cannot stay the same as they were because the culture has shifted. Instead they must be transformed. What remains, however, is significant. Elements of the fairy tale designated as motifs remain as links to earlier variants. ${ }^{33}$ These motifs represent human problems or conditions that continue to affect society. In addition, the portions that are kept demonstrate some of the fundamental building blocks of how the culture sees itself and the following generations.

\footnotetext{
${ }^{33}$ Scholars who study the classification systems will quickly see that many of the motifs overlap between tales. Thus, what makes the tale a recognizable variant is not only the motifs it presents but the order in which they appear. The stories in A Magical Country: Stories from Appalachia attempt to keep some, but not all, of the motifs from the source variants. However, they are all recognizable due the sequence of the motifs.
} 


\section{CHAPTER V CRITICAL AND ARTISTIC DISCUSSION OF THE CREATIVE WORK}

This chapter addresses the cultural, historical, and artistic context of each major tale in the creative work. Each section offers a description of the development of the fairy tale serving as the foundation of the narrative, a discussion of the oral components introduced, and commentary on how the two interplay in comparison to previous variants. 


\section{Roses and the Magic of Transformation in "The Consequences of Beastly Behavior"}

The story in this collection "The Consequences of Beastly Behavior" offers up an intersection of two major elements, the fairy tale of "Beauty and the Beast" and an oral story from the western borders of Appalachia that describe a man using a gorilla suit to frighten his wife and her friend. These two stories are interlaced with the themes of family, relationships, and the expectations of civility in small communities. In the new variant, a group of young boys decide to don a gorilla suit to frighten the local beast, a widower who has lost much of his good manners once the close personal relationships in his life all vanished. The beast catches one of the boys in the act and kidnaps him. The only person who can save the captured boy is a young girl from the community who manages to see past the beastly behavior of the older man and offer him some hope for community again. In the end, the beast's behavior is forever changed, and the young boys and girl work toward building other positive relationships in their lives.

The history of the "Beauty and the Beast" story, AT type $425 \mathrm{C}$, is somewhat unique in the context of the other fairy tales that influence this collection. One of the most well-known variants of the story exists in the form of a novella, not in the shorter prose form that many later variants take. The author, Gabrielle-Suzanne Barbot de Villeneuve, published the work in 1740, placing her in what appears to be a second wave of writers working the French préciosité style that developed out of social gatherings of the French elite in the seventeenth century. ${ }^{34}$ The title of the story, La Belle et la Bête,

\footnotetext{
${ }^{34}$ Writers of the first wave of this style included other well-known fairy tale authors such as Madame D’Aulnoy. Préciosité writers were likely influences for Villeneuve and Charles Perrault.
} 
remains the most common title for the work in translation. Villenueve's story spans over 100 pages and contains a much more aggressive and hostile beast than later variants; he is truly savage and not redeemable. In addition, the story opens with an urban setting, an unusual characteristic for a fairy tale but one that seems rooted in the time period that the story was printed. Villenueve's work also led to future variants, such as the one by Madame de Beaumont.

Beaumont's variant would likely appear most familiar to American audiences, as it later became Disney's primary source for his animated Beauty and the Beast. Beaumont's variant cuts away much of the length of the story and recasts the beast, leaving the story as a much simpler and direct tale about marriage, trust, and gender roles. Windling confirms this in her analysis of the Beaumont's variant:

In the [Beaumont's variant] the story becomes a more didactic one. The emphasis shifts from the Beast's need for transformation to the need of the heroine to change — she must learn to see beyond appearance and recognize the good man in the Beast. With this shift, we see the story altered from one of critique and rebellion to one of moral edification, aimed at younger and younger readers, as fairy tales slowly moved from adult salons to children's nurseries.

This transformation of the beast coincides with the transformation of the story itself, in terms of the characters and how the story is used in Western cultures. In one way, the tale is used to emphasize the woman's responsibilities in a relationship:

That the desire for wealth motivates parents to turn their daughters over to a beast points to the possibility that these tales mirror social practices of an 
earlier age. Many an arranged marriage must have seemed like a marriage to a beast, and the telling of stories like "Beauty and the Beast" may have furnished women with a socially acceptable channel for providing therapeutic advice, comfort, and consolation. (Tatar, "Beauty and the Beast Introduction” 27)

Tatar emphasizes the value a young woman might get from this story, but what is important is that this value does not include a separation from the beast but rather ways to deal with remaining in his presence. Women are encouraged to realize the "importance of valuing essences over appearances” (Tatar, "Beauty and the Beast Introduction” 27). This encouragement develops despite the fact that her name is usually some form of the word Beauty. The central female character is frequently tormented by the forces of the story that draw her into closer and closer contact with the Beast, yet she remains repulsed by him. Over time, she must change to overcome her inability to see his true value through his ugliness. This, of course, leaves out that the Beast's condition is of his own making; he was a cruel and vain person until cursed with his appearance, and only then did his essence change. Clearly, the female role and her "transformation" have become central to the tale by the time readers experience Beaumont's variant. ${ }^{35}$

Overall the story continues to grow in popularity. According to Ashliman, heroines marrying animal bridegrooms is one of the most popular folk story families in

\footnotetext{
${ }^{35}$ Though the commentary focuses here on a specific lineage of the story, de Villeneuve to Beaumont to Disney, other related tales have been popular, including the story of Cupid and Psyche found in Apulius' novel The Golden Ass, "The Goose Girl" by the Grimm Brothers, and "The Pig King" by Giovanni Francesco Straparola. Samuel Richardson released Pamela: Or Virtue Rewarded, an epistolary novel with a related theme in 1740 as well, the same year as de Villeneuve's publication. There are many more variants of this story, some of which are films are available in Appendix B: Bibliography of Films with Magical Content.
} 
Western culture, existing in hundreds of literary variants, at least thirty film adaptations, ${ }^{36}$ and a popular U.S. television show in the late 1980's that now boasts a variant starting in $2012^{37}$ (176, Folk and Fairy Tales: A Handbook). Walt Disney added yet another layer to this story in 1991, this time commenting on the motifs of love embedded in the core of this tale. ${ }^{38}$ True love becomes the central focus, with all actions, events, and themes rapidly approached the final moment of a kiss between lovers so powerful that it revives the body and reattaches the soul. ${ }^{39}$ His story is significant, as true love has developed into a common trait of new variants. Disney's variant continues to enjoy wide popularity in the United States.

The variant of the tale included here in this collection offers new interpretations of the central figures in the tale. The characters seem to subvert Bettelheim's perspective that the tale completes the Oedipal transition from the father to the new male focus, in most cases restoring "the father's failing health and provid[ing] him with a happy life in proximity to his daughter" (308). Jenny's father has died before the time of the story, so the Oedipal transition is shifted. Jenny comforts and reforms the old farmer, who is of no relation to her, leaving him with a context for happiness despite his loss. Her suitor or possible love interest, Tucker, is a lumbering and ungainly teenager, a beast of his own sorts. His transformation from beast to man is one born of experience and time, and it remains unresolved at the end of the story. The story retains one of the fundamental motifs of the earlier variants, the significance of the rose. Beaumont, for example, has

\footnotetext{
${ }^{36}$ According to Ashliman, the first film adaption was a 1903 Lubin silent film titled, as most of the adaptations have been, Beauty and the Beast.

${ }^{37}$ The bibliographical information for many of these works, not specifically mentioned in this section, is available in Appendix B: Bibliography of Films and Television Series with Magical Content.

${ }^{38}$ The link here is strong. Disney credits Beaumont's variant as his source in the opening credits of his film.

${ }^{39}$ This idea, for Disney, is not unique to Beauty and the Beast. Disney uses the motif of the restorative power of true love in many of his stories, including the final scenes of Snow White in 1937, his first fullfeature length animated film.
} 
the beast proclaim his garden of roses as his most prized possession. Disney has the rose at the center of a magical curse designed to force a reform of his personality. In this story, the rose is not explicitly connected to a curse that affects the beast, but rather the roses rise and fall in vitality according to depth of his beastly behavior.

The oral tale included was performed by Dan Maupin and includes portions of verifiable historical account and embellishments. The basic outline of the story is a prank that goes wrong. A truck driver who lives on a farm in the countryside is given an adult, male gorilla suit as a gift for a potential prank. The driver's wife spends several afternoons a week exercising with her close friend by walking up and down the country roads nearby. The roads do not have proper shoulders in the area, so the women must walk against the traffic on the road's edge. The roads are rural and tree-lined, but the women must walk in area that leaves them exposed to both traffic and anything that might be hiding in the trees along the roadway. The driver plans to wait until his wife and friend take a daily walk, don the suit, and jump out at them from the side of the road. He chooses a spot relatively close to their own residence, jumps out at the women, and frightens them terribly. They run screaming back toward their own home, but the driver has taken a shortcut back to the farm and is there, in normal clothing, when the women arrive. He plans to keep his prank a secret for a day or two to see how the aftermath will play out, but his wife discovers his costume in the truck and later uses it herself to prank her husband by wearing it and hiding in the cab of his truck before he leaves one morning. Her revenge is successful, and they laugh about it in the end. Dan Maupin claims that his version is the first retelling of the gorilla suit story, and perhaps it is an account of a personal experience. However, the gorilla suit seems to appear in other 
Appalachian stories as well. Loyal Jones and Billy Edd Wheeler mark that the gorilla story has often travelled in humorous contexts throughout Appalachia, often in the context of someone succumbing to pride, as in a boxing match where a gorilla pretends to be vulnerable but delivers the winning blow (197). Cormac McCarthy also uses the gorilla fighting element in his novel Child of God. Contemporary variants continue to be developed, as in Dragon's Avalanche and Gorilla Jim: Appalachian Trail Adventures and Other Tales. No written text is available for Maupin's variant. I heard it in a storytelling moment at a family gathering, but it is clear the gorilla runs throughout Appalachia.

Both the fairy tale and the prank story already have something essential in common. They deal with the relationship between husband and wife, tensions between them, and the idea of transformation. These are of course universal themes, but they are examined in the specific context of rural Appalachia and its concerns. Overall, this new variant maintains the need for transformation for the beast, and it offers sympathy for his plight. Additionally, it introduces the idea of inappropriate male behavior in relationships and the tensions that creates. The moralistic perspective is not present in some of the earliest root of the story. According to Marina Warner, in one example the story of "Cupid and Psyche" from Apuleius differs from the variant by Charles Perrault, and later writers, in its bawdy nature and lack of moral instruction (4). However, later writers sought to deliver specific directives. Perrault, for example, connected his stories to the romances of what Warner calls the Ancients:

They were made to please without a thought for good behavior. This is not the case with tales that our ancestors invented for their children. They did not recount them with the elegance and the ornament with which the 
Greeks and Romans adorned their fables, but they always took the greatest care that their tales contained a praiseworthy and instructive moral. (qtd. in Warner 4)

The nature of this moral instruction generally focuses on how to live inside a marriage that begins under negative circumstances. The union "not only charts the challenges facing Beauty but also registers the transformation sustained by the Beast, showing how these two antithetical allegorical figures resolve their differences to be joined in wedlock" (Tatar 25). To work within this theme, while building on it through Appalachian elements, my variant depicts the romantic relationship with both the psychological and physical development of young lovers and the suffering at the loss of close partnerships. 


\section{"Shifty the Clever Foal": \\ In Kentucky, A Horse Will Go Farther Than a Cat}

The story in this collection titled "Shifty the Clever Foal" focuses on the class of stories that include animal helpers. Even though the helper animal has been a wide variety of species in the history of the fairy tale, it is often a feline in popular contemporary variants. Here it is changed to a different creature and combined with a local tale recounted by Catherine Leary that takes place near the Levy Store which serves as the loose setting for most of these stories. ${ }^{40}$ This allows the tale to follow in the tradition of stories that is a well-established pattern in European oral stories, an animal with magical abilities assisting a human protagonist. These two elements combine to offer a commentary on the utility of work animals in the rural environment and the close relationships both youth and adults develop with the animals that help them earn their livelihoods.

The fairy tale at the root of this story is, in general, classified as ATU Type 545, or "The Cat as Helper" (315). Uther does not offer a general description of this type, instead splitting it into two separate subgroups divided by the gender of the protagonist. Type 545A, "The Cat Castle," offers a female protagonist who pretends to be a princess and, with the aid of a helper cat, overcomes a series of trials that earn her a castle, a royal marriage, and great wealth by the end of the tale. Type 545B, "Puss in Boots" offers a

\footnotetext{
${ }^{40}$ A description of the current, at least of 1997, status of this country store can be found in "Store Keeps Plum Location." The store remains in operation, and readers will find some of the names of the fictional characters in this collection similar to those of the current generation of owners.
} 
similar storyline, this time with a male protagonist being helped by the cat. ${ }^{41}$ Tales that follow the successes and rise to glory of the protagonist are often referred to as "Rise" tales by scholars, and according to Bottigheimer, the first of these types of stories that has remained popular is Straparola's variant of "Puss in Boots" published in 1553 (12). ${ }^{42}$ The story is later reworked into variants by Giambattista Basile, Charles Perrault, and Jakob and Wilhelm Grimm. A variant in circulation provided by Peter Christen Asbjørnsen and Jørgen Moe in their collection of Norwegian tales even features a horse as the central helper animal. ${ }^{43}$ The story type remains an important one, recently receiving a wide audience in the Dreamworks animated variant titled traditionally as Puss in Boots starring Antionio Banderas and Salma Hayek. The variant included in this collection follows closely the narrative structure found in Charles Perrault's "Puss in Boots.”

"Shifty the Clever Foal" opens in a similar way as many variants. The animal helper is introduced as a consequence of death. The protagonist, Ida, finds herself facing an uncertain future once her father dies. All of her brothers receive an inheritance of land to grow professionally as farmers, but due to the general division of labor on farms, Ida is

\footnotetext{
${ }^{41}$ Uther offers a description of the tale. $545 \mathrm{~B}$ provided here instead of $545 \mathrm{~A}$, as the narrative structure is closest to the variant in this collection. An animal cat, fox, jackal, monkey intends to help a poor man to become rich. To gain the emperor's confidence, the animal tells him that the poor man is wealthy. When the poorly dressed future bridegroom travels to his bride's residence, the animal simulates an accident, in which all his clothes are lost. Thereupon the king gives the poor man good clothes and he is accepted as a bridegroom. When the man has to display his property, the animal leaves before him and coerces the shepherds and farmers to say that their herds and farmlands belong to the poor man. The animal kills the real owner of the properties, a demon, by burning, slaying, shooting him, or through a trick. When the bride arrives with her entourage, the bridegroom presents himself as the real owner of the property. The animal tests the gratitude of the poor man by feigning death. In some variants the man behaves ungratefully or does not keep his promise.

${ }^{42}$ The story was published in the second volume of his work, listed as the first fable under the eleventh night. The translated title of this story often includes the name, Constantino. Many translations title Straparola's story as "Constantino the Cat" or "Constantino Fortunado."

${ }^{43}$ This variant is titled "Dapplegrim" and is a story about a horse who escapes slaughter and gains special powers by nursing on all the mares that have several foals. Asbjørnsen and Moe provide it in Norske Folkeeventyr. Andrew Lang also offers the variant in The Red Fairy Book.
} 
left without land to support her future. Instead, she is gifted, or perhaps cursed, in terms of her first reaction with a horse. The talking horse quickly reveals himself to be an extraordinary creature and offers to help Ida find her way in the world if she will only help him find new shoes and saddlebags. These are the only tools that he needs to help her, so once he acquires them, he sets to work on improving her fortune and his own by proxy. The events are arranged in a set of three, and each one illustrates an attempt to win the approval of the local community, North Middletown. First, Shifty collects apples to be sold at market, and they gain Ida a reputation for farming some of the most delicious apples available. ${ }^{44}$ The second stage is the rescue from water, where Ida must pretend to be drowning for the horse to explain her appearance. This convinces the mayor of North Middletown that she is simply a landowner who suffered an accident. The third stage involves the presentation of Ida as a landowner. Shifty wins Ida a successful and amazing farm through a race which involves a slight bit of trickery. The mayor is so impressed with her land, Stonewall Farm, that he offers this son in marriage. Ida accepts, becomes connected to a steady income, and gains a reputation as a great farmer. Shifty, for his part, ends up well cared for and living a life of luxury.

The basis for Shifty the Horse is an oral story passed down within my own family living near Madison County but relocated for the purposes of this story to the Levy Store setting. ${ }^{45}$ A close friend of the family lived at Poosie Ridge in Madison County as a young girl named Virginia Bailey, and the family had an old, but reliable, horse that was often used for travelling around the area before the automobile was readily available

\footnotetext{
${ }^{44}$ The story offers more than one crop here, but the first stage in the story is fruit.

${ }^{45}$ See "Store Keeps Plum Location."
} 
(Leary, Personal Interview). ${ }^{46}$ The horse had lived in the area for so long and become so trustworthy that Virginia, between the ages of 8-12, would ride the horse from the farm to the local mill and back without any real guidance. The horse was so trusted that young children, who did not know the way to the mill, could be placed on his back, and he would invariably take his passenger directly to the mill to pick up supplies or deliver payment. He could even be trusted to make the journey without a rider.

The frame tale asserts that the story is a true one, and Helen seems fascinated by this ability. She is young enough to see a world where magical events and reality are blended, and the story about a horse with exceptional abilities offers an excellent vehicle for this. Ray Workman tells her the story for multiple reasons. On one hand, they are all trapped in a natural disaster, so the humorous quality of the story serves to entertain and delight. The horse as the central figure suggests the real value of work animals or helper animals to the rural farmer, as much of the land is unforgiving without horsepower. Shifty himself would likely be outdated in a contemporary farming environment, at least as far as farm work duties would be concerned. Mechanization replaced horsepower for much of the heavier lifting, but Shifty remains valued in a fundamental way. Regardless of his ability to do work, his role as a companion is far greater.

Thus the central purpose of this variant is less subversive than some of the others in this collection. Shifty takes a traditional path. He moves through the narrative in a similar way to Constantino or Puss. The story does, however, emphasize the relationship between human work and animal work as well as human relationships and animal relationships. Farmers, at least those who deal with livestock, face a unique relationship

\footnotetext{
${ }^{46}$ The exact name of this person is unknown, but it was either a great grandmother of mine or her sibling. During her genealogical investigations of the family, Catherine Leary discovered that several family members repeated this tale.
} 
with the creatures on the farm. Animals are to be taken care of for one's livelihood, watched for signs of danger including wolves and coyotes used for sustenance, invited into the family as pets, and studied for their connection to spirituality. ${ }^{47}$ Animals considered resources or utilities often cross that barrier on the farm. My mother had a pet goat and a pet goose. I had a pet cow as a child. All of them were later eaten, so the lines are clearly crossed; however, even when they were slaughtered, they were killed with a personal reverence and consideration that animals eaten today do not experience. This complex relationship between the land, farming, and survival is captured in Wendell Berry's lines in "The Peace of Wild Things," "I come into the peace of wild things who do not tax their lives with forethought or grief.... I rest in the grace of the world, and am free." Berry's lines hint at the stewardship of the land that so many farmers offer up as a refrain of purpose.

In "Puss in Boots" stories, the cat and master often live happily ever after once wealth, land, and love are acquired. The variant included in this collection indicates that the spiritual and emotional connection to the animal helper is just as significant in developing what many fairy tales protagonists seek, some version of the good life that includes the security of wealth and family.

\footnotetext{
${ }^{47}$ Animals are important as representations of the Garden of Eden and as manifestations of God's providence.
} 


\section{"The Boy Who Went Forth to Learn What Fear Was": From Fish to Opossums}

The story in this collection titled "Playing the Opossum Harmonica" is a fusion of at least three elements to create a new variant that is a combination of ATU tale types 326, "The Youth Who Wanted to Learn What Fear Is" and 570, "The Rabbit Herd." The first element is a tale of type 326 , which serves as a frame (even if it gets twisted) for the overall narrative structure. ${ }^{48}$ The second element is a geographical location in Bourbon County, Kentucky, that serves as the overall setting for the frame tale in the collection as well as most of the individual stories. The third component includes elements of the story of the Pied Piper. ${ }^{49}$ All three of these combine to form a story that addresses overcoming incredible fear that harms a young man's progress into adulthood.

The primary narrative structure of "Playing the Opossum Harmonica" follows that of "A Tale About the Boy Who Went Forth to Learn What Fear Was." translated title still manages to catch the essence of the story, an implied journey and a quest to understand fear. The story features a young boy depicted as the stupid sibling of his far superior brother. The boy's brother has the favor of his father, and the young lad is further troubled by his inability to react to fear as others do. He frequently refers to it as getting the creeps and laments he has never experienced the emotion. The young boy fixates on this and decides that he would certainly fall back into favor with his father if he were to finally get the creeps like everyone else, most notably his brother. His father

\footnotetext{
${ }^{48}$ The story used as a base for this narrative comes from The Complete Fairy Tales of the Brothers Grimm translated by Jack Zipes, pp. 11-17.

${ }^{49}$ The components used here are loosely based and not sourced from a single story, but several variants are available on D.L. Ashliman's website as ATU 570.

${ }^{50}$ Jack Zipes, The Complete Fairy Tales of the Brothers Grimm.
} 
hatches a plan with the local sexton to frighten the boy, but it goes terribly wrong, resulting in injury to the sexton, public embarrassment for the father, and a confused boy who still has not been frightened by anything. The transgression against the family now too great, the father gives the boy some money as an inheritance and bans him from his sight. The boy sets off on a journey to discover fear, gain his father's love, and return triumphant. He goes through several trials that would chill anyone to the bone before finally staying three nights, unafraid, in an enchanted castle, thus winning the castle and a princess for marriage. The story ends with him finally discovering fear after annoying his wife for quite some time. She dumps a bucket of water and minnows on him, and he immediately reacts with fear. He may behave this way because for the first time in his life, he is loved by someone, the princess, and now has something to lose. Overall, the story focuses on the theme of the necessary link between fear and love, and the human quest to understand that relationship.

The setting of the tale included in my collection allows for a reversal of the boy's condition. Luke, the story's protagonist, finds himself cursed with fear, rather than not understanding it. He fears loud noises, unexpected motion, and a variety of other surprises. His relationship with fear is just as debilitating as the one in the Grimms' variant. Just as the Grimms' boy cannot feel love from his father due to his affliction, Luke's relationship with his father is troubled by his reaction to fear. Because Luke faints at the sounds and surprises of everyday farm life, his condition places the future of the farm and the family in danger. His father banishes him from the farm until he can cure his curse, offering advice to travel to a more populated area where he can learn a soft skill that does not require him to confront the natural world. To win back his father's 
love and respect, Luke sets out on a journey to resolve his fear issues and become a proud and successful farmer. He encounters a series of trials as well, modeled after the stages in the Grimms' tale. The final castle is instead a tenant house that is in serious disrepair that tests Luke's willpower and serves as his site of redemption. After facing his fears of the physical spaces of farm life, represented by the tenant home, and the natural forces in perpetual tension for farmers (represented by the introduction of wild animals that can evoke fear in younger children), Luke proves himself as a worthy successor to farm stewardship and wins the love of a young woman and the respect of her farmer father. This models the young boy from the fairy tale who never in fact returns to his father. Instead the boy wins over his wife and the respect of her father on his own terms, supplanting his biological father.

The tenant home in the story is one of the features related to the geographical setting of the stories and the frame tale. The house, partially standing today, has been a central figure in the history of our family, at different times offering a residence for migrant workers; a refuge for family members needing a somewhat temporary home; and storage for old appliances, furniture, and building tools that required relatively dry storage. The property still has a working farmhouse at 1182 Levy Road in a rural area outside Paris, Kentucky, and the tenant house rests about 150 yards away on the hillside, slowly deteriorating with disuse. Inside, rafters have fallen through, the floorboards have rotted away in some places, and washers, dryers, and steel sinks rust away under a thick layer of dust. The home mirrors a location in the fairy tale where the young man stays overnight as part of a challenge he hears from a barkeep. If he can stay three nights at the haunted castle, he will earn wealth, property, and a bride. 
The elements from "Pied Piper" type stories allows the introduction of mastery over natural or wild elements. Although often popularly classed as a fairy tale, the story does appear in the Grimm brothers' collection of legends. Mieder also associates it primarily with legends, and he argues that scholars generally believe there to be an historical context at its core. ${ }^{51}$ However, the tale offers many variants in transmission, and Uther claims it to be one of the most popular tales in the United States (129, "Fairy Tales as a Forerunner"). The core element borrowed from the story is the practice of leading children from the town into the wilderness after the Piper is refused compensation. ${ }^{52}$ In both stories, music and leadership serve to provide the resolution, and they do so in my variant as well.

"A Tale About the Boy Who Went Forth to Learn What Fear Was" may not be a fairy tale that is typically offered for child audiences, or perhaps it is not as popular in the United States because Walt Disney had not yet found time to incorporate it into his repertoire during his lifetime, but the story remains a profound statement on love, family, and the interconnectedness of human emotions. The variant offered in this collection continues with this tradition while adding the concerns of the rural farmer.

In the context of the frame story, the tale is delivered for a couple of purposes: it is designed to educate young Hoss on the nature of growing up to be a man, and opossums serve as familiar creatures to delight the young children. Hoss is at a critical age in the story; he is considered a child by most around him but has already begun to mature physically and is completing his own share of farm labor. On the cusp of adulthood, he has a chance to understand the adult messages in the stories and still be

\footnotetext{
${ }^{51}$ Mieder offers portions of the Grimm variant in "The Pied Piper: A Handbook," pp. 38-40.

${ }^{52}$ See James Owen's "Snakes in Ireland: Blame Ice Age, Not St. Patrick" for a more modern explanation of the phenomena.
} 
entertained by the ridiculous swarm of opossums. Thus, the story is itself a tale of this type, one that has significant messages about the nature of adult life while still offering a bit of whimsy, and shows that context at work in the social environment of the frame tale. In the end, it delivers an important message, whether the boy seeks to gain fear or lose it; he must work to master his own shortcomings, and through that journey, he learns to love and understand the true meaning of family. 


\section{"Hank and Ginger Go Snipe Hunting": "Hansel and Gretel" in New Country}

Even in contemporary society, food remains a scarcity for many people. In the most highly developed countries of the world, the vulnerable in populations of the elderly, the homeless, and children frequently face the reality of insufficient or lack of food. Food and access to it, one of the primary drives of human survival, inhabits the heart of stories about a young boy named Hansel and his sister Gretel. ${ }^{53}$ In A Magical Country, the tale is reworked into "Hank and Ginger Go Snipe Hunting." This new variant captures the central focus of food and child abandonment and wraps the central plot in a prank and oral story that appears in many rural areas throughout the southern United States, snipe hunting.

"Hansel and Gretel" is related to a series of tale types (ATU 327 cycle), all of which deal with one of the primary anxieties a young child might face, abandonment, and with that, a lack of sustenance. The fear of abandonment infused with the story is not a trivial one, "Another repugnant but well-documented ancient practice reflected in fairy tales is the right of parents to abandon unwanted children, leaving them to die of exposure.... These [stories] suggest that at the time the tales were invented infanticide was still commonly practiced" (Ashliman, Folk and Fairy Tales: A Handbook 16). Even if not still in practice, the fear is real. Once abandoned, children must either die or find sustenance.

\footnotetext{
${ }^{53}$ They may or may not be named in the stories, but Hansel and Gretel are the most common names used for the central characters.
} 
Type 327, listed by Uther as "The Children and the Ogre" often combines the three subtypes into a larger story arc. However, the traditional variant that appears most common in the United States is the subtype 327A, the Hansel and Gretel story. ${ }^{54}$ Uther's description provides the general frame for the tale:

A father abandons his children in the forest. Twice the children find their way back home, following scattered pebbles. On the third night, birds eat the scattered peas. The children come upon a gingerbread house which belongs to a witch. She takes them into her house. The boy is fattened, while the girl must do housework. The witch asks the boy to show his finger in order to test how fat he is, but he shows her a bone. When the witch wants to cook the boy, the sister deceives her by feigning ignorance and pushes her into the oven. The children escape, carrying the witch's treasure with them. Birds and beasts help them across water. They return home. $^{55}$

Even within this description, the possibility of food as salvation takes central focus. This aligns well with Maria Tatar's discussion of the tale, "Wish-fulfillment in fairy tales often has more to do with the stomach than the heart" (179). Robert Darnton's discussion of the realities of adult peasant life also seems applicable: “To eat one's fill, eat until the exhaustion of the appetite, (manger à sa faim), was the principle pleasure that the peasants dangled before their imaginations, and one that they rarely realized in their lives" (34). Yet if the peasants are concerned about what is for dinner each night as a

\footnotetext{
${ }^{54}$ The Grimm brothers are primarily responsible for its popularity, even in the United States.

${ }^{55}$ This text is quoted from Uther; however, this passage does not include the extensive parenthetical notes and bibliographical references that he provides in each stage of the story.
} 
primary locus of anxiety and fantasy about fulfillment, the variants of tale type 327 introduce an even more frightening anxiety, being consumed alive.

Though the setup for the story varies to a great degree, the Grimms' "The Children of Famine" introduces a mother who laments that she might have to kill her two children to have something to eat. In the more common variant the Grimms offer up, "Hansel and Gretel," the children are not intended for consumption by their parents, but starvation is a real possibility. The impetus that drives them out into the forest is a lack of food sufficient for father, mother, and the two children. The mother plots to have them left in the woods to facilitate her and her husband's survival. Tatar also offers an interesting side comment about his particular story, in that the mother here is described as a stepmother, not previously a standard part of the story. She speculates that Wilhelm Grimm must have made the change, "because he could not bear to pass on stories about mothers so intent on surviving a famine that they are willing to sacrifice their own children" (180, The Classic Fairy Tales). The stepmother, presumably, is a more comfortable villain. However, if the story is a depiction of the realities and harshness of life in the pre-modern era, one of the explanations offered up by numerous scholars to explain the cruelty of the parents, then the introduction of the stepmother is simply a deflection that would minimize the terror that might accompany a child's understanding of the tale in a family of two biological parents.

Other scholars, such as Bruno Bettelheim, suggest even deeper Freudian interpretations of the tale type. Bettelheim, focusing on the relationship of the children to the female adult figures, describes the tale as one where the witch at first offers great gustatory pleasure but then removes it. He then frames it this way: 
This is how the child feels when devastated by the ambivalent feelings, frustrations, and anxieties at the oedipal stage of development, as well as his previous disappointment and rage at failures on his mother's part to gratify his needs and desires as fully as he expected. Severely upset that Mother no longer serves him unquestioningly but makes demand on him and devotes herself ever more to her own interests—-something which the child had not permitted to come to his awareness before- - he imagines that Mother, as she nursed him and created a world of oral bliss, did so only to fool him---like the witch of the story. (163)

Perhaps, then, this is one of the reason that the father becomes the place of return for the children in the story. He is often the one reunited with the children at the close of the tale, and the witch is gone, having been consumed, burned, or destroyed by the cleverness of the children in overcoming the adult female restrictions on the acquisition and pleasure of food.

In addition to the elements from the fairy tale, oral stories from the rural countryside influence the form of abandonment that appears in the story. Snipe hunting is an activity that is part urban, or rural in this case, legend and part practical joke. Once someone in a community has suffered the fate of this prank, they not only become a more central member of the community, but they also will never live down the retellings of their adventures to anyone who lives in the area. It takes on the same forms as an initiation or rite of passage, and most people from central and eastern Kentucky who live in rural areas have been tricked into snipe hunting themselves or heard the tales of those who were duped. The activity itself is usually harmless in terms of physical risk to the 
victim. Some pranks are simpler than others, depending on the number of pranksters involved:

[Snipe Hunting is a] North-American prank and rite of passage wherein older adolescents take younger boys into the wilderness for the supposed purpose of "snipe hunting." Snipes are an imaginary game bird purported to resemble quails or pheasants or what have you (the fictional snipe is not to be confused with the extant North American shorebird of that same name). Snipe hunts take place on moonless nights; the victims are provided burlap bags with which to catch the birds, while the conspirators spot them with flashlights. (“Snipe Hunt”)

The pranksters conclude their role in the series of events by abandoning their victim(s) in the field. The victim is then left to discover the fear of abandonment in the face of an unfamiliar task, one that might also include a sense of danger. The snipes, which seem real enough just for the fact that snipes do really exists as a species of bird in North America, ${ }^{56}$ are often portrayed in the prank as dangerous in some way:

Snipes are very tall birds with long legs. They are very ugly and are a little bit scary. They make little noises, but are kind of hard to hear. They can run very fast and they will bite you. This is why you need to make sure that when you see a snipe, you throw the sack over its head. Just a split second after throwing the sack over its head, you have to knock the snipe over the head. Make sure you do this fast, because you might get bitten if

\footnotetext{
${ }^{56}$ See "Common Snipe" in References for a description of the bird species. Of note is that the bird is a wading fowl, one that is suited to skittering along the ground at high speed. This makes it an excellent choice for the prank. However, in the portion of the prank where the snipe is described, instigators will often exaggerate, modify, and obfuscate the form of the animal to make the experience more frightening. Oral variants have included birds, lizards, and mammals all as types of snipes.
} 
you don't. Once you have hit the snipe, make sure it is knocked out cold. Then you can drag your kill home. (Sanders, Cisney, and Cullen) The prank, at its core, clearly has a layer of cruelty that connects it to other social initiation rites; once one has been snipe hunting, the victim then becomes the prankster and seeks out new outsiders or new community members coming of age for targets.

"Hank and Ginger Go Snipe Hunting" incorporates the snipe hunting activity and much of the above critique of the fairy tale variants in the course of its plot development. The synopsis of the story in many ways matches that of Uther's tale type description. Put in similar language, the story would be described in the following way: A father abandons his two children in the forest to go snipe hunting while he and his wife eat some delicious treats at their farmhouse. The children find their way home from this first trip because Hank has used a bag of marbles to mark his path. When they are left to snipe hunt a second time, they are unable to find their way back and become lost. They encounter a house where a witch, living as a homemaker, has left delicious pies and cakes to cool in the window. The children are drawn in by their hunger, and the witch captures them, making Ginger her house servant while she works to fatten up Hank for a meal. The children escape after Hank deceives the witch and tricks her into entering an outhouse, where Ginger shoves her and drowns her in the pit below. The children gather all of the rest of the sweets and return to their father's house where everyone eats their fill and lives happily ever after. Many of the elements of the story remain the same, but it is in the cultural details of the south that the story takes much of its new turn.

The story mirrors, in form and some language, the variant provided by the Brothers Grimm titled "Hansel and Gretel." The woodcutter has become a farmer, but the 
conflict between the wife and the husband over their sustenance, including how their children are a problem in this scenario, takes central focus at the beginning of the story. While the Grimms' variant focuses on the fear of starvation, "Hank and Ginger" utilizes the rural conditions of scarcity for an opening. In other words, the family is not in danger of complete starvation because of how they earn their livelihood, but they are starved of the pleasures of food. They eat foods that are nourishing but repetitive, and this causes them suffering in the deep months of winter and early spring. This mirrors conditions in remote areas, where much of the stores of food are things which have been grown earlier in the summer and are suitable for canning or preservation; thus, the variety suffers.

The snipe hunting takes central focus as the means of abandonment. Since the stakes for food survival are lesser, so is the abandonment. The father chooses a location and activity from which the children are likely to return, but they will only make it back once the mother and father have had their fill of delectable foods. ${ }^{57}$ Yet this activity also leads to the same lost wanderings that Hansel and Gretel face.

Hank and Ginger encounter their own witch, but the gingerbread house, an embodiment of the lack of all types of food, is replaced by a farmhouse wafting the smells of rare treats out through its windows and into the countryside. This works well with the lesser stakes of hunger that Hank and Ginger experience. Their imprisonment is just as real to them, however, and still at the hands of a witch. The frame story provides clues to this change. Shirley Bishop is telling the story to the two young children trapped

\footnotetext{
${ }^{57}$ These foods are also uniquely appreciated in farming environments. Salted watermelons are amazingly satisfying after a long day of exhausting work. Mushmelons are a type of cantaloupe like melon more easily grown in rural environments in the southeastern United States.
} 
at the Levy with the adults, and he makes it relevant to the qualities of life near the Levy while retaining some of the magical content to enchant the children. ${ }^{58}$

Once the children encounter the witch in their community, the story maintains a similar path to that of the Grimms. Rhymes and deceptions initiated by the children are recast in the language of the Levy. Hank is still imprisoned, and Ginger still aids the witch in her preparations. Their escape does not make use of an oven but rather engages with rural humor over the outhouse. The witch's final resting place is at the bottom of the privy's pit. However, her fate is still linked with food and consumption, as the outhouse is the final resting place for all that can be consumed which does not nourish the body. In other variants, she is often burned alive in the oven, a fate no less horrifying; both indicate her removal from the community and presumed return of safety for children living in the area. The Gretel character, Ginger, remains the heroine, as she is vehicle of their rescue.

Upon their return to the farmhouse, the father is clearly still the focus of love for the children, echoing the variants in which the father reveals his affection for them both before and after they are abandoned in the woods. His wife, as in many variants, has conveniently died, so the family is reunited. While the children have learned their own lessons about trusting others in times of need, the father has learned a vital lesson about succumbing to greed at the cost of sacrificing family. Family is more important than sufficient sustenance in life, and if one chooses to ignore this, the rest of one's life will crumble and fall away.

\footnotetext{
${ }^{58}$ This is not to say that witches of a different type are not present in the reality of the Levy. Highly religious and close-knit communities such as the one the story is based in do often hold great suspicion of those who appear to align themselves with the evil forces of the world. In the boundaries of A Magical Country, these could be people from the area who purposefully isolate themselves from other members of the community or those who move in from the outside, as the witch does in this tale.
} 
While the variant in A Magical Country surely includes many of the same elements that Bettelheim and others would indicate are important to the psychological development and anxieties of the child, the story also infuses the traditional tale with a heavier emphasis on family being far more valuable than any precious sweets. In rural areas, where perhaps even a large percent of the community population is genetically related, "Frank and Ginger Go Snipe Hunting" underscores why "blood is thicker than water" is a phrase that is commonly heard, recited in confrontations with outsiders, and used to convince the reluctant teenager to participate in the yearly agricultural work that provides the few delicacies the community enjoys. 


\section{From "Little Red Cap" to "Big Red Cap": \\ Urban Wilderness}

The short story "Big Red Cap" from A Magical Country serves to emphasize the intersection of rural and urban life by using elements from the Little Red Riding Hood, ${ }^{59}$ LRRH, story. The story maintains some of the necessary central motifs outlined by the scholarship, but many of the setting and character details have changed to present a clear set of anxieties related to the rural community depicted in the collection. Just as Charles Perrault and Walt Disney recast the tale to fit the cultural experience most familiar to their own audiences, this variant highlights certain attitudes of the rural south and Appalachia.

This new story, however, must still remain in the tradition to maintain a relationship that evokes the earlier retellings. The most well-known of these variants among American viewers is "Little Red Cap" by Jacob and Wilhelm Grimm. Their text includes all the motifs of the LRRH tale that often make it into oral variants, a warning not to leave the path [J21.5]; the sick grandmother; the basket of goodies to be delivered; the deceptive and charming wolf; the refrain over the size and function of the wolf's big ears [Z18.1], eyes, hands, and mouth; and the final rescue [F913] (Uther 224, The Types of International Folktales). This variant arrives in print in the 1812, which places it after Perrault and before Disney in history. However, the tale has clearly been worked into a specific form that removes much of the sexual innuendo and cannibalism that appear in

\footnotetext{
${ }^{59}$ This story is tale type 333 according to Hans-Jörg Uther in The Types of International Folk Tales: A Classification and Bibliography. Of note in the reference work is his change of the type name from "The Glutton" to "Little Red Riding Hood." This is a shift also reflected in most of the scholarship about the story; over time, the Red Riding Hood character has taken much more of a central focus than the wolf.
} 
some of the stories collected by folklorists in the nineteenth century. Therefore, in its own way, "Little Red Cap" is a subversion of a more traditional variant by cleansing the story for a particular German audience.

One of the variations of the Little Red Riding Hood that, according to Maria Tatar in "Introduction: Little Red Riding Hood," reveals roots of the earliest characteristics of the tale can be found in Paul Delarue's "Les Contes merveilleux de Perrault et la tradition populaire," and she claims that it was "presumably told by the fireside at least a century earlier" (3). ${ }^{60}$ His variant, titled "The Story of Grandmother" reveals a more sexual root to the tale. Red Riding Hood finds herself delivering sundries to her grandmother, much like the usual conditions in the story. She must deliver bread and milk along a path in the forest to her rural granny. However, the setting details are brief enough to be nearly nonexistent. The narrator does not reveal the grandmother to be sick or in need of anything, a common condition of other variants. With this absence, the variant focused entirely on the interaction of the wolf with the child. Along the often lyric repetition of LRRH's observation of the wolf's un-grandmotherly features, many of the more contemporary variants feel the need to offer some reason for LRRH's journey into a dangerous forest greater than meal delivery to a presumably healthy woman. Readers of Delarue's variant find themselves squarely in the middle of an interaction between the wolf, a manifestation of masculine violence and trickery, and Little Red's presumed personification of innocence.

However, another character does appear, possibly as the voice of the community of listeners who might have heard this story performed. There is a cat that makes a brief

\footnotetext{
${ }^{60}$ Though the story is sourced from Tatar and her translation, Delarue's work appeared in the Bulletin folklorique de I'lle de France, 1951. The story was collected in 1885 by Louis and François Briffault in Nièvre but later published by Delarue.
} 
appearance. Though the cat is an animal that appears in numerous tales, sometimes as a demonic presence, as in The Boy Who Went Forth to Learn What Fear Was, ${ }^{61}$ and other times as a magical helper Puss in Boots. Here the cat appears as a marker of the sexual innuendo that the story entertains. A naïve young, girl encounters the predatory male, intensified through the guise of copious body hair, large ears, enormous mouth, and big nostrils to snuff tobacco. The cat's commentary is often startling to readers. After LRRH is tricked into eating the flesh and blood of her grandmother in the guise of meat and wine, ${ }^{62}$ the cat declares, "Phooey! You're a slut if you eat the flesh and drink the blood of Granny" (10). However, LRRH does not appear to hear this or does not react, as the text shows no indication that she notices the cat. In turn, the cat seems to speak directly to readers or listeners as perhaps a warning of propriety to young girls.

This warning, centered on the flesh, is extended beyond the cannibalistic realm and into the sexual, as the wolf suggests the girl disrobe and join him in the bed. All of her clothes are burned in the fire, so readers are left to assume the young girl is completely disrobed and vulnerable in the wolf's presence. After she follows through with the traditional observation of his body, the variant hints at the possibility of soiled bed sheets. ${ }^{63}$ All these references to sexuality and trickery belie the contemporary response that many children have regarding the story, that one should never talk to strangers. Distilled to that more generic message, both young boys and girls can take the

\footnotetext{
${ }^{61}$ This story appears as the fourth in the Grimms' collection and appears in Andrew Lang's The Blue Fairy Book from 1889. The tale is type ATU 326.

${ }^{62}$ Tatar provides some commentary about these victuals. She indicates that other local variants of this tale offer specific foods relative to the culture of origin. A local Italian version has the grandmother's flesh turned into stuffing for tortellini, and a French version presents her as sausage ("Introduction: Little Red Riding Hood").

${ }^{63}$ Though the soiled bed sheets are a reference to either urination or defecation, the sexual nature of the story calls to mind the historical expectation, and often direct observation by third parties, of the proof of a young bride's virginity, blood and ruined sheets.
} 
same message away, rather than one that warns them of the pitfalls of their future gender roles in society. It seems likely that parents are still offering up the tale, however, as a defense against sexual predators, even if children are not able to consciously grasp the dangers of "wolves in the forest." With Western society's tendency to minimize or redirect the overt sexual components of these stories, the transition of the tale-type from low-humor adult entertainment to an instructional tale for children becomes clear (Tatar "Introduction: Little Red Riding Hood," 5). Although many contemporary variants use the less-sexually overt model provided by Perrault, contemporary authors often return to the obvious sexual nature of the many other variants. Whether polished by the polite veneer of French Enlightenment aristocratic society or presented as a salacious strip tease, the story's core includes warnings about the dangers of the forest and the pitfalls of male predators in the human social world, it is no coincidence that the wolves are frequently transformed into polished and well-spoken bachelors who hound the young protagonist in the bed and along forest paths. ${ }^{64}$

The young bachelor in the animated variant by Walt Disney is reminiscent of the more wolfish gentlemen in Charles Perrault's text. These adversaries have the gift of persuasion. Perrault's adversary remains the beast that many readers expect. He even appears in a similar fashion to the later variant by the brothers Grimm. However, Perrault felt it necessary to take the folk narrative and emphasize just how difficult it can be for the naïve to detect the dangers of the adult world. He begins his moral by

\footnotetext{
${ }^{64}$ Walt Disney's animated short from 1922 offers up the wolf as a dapper gentleman. Charles Perrault, in the "Moral" provided at the end of his text, references the "tame wolf," men who have mastered the graces of aristocratic society but possess the desire to pursue young, innocent girls when they wander away from observing eyes.
} 
proposing that young and well-bred girls should take care and not listen to just anyone, ${ }^{65}$ for young girls get gobbled up by wolves all the time. However, these wolves are clearly men:

I say a wolf, but not all wolves

Are exactly the same.

Some are perfectly charming,

Not loud, brutal, or angry,

But tame, pleasant, and gentle. (13)

These wolves then follow these young ladies into their homes and bedrooms. Perrault warns at the close: "But watch out if you haven't learned that tame wolves are the most dangerous of all" (13). Perrault clearly indicts the young and well educated men of his own social class, framing the tale then as a warning for young girls and even perhaps as a lesson to young boys that the adults know what they seek.

Disney's wolf does not even retain the beastly form. His antagonist, despite the lack of presented speech in the cartoon, reveals all of his nature via his body language, dress, and possessions. His Laugh-O-Gram cartoon from 1922 depicts the wolf as a finely dressed gentleman traveling via one of the latest technologies, the automobile. Not only is the car fast, nimble, and collapsible for easy carry, it delivers him to the countryside to find his victim. His top hat, fine clothing, and flashy smile mark his social class in the animation; he is wealthy and avaricious. Red Riding Hood also has a vehicle of sorts, but it is driven by a beast of burden, her dog in this case, and is clearly the technology of the past, as the wolf-gentleman's automobile is newer, shinier, branded,

\footnotetext{
${ }^{65}$ This passage also serves to strengthen the perception of class division that would have found a receptive audience in the aristocratic circles and salons that Perrault and the French elite frequented.
} 
and faster. She is saved in the end of this variant by an even newer technology, the airplane. Disney takes the tale from Perrault and updates it for his own generation and culture, yet the predator remains much the same, a man tracking a young girl for his own secret desires and satisfactions.

To refresh the story in contemporary society, an artist must contend with this new polished wolf, and, in an interesting twist, reignite the taboo sexuality or transform it into something new altogether. At the same time, the writer must keep enough of the components that the story is recognized in the tradition of the related variant and thus recalls to mind all the lessons, experiences, and cultural concerns that the historical variants provide.

In terms of what is preserved in the tale, much of the basic plot structure remains the same. This is intentional, as one of the most characteristic aspects of the folk tale is its lack of depth in terms of almost anything other than a sequence of events (Lüthi 11). The characters have little depth and seem to exist in a universe without a sense of time. This last quality certainly works in favor of setting the story in a rural environment; while rural places do in fact change over time, the speed of change and dissemination of new ideas occurs at a rather slow rate, often appearing stagnant and unchanging to outsiders.

In regards to the characters in the tale, they do not reveal the internal dialogue often utilized in narrative fiction to great effect. Fairy tale characters, and in ATU333 Little Red Riding Hood, do not reveal an internal struggle to illustrate their decisions or feelings about the hardships they face. In most cases, readers are simply made aware of the emotional response a character might have and then are shown a connection to a point of action or description. For example, in Perrault's variant, the audience learns of 
LRRH's fear through this narration, “Little Red Riding Hood was afraid at first when she hears the gruff voice of the wolf, but thinking that her grandmother must have caught cold [she addresses the wolf]" (12). In this moment, the narration of her emotional life is sparse. Her fear is not revealed through other possible techniques; the reader neither sees her panicked internal thoughts nor her body language. Her fear is stated, as well as her response; however, readers are left to ponder what the true condition of her internal mind must be like.

If "Big Red Cap" can be seen as a series of shifts or transitions from the early variants of the LRRH story into a contemporary variant that addresses some of the concerns of an American contemporary culture, then the internal life of the characters is one of the most significant. Red Cap reveals a number of details about his own personal life, and the narrator fills in much of Red's internal thought for the reader as well. The other characters in the story remain folktale-like. They don't reveal more than is necessary to complete the sequence of events. However, Red reveals himself in greater detail. He manifests concerns about family, sexuality, and adulthood, all of which are part of the LRRH tradition, but they are presented more openly in this story. This is done to emphasize the separation between the urban and rural in the story and illustrate Red's separation from the protagonists in the other stories told at the store in the frame narrative. Red's story is singled out by his narrator as something different or special and serves as more of a personal-narrative tale. This shift in the narrator, and intended audience within the frame, offers a greater description of internal conflict. In turn, it reveals the possibility that the narrator may be telling a story that contains a partial, personal truth. 
A second shift in the story involves the gender roles in the tale, and these are importantly linked to the setting. Because most variants feature a character traveling from the safety of a home location into a dangerous area, the whole plot development hinges on the protagonists naiveté and innocence in the face of unfamiliar territory. For much of Europe this involved a child or young woman leaving the safety of the town and taking her journey through a dark forest where dangerous creatures lurk. These conditions are reflected in variants by both Perrault and the Grimm bothers. For Walt Disney, this shift is left obvious, but it appears that a young girl leaves the safety of her parents' home for the outside world, a sort of coming of age into dating and adulthood. Even though she still pauses to smell the flowers, the adult world outside is populated with new and curious technology that allows her pursuer greater access. In "Big Red Cap" the rural versus urban is reversed, as the suspicion and fear in rural, isolated areas turns outward rather than inward. Suddenly the dark lines of forest and animals of the landscape become familiar territory, and what lies beyond is the dangerous and unexplored city life. Therefore, Red Cap reveals his fright about leaving his home farmland and traveling, for the first time in his experience, to a metropolitan area. The warnings he receives are about the dangers there, much like LRRH is warned about the dangers in the forest.

In turn, the gender of the protagonist changes to capture the intensity of the setting shift. Uther's description of ATU333 only mentions female protagonists (226). Wolfram Eberhard does, however, mention a possible introduction of the male protagonist. In Dundes' Little Red Riding Hood: A Casebook, he offers up the interplay between tale types when discussing another story, "Grandaunt Tiger:" 
Whether or not one considers "Grandaunt Tiger" to be a cognate of "Little Red Riding Hood" depends in part on the relationship, if any, between Aarne-Thompson tale types 123, The Wolf and the Kids, and 333, The Glutton (Red Riding Hood). ... In the tale type index, there is a specific cross-reference to AT 333, which suggests that folklorist Stith Thompson thought there might be some connection between the two tale types. (22) Tale type 123 does have variants with a male protagonist, so there is at least a precedent; however, most readers are more familiar with a young girl in the central role. In the variant created here, Red Cap becomes a young and inexperienced male about to embark on a ritual of adulthood that becomes necessary in rural life, leaving the country to acquire goods or machinery in the city. The earlier variants' implications of domesticity are not lost entirely with this change; Red Cap must make this journey to ensure that his domestic life remains intact as he has known it. His adversary, in this case a young female working in a sex industry, still embodies one of the greatest dangers of the outside world as perceived within rural communities, the untrustworthiness of city lovers and an assumed lack of morality that leads to deception and fracturing of strong community ties. The "wolf" in Red Cap's life earns a living through a deception, the guise of sexual attraction in exchange for money. Since the moment in the story where he encounters her occurs after readers have discovered that the money he carries is necessary to maintain his life and his family as farmers in the countryside, the possibility of his inexperience leading to the loss of all of his income feels much to Red like a life and death situation. His life as he has always known it is already in disarray and could dissolve away completely if he were to succumb or be tricked. 
Red Cap's experience in A Magical Country is not without context; the story is told as a warning to young Hoss, who may find himself in related situations in the future. Even if the story alters some of the characteristics of earlier variants, the settings, the gender of protagonist and antagonist, and the goal of the journey, the narrative still reveals the heart of ATU 333, a warning of the dangers outside one's boundaries of experience and the implication that each individual as they come of age has no choice but to journey, unguided, out into a great unknown rife with unique dangers. 
SECTION II: A MAGICAL COUNTRY: STORIES FROM APPALACHIA 


\section{PART ONE}

Farmer's Home Journal (1904): “Some Don'ts for Farmers”

Don't talk war nor argue politics with your neighbor while the weeds are growing in your fields. Keep posted on these matters, by all means, but remember the farm should have a generous portion of your attention.

Don't fail to have your country paper and two or more good agricultural papers coming to you. They will lend you a helping hand by timely hints and suggestions.

Don't forget Poor Richard's maxim: "he that by the plow would thrive, himself

must either hold or drive." Your hired hands are doubtless all right, but you should be at the helm yourself.

Don't let your hogs run at large unfed, if you would have them thrive. They will grow breachy and get up trouble between yourself and your neighbors.

Don't put off till tomorrow that which should be done today. A few days of growth of the weeds will make an extra day's labor for your force.

Don't grow a crop and then let it go to waste before gathering it.

Don't allow the boy who drives your cows to and from the pasture to throw stones at them, nor to run them to see which one is the fastest on foot.

Don't fail to mix a liberal portion of whistling with your grumbling.

(Frank Monroe Beverly qtd. in Mt. Sterling Advocate) 
"Make hay while the sun shines." This probably gets uttered over and over by folks who have no sense or knowledge of how important those words really are. Cattle refuse to eat moldy hay until they're nearly starved, and if a man's cattle starves, he's halfway there with them. After the first cut in May, everyone around Peyton's Lick bales up their hay and hopes for a good growing in June and July so they can have a second cut in August before the growing season slows and the tobacco harvest begins. This same sequence happens nearly every year in Peyton's Lick or nearly anywhere in Kentucky where farmers and livestock can be found. A farmer's life is dictated by the forces of the natural world, and as such, the time things get done is decided, most often, by the weather. The summer of 1993 offered up little rain until the early parts of August when a steady but weak drizzle settled in for the first week.

The families of Peyton's Lick made profit on the time by preparing equipment. Balers, both square and round, were oiled and prepped for field work. Tractors were fueled, and mothers and grandmothers rolled, cut, and froze biscuits for the upcoming long days out in the rows. Water, and the coming and going of it, drew all of Peyton's Lick to attention. As everyone gathered around and under it, the water itself circled the community as it had for generations.

Peyton's Lick, and in particular the Levy Store, spanned a watershed valley pregnant with streams and heavy, black flood silt. This earth piled up to form some of the best bottom fields in all of Kentucky, and farmers all around grew both hay and tobacco in these fields, rotating crops every few years. Once the tobacco has drawn up 
the rich nutrients like so many straws, the wild grasses resumed and cattle were allowed to graze and replenish the soils in their own natural ways.

The little store still had one of the old-fashioned drink machines where the lid opened upwards and bottles slid out along a track, furnishing a loud CLUNK at the end when pulled out. In the tracks, the store still sold small-sized Cokes, but the larger bottles of Ale-8, the most popular soft drink, and a local one, wouldn't fit. Instead, they were stocked in a washtub full of ice that was emptied and then refilled each morning. Next to the counter sat a small freezer with a simple selection of ice cream sandwiches or creamsicles. For workers who weren't allowed or able to eat at the family table, the store would make sandwiches at lunch. The choice was limited and often determined by what was around at the time, but a person could always count on bologna and American cheese and white bread. Ray Workman, or his wife Louella, would get out a giant roll of the meat and slice off a single, thick piece. Louella, with a small amount of prodding, would skillet fry the bologna in the small white house they lived in next door. The wooden floor of the country store often offered up an oily sheen from the cleaner and finisher the Workmans used on it weekly. Sometimes the bread and sandwiches would take on a hint of the strong cleaner when the floor had been redone.

Behind the Levy Store, a decrepit rowboat leaned against a diesel tank. The faded and stripped oil based paint neglected to hint at the important missions the small craft embarked on, but the Workmans or any of the men or women who visited the Levy could fish harrowing tales out of recent memory. The geography of the land itself made the craft necessary and vital but not for the families of the Levy. The boat was for the outsiders. North Middletown Road and Bunker Hill Road intersected immediately in 
front of the store. Though the Levy area was also bounded by several smaller lanes, many still gravel, that led farmers to back fields and tenant houses, the true borders were the creeks. Johnson's Crick led North Middletown Road through the valley and into the county. Smaller tributaries weaved throughout the valley. These streams barely trickled during the hottest summer months. Dry spots would expand in the beds, and heavy green moss would stink and fester in the hot summer sun. Before the roads in the area were surfaced, families would drive Model T's up the dry creek beds to church, as better driving could be had there.

When the rains came, usually beginning in the late fall months after the tobacco had been hung up and the hay long put up in bales, the streams swelled to creeks and small bloated rivers. The waters spread out over bottom fields and blanketed the roads, asphalt or otherwise. Outsiders would quickly see why all the barns and farmhouses ringed the crests of hills, and homesteads all became small family islands with the livestock clustered to the fences around yards full of fruit trees.

Perhaps most unique about the Levy was the confinement. Once the floods came to the bottoms, farmers could not return home to their wives. Each home on a hill had a driveway with a creek to cross. The residents of the Levy dared not cross the swift waters, as livestock and vehicles would be lost at the mercy of the current. Thankfully, the area drained swiftly after hard rains, and the waters would recede as quickly as they had risen. Within three to four hours, the valleys resurfaced and men would begin the work of cleaning debris from fencerows and roadways.

Farmers could also begin the task of checking and mending broken fences and in particular water gaps over creeks. These wood and wire gates across creeks allowed the 
water to pass beneath but kept cattle hydrating in the waters from crossing property lines onto another's farm. After the rains, the gaps needed to be checked, and inevitably one would be breached somewhere along the course, and the cattle would be in another's fields. Men, women, boys, and girls shooed and clicked and rounded them back to their proper fields. Somber caretakers retrieved the carcasses of calves fallen into the rushing waters, having suffered from their first and last encounter with what some called the Lord's Waters.

If these waters arrived too soon, the damage escalated. Hay fields ripe with alfalfa or fescue resurfaced flattened, layered with silt, and ruined until the next grow in the spring. Bottom fields with tobacco faced certain destruction. Uncut tobacco could be broken, washed out, and destroyed. For farmers this scene would be heartbreaking, a summer's worth of hard labor and investment trampled by an uncontrollable and unpredictable force. Yet the richest earth was found there and replenished there by those identical forces. Tobacco that had been cut in the field and remained on the stick would at best be muddy and worth only a pittance at the warehouse. At worst it would be swept away.

To escape the waters would have been impossible. Not only did it keep farmers away from the homestead from returning, but it also kept those at home up on the hills. Roads in and out of the valley were cut off, so leaving the Levy could only be done by boat. But farmers fish in cattle ponds and creeks, not on lakes, so boats were scarce. The only one around was the small rowboat at the Levy Store. Inevitably, every couple of years a visitor would be trapped passing through the several square miles of the Levy when the rains came. Rather than waiting out the rising waters, visitors would attempt to 
drive out through them. Ray Workman and any others who happened to be waiting out the flood at the store would fish them out using heavy tractors if possible or the row boat if the waters were deep and warm and feed them until the roads dried. Then the tow trucks would drive in from North Middletown and dreg the carcasses of cars from creek banks and mud holes.

So when the early August drizzle began in 1993, the farmers took note. When it lasted for a week, they became wary. Heavier rains always came later, after the hay and tobacco harvests, so when rains started early, all eyes in the Levy looked to the sky and to the fields in hopes the two would not meet until the leaves changed. The curse of a wet August broke for a short period after the week; the slow soaking gradually dried out and farm houses buzzed with talk of cutting the bottom fields and the luck of dry weather to begin curing and drying tobacco. Homer Johnson hired his usual crew of six illegals to work his bottom three acres of tobacco. Within the week, all the head-tall burley plants lay aligned in rows along the dark earth, each bundle heavy as a bag of sand and ready to hoist into the barn for curing. Homer, well into his sixties and technically retired from farming, set his two sons in charge of gathering the bundles onto the wagons and set off to the Levy Store to loaf. The boys knew well enough by this point how to do the work, and even if they did not, the strength to manhandle the bundles had mostly left him. Once he arrived, he saw an old green Chevy parked out front that he knew belonged to Julian Bowles.

Julian and Homer were related by marriage through second cousins, but they shared ownership of a round baler that Homer kept on his property. With each hay cut, Homer would either bring the baler down himself and get Julian's hay up and take half-a- 
dozen bales home himself for the work, or Julian might use it himself if the field was light or the hay too brittle and dry. Julian himself had two sons and a daughter, but they were all still young, too young to do much tobacco cutting or housing. In his early thirties, Julian still led the work himself, but even at five years old, his daughter Sue would be taken to the fields and to the barn during the whole process. Once she was a young teen, she would be rolled into the farm labor force, joining the boys who had been put to work before her. No available farm hand ever rested idle during tobacco harvest season.

Julian sat in the far corner of the store with an Ale-8 and a sandwich in his hand when Homer entered. Two small tables and four chairs provided a dining and conversation room for patrons. Ray Workman leaned his elbows on the counter next to a mechanical cash register, nodded to Homer as he stepped in, and resumed his conversation with Julian. "So Beulah is up in Paris, at the hospital?"

"Yessir, she's visiting her Aunt Mamie who has the diabetes and the legs that are bothering her."

"She be back today?" asked Ray.

"She'll be back before dusk, I reckon. The kids are with her."

"Afternoon, Julian," said Homer. He touched the brim of a Bunton Seed cap as if to wave and took a nod towards Ray. "Ray, I see you're up to no good as usual."

"You know," said Ray, "I wouldn't be a Workman without it. What can we do for you?"

“I don't need nothing, just lettin' my boys get at the work today." He looked over to Julian, "So how's Mamie?" 
"In Paris, as you heard. They took her up there, ah, I'd say it was Wednesday night last week, and Beulah's been visitin' with her every other day or so.”

"Well, I suppose that's a good thing," mused Homer, "good to have company for healing. But," he stopped to chuckle, "that leaves Ray here cookin' for you."

Julian nodded and half-smiled but didn't comment. This was his typical style, the pensive farmer, as the others in the Levy came to see him. Everything he said seemed to be rolled over in his mind for several minutes before it worked its way out. "I would never be one to complain. She's gone as long as she's visitin' the sick."

"I hear that," said Homer. "So, Ray, what's the word on the weather? Are we drowned soon?"

"Weather station has us as overcast but not much else for the week. The Almanac says the August should be wetter, but we've already had a week of drizzle."

"Reckon I could come and get your bottom hay up for you this afternoon, Julian, if you're inclined," Homer proposed.

"That'd be right nice. It should be dry enough from the rake if you can get it up. I'll be up in the holler working on tobacco this afternoon."

"Yeah my boys are into it today,” Homer said. "I don't envy all that liftin'. I'll leave you young'uns to it. I'll take riding in John Deere's air conditioning any day over that."

Both Julian and Ray nodded in agreement. Ray owned about thirty acres of farmland as well, but the store kept him more occupied than he needed. He didn't grow tobacco as a result, instead focusing on keeping heads of cattle. Homer ran up an account 
with him each year on feed corn and foodstuffs, and when Homer made his baling rounds in the fall, he took to Ray's fields as well to settle up part of the tab.

The men loafing in the store turned their conversation to alfalfa seed vendors as Shirley and Russel Bishop both stepped in from the fields, their overalls stained with tobacco juice and their hands browning from cutting all morning.

"Well, ain't that a sight," teased Homer, "two forty-five-year-old rats lookin' for a shed!" The men were fraternal twins, but Shirley's face was as round and squat as Russel's was large and long. They stood the same height, and a stranger could know they were twins almost by watching them walk in-step from place to place. The Bishops owned a farm about mile down Bunker Hill Road, where the old train trellis butted up to a stone fence built to keep livestock off the rails. The asphalt road was laid down on part of the old rail bed and veered off at the beginning of the Bishop property.

"Rats are a sight better lookin' than an old man bein' lazy," Shirley retorted, his round face twisting into a giggle. "We've been out since daybreak."

"Please tell me," Russel continued, "that you weasels haven't been here loafin' since then. The Lord don't associate with idlers from what I hear."

"Shoo, boys, I done more work before I was six than you young'uns have done in all your years," roared Homer. Julian, Ray, and the Bishops took to a hearty laugh with him, and the afternoon began like so many others in the Levy. Noon struck on the cuckoo clock in the store, and the men steeled themselves for the second half of a long and arduous day. Summer hours were the longest, as farm work did not proceed in shifts but passed by the light. More work than could ever be done waited out in the fields and barns, so work started at dawn and ended just after dusk. The men chatted until a few 
minutes after noon before the conversation grew sparse and their thoughts turned to what needed to be done on the farm in the afternoon and evening. As they turned their thoughts to leaving, the topic of weather came up again, and Ray confirmed again that the weather service indicated no rain in the area for the day despite the cloud cover.

Julian stood to leave first, thanking Ray for the sandwich.

"That's right," added Homer, "Ray, you got the freshest week-old bologna in all the Levy."

Then men heard the faint sound of a small four-stroke engine growing louder. They all, except Ray, stepped out to the front porch of the store and watched as Billy "Hoss" Hayes, a scrappy thirteen-year-old with a penchant for rifles, and his sister Helen veered into the lot on a Kawasaki four-wheeler.

"Howdy to the Hayes, there," called Homer. Julian nodded at the boy. The Bishops exchanged glances. "Helen, what're you doing out and about with Hosscat here?"

"Hossy is showing me how to get feed corn from Mr. Workman," the little girl said. At eight years old, she was already set to task on some of the simpler farm chores. Two generations prior, her grandmother would have mounted the family horse, Shifty, and ridden down here alone by age eight. Her grandmother as a little girl did not know the exact way to the Levy Store from the Hayes farm on the outer edge of the Levy area, but Shifty knew the exact route and would walk it without guidance. The storekeeper would have loaded the sacks of feed corn on the horse behind the saddle, and with a quick pat on the rump, Shifty would turn and lazily pace back to the Hayes house. Now that upkeep on a four-wheeler was cheaper than keeping a horse. The Hayes used it to 
make quick trips back and forth from the store. Hoss struggled with the heavy seed bags as he tried to situate two on the rear rack of the four-wheeler. Without a word, Julian stepped over to help him adjust. As Julian pulled a ratchet strap taught to secure the load, a heavy crack of thunder penetrated the cloud cover and rocked the valley.

"No rain, no rain, no rain," muttered long-faced Russel Bishop. His brother playfully slapped him across the chest.

"Hush up, Russ. You'll curse us for sure. If the Will wants to rain, it'll rain." "Hoss, you and your sister ought to step inside here for a bit and see if that thunder has lightning with it before you go. Don't see no need to be out in the open on that machine if the lightning's coming in." With that, he swung the door open allowing the Hayes children to step inside. The Bishops went back in as well, this time to have their own lunch and buy a quart of oil for a chainsaw. Julian and Homer remained out on the porch, just barely covered by the awning of the store.

Julian looked skyward and pursed his lips. Homer scanned the fields of grasses nearby and watched the waves of wind dip across them. "Don't look right," he muttered.

Julian considered this for a moment, and then said, "I trust the almanac a sight more than I do the weather station. I figure this August is hard one. That cloud span yonder looks like rain whether we are to get it or not."

"We best get to your place to get that hay off your ground if it's to be baled," said Homer.

The men had not yet moved from the porch when the loud pings of raindrops hitting the tin roofs of the Levy Store and the Workmans' home signaled an approaching 
downpour. The children immediately came to the door and Workman questioned from the inside, "Looks like a downpour boys?"

"Something like that," answered Homer.

"It'll soak into the hay, though," spat Julian. "I'll have to turn it again."

"You can't turn nothing while it's raining," answered Homer. "We'd better get back inside."

The rains came to all of the Levy. The clouds swept from the northwest to the southeast on a great belt of moisture. The weather service posted a brief message about the potential for flash floods, but they did not explain the sudden development of precipitation. Two weeks later, the weather service would broadcast a follow-up piece that explored the possibility of flash rain showers developing as a result of sudden velocity changes in water particles at altitude. The service would describe the wonder and awe of primitive societies at these types of unexplained weather events and offered up dismissive recastings of pre-scientific theories that involved revenge from gods or direct connections to human sin. However, in the Levy, it was just an unexpected rain. Most importantly, it was a hard rain.

The rain fell so quickly and with such purpose that the space between land and sky became a thick, gray mist. In the intermittent clarity of sight that comes through rain bursts, the store occupants watched as the rain doused the pick-ups, the four-wheeler, the bags of seed corn, and the roadway surfaces. The rain shed from the asphalt in thick rivulets and filled the usually dry tributary that ran near the Levy Store. For these men and children who lived in the Levy, the swelling of the creek was a familiar sight, but rarely had it risen so quickly. The weather service would later claim rates of near 1.5 to 2 
inches per hour of rainfall.) Within thirty minutes, the creek was up; within an hour, it was up enough that Homer's children called the Levy Store to warn him that the drive was covered. Julian knew that meant his own wooden bridge across the creek, built from sturdy poplar tree trunks embedded in concrete and stone, would be submerged. The Bishops had to cross the creek to their farm, but the waters were usually so shallow they had never needed to even build a bridge; now their shallow crossing had become a violent pool. For the Hayes children, water would have been too high in several spots along the road back to their home.

So they all stayed and waited for the waters to recede. In their experience, these floods were brief and dissipated quickly; they'd all likely be home for dinner. So in the meantime, Homer suggested they engage in his two favorite activities of tellin' gossip and pie eatin'.

The pie, made from gooseberries picked on the Wayley farm just outside the Levy, was delivered from the homestead next door by Louella Workman. She had chores to tend to in the house and enjoyed her privacy, so while she didn't want the whole loafing crew as houseguests, she did feel hospitable enough to bring the pie over and scold Ray into giving the children some ten-cent taffy bars while they were trapped in the store. Once she left to continue her own work, the stranded sat to finding out how to keep themselves occupied. The children began stuffing their faces with pie and candy while Homer challenged the group to see who had the best story from around the Levy. His only conditions were that they were true and that they happened somewhere in the Levy. Homer, however, like most good storytellers, had his own versions of truth, and that became clear when he took the first turn and began his story. He turned to young 
Hoss, poked him in the belly with a wrinkled finger, and asked him, "Son, you ever seen a gorilla? A real, live one?"

When Hoss said no and revealed his wonder with a wide-eyed stare, Homer had him and the others hooked. "Beastly things, they are," he said. And he began his story. 


\section{HOMER JOHNSON'S JOKE TALE: THE CONSEQUENCES OF BEASTLY BEHAVIOR}

One thing Tucker and all the boys knew about Gerber Stubbs had to do with his wife; she was dead. She died three years ago when she lost her footing hanging tobacco and fell two stories out of the tar-colored barn after her head hit a crossbeam on the way down and snapped her neck. Stubbs never forgave himself, and neither did the others, really, as they felt a woman should have never been up in the barn anyhow. Stubbs came to think this as well, despite his own vivid memory of her strong will: "I can do it as good as any man could!” And she was right, as men have also fallen from barn beams and died.

Her death changed Stubbs, and pretty much everyone knew it. The boys in Peyton's Lick certainly did. They watched him from the bushes just down the holler with the binoculars that Tucker's dad brought back from town. Rooter kept watch. Bags handled the strategy. Most days the boys slipped by the property on their way to fish for crappie or harass turtles in the still water of the creek bend. They didn't tarry long until Bags realized that Stubbs seemed to be ranting and raving in his front yard more than usual. Stubbs had always talked to himself after his wife's death, but this was new. He seemed angrier, more determined. He yelled at trees and pissed all over the morning glories. Tucker peered through the glasses and discovered that Stubbs had stopped shaving. "He looks like a drowned squirrel in the face," he said. 
Tucker, Rooter, and Bags had no relation to Stubbs, not that they knew about anyway, but they had been visiting his land and adventuring across and around it since they could walk. At their youngest, Mrs. Stubbs, alive and hearty, loved to see the boys around. She would shuffle them inside and fill them with rhubarb jam and biscuits. She'd then shoo them out to go play again. Old man Stubbs and his wife once had children around the farm, but they'd long since left and won jobs and wives in town. So it was a grandmotherish thing for her to take care of the boys, and everyone seemed to enjoy it, even Stubbs to a degree. He never revealed much of a liking for the boys, but he tolerated them and occasionally gave them some work, like bringing in firewood or collecting tobacco sticks, when they seemed to grow listless or lazy around his farmhouse.

The boys didn't resent the extra work, really, so they helped out in the nature of being neighborly and friendly. But being boys, they still performed a bit of mischief now and then. One day, when Tucker lit the tail feathers of Stubbs' prized Jersey Giant hen, the bird screeched bloody murder until Mrs. Stubbs beat the flame out with a stick broom. Old Stubbs gathered the boys up and tore into them until spittle pocked all their faces. So they knew Stubbs could get angry, but they'd never seen him the way he'd become as of late.

Despite the risks, boredom itched at them too much, and they decided that maybe a jolt of some sort would snap Stubbs out of his funk and get him on his merry way. Bags was the kid who came up with the brilliant idea, and this was no unusual thing as both Tucker and Rooter would easily admit Bags to be the brains of the holler. Bags himself would claim it too, and so when he announced his plan, he did it in style. 
In the July dusk near the fishing bend of Peyton's Lick Crick, Bags donned an old leather bomber jacket he thieved from his father's "too small" closet section and even slipped on some sunglasses for effect. "Men," he began, "what we have here is a mission to help one of our neighbors. He's a proud country man who has fallen to the wiles of the devil, now ranting and raving across the field over yonder without any recollection of how to live a normal human life."

"What do you mean by a normal human life?" asked Rooter.

"Shut up Rooter," snipped Tucker, "this ain’t school.” Rooter pouted a bit but kept his trap shut. He had failed the second grade three times, and both Tucker and Bags would tease that hair as often as possible. "Go on, chief," said Tucker.

"As I was saying, we are going to help Old Stubbs out by playing a little joke on him that he'll think is funny as hell."

"How is that a way to get him to be nicer?" asked Rooter. "Ain't he just already mad anyway?"

Bags straightened his back, stood firmly on a log, and pronounced in his most adult voice, "As my politician has told me, laughter is the best medicine."

"You don't have any politician telling you that," said Rooter. "He just tells you to behave and brush your teeth and don't eat souse too much."

"Maybe I got a better one," snapped Bags. "Anyway, making people laugh is always a good thing. It even says so in the Bible.”

"It don't say that in the Bible," said Tucker. He spit at the log Bags had claimed. "You don't even know what the Bible says," replied Bags. "Hell, I doubt you can even read, Tucker, unless it's some love letter you wrote to Dirty Jenny Dieter." 
Tucker jumped up and grabbed Bags by the head. Tucker was a good six inches taller and 30 pounds heavier than Bags, and with all that extra meat lifted him up and promptly dropped him butt cheeks first into the crick. Tucker braced himself for Bags to charge at him like a bull, but Bags simply jumped up like a lightning bolt and screamed, "BANG!"

"Bang at what?" asked Rooter.

"I've got the idea!" Bags smiled like a donkey in a shithouse. "My pa has an old gorilla costume he used to scare my cousins. We'll get it and have old Tucker Gorilla here wear it and sneak up on Stubbs while he's out in the yard!"

"We should go at night and act like the gorilla is watching him through the windows," began Rooter.

“Boy, you'll get your ass shot doing that. Don't sneak up on Stubbs while he's inside with that shotgun. You gotta' sneak up on him while he's outside ranting and raving and away from the firearm."

And so this was their plan.

They sprung the trap on a Thursday. Bags had snuck the gorilla costume from the cellar and hidden it in the shrubs beneath a stand of poplar trees bordering Old Stubbs' property. The boys crept to the meeting spot just before dusk and Tucker squeezed into the suit.

“Shit, boy, do you look the part!” hollered Bags.

“Dirty Dieter told me he was already part gorilla, anyhow!" piped Rooter. 
"SHUT UP ROOTER," the other boys chirped. Bags added, "We have some serious shit to attend to here. Tucker is about to become a legend."

"What's the plan?" asked Rooter. "What's Tucker going to do?"

“Tucker knows what to do," said Bags. Tucker mumbled a muffled noise through the suit, but then just nodded. He gave a thumbs up. "Go on, Tucker. We'll watch here and make a distraction for you to escape if Stubbs gets weird. I mean weirder than usual."

Tucker crept out of the shrubs as the other boys knelt and peered on toward the action. Gorilla Tucker took long, huge strides, like he once saw in a Bigfoot video. Stubbs paced the yard, clearly drunk. A harrowed beard clung to his face, straggling hairs and tufts poofed out all over. He lilted to his left side every so often, his teeth bared through one corner of his mouth. He carried a tobacco stick in one hand, swinging it first at the salt tub, then at the woodpile, then up, as if he were beating dragons from the sky. He screamed with fury at the universe.

Tucker lurched around the corner of the house, behind Stubbs. At the end of one set of paces, Stubbs turned abruptly. He looked square on at Gorilla Tucker. Stubbs let out a wail that sounded like a cross between a cattle call and the death cries of a pea-hen. Tucker weakly raised his arms and spread his fingers out. He roared like he thought a gorilla should sound. Then, Stubbs charged.

Stubbs' ferocious reply surprised all the boys, but most especially Tucker, who was vulnerable out in the open. Under normal circumstances, Tucker would have been at least as strong as Stubbs and likely to overpower him. Maybe this is what kept Tucker from running when Stubbs raised the jagged tobacco stick and leaned full-on into a 
charge. Stubbs' Last Stand, as the event would later be remembered, began and ended in a matter of seconds. It went like this. Stubbs charged. Gorilla Tucker panicked and turned his back to his enemy. He tried to run, but Stubbs was already in full motion. The stick, only about two feet long, slammed hard into the cusp of Tucker's shoulder, staggering him. The second blow sent the gorilla directly into the arms of a climbing rose bush, full of bright red blossoms. Tucker struggled in the branches, rolling, moaning, and clutching the curve of his head behind the ear. As he crawled out of the ruined bushes, hot colored petals clung to the fur of the suit and blood seeped into the black polyester fibers. As Stubbs clenched the furry gorilla's leg, he pulled him from the bush and began dragging him toward the house. Struggling inch by inch, Bags and Rooter flashed a look of fear at one another and ran off.

"If he were going to kill him or skin him he would've already done it," Bags said. "We would have heard it, so Tucker must be alright in there somehow."

“Shouldn't we just get some help? Dad's out in the holler, but I bet Mr. Lyons is around and can help. He was a volunteer firefighter!"

“Rooter, just shut up unless you're going to help me. If we tell anyone, they'll say it was our fault for talking Tucker into it. Plus, we ain't got time. Stubbs might be ready to skin him right now. I got a plan, but we need to get Jenny Dieter over here. Stubbs has gotta' be sweet on the ladies, at least more'n us. Rooter, and now this is important so listen up, I want you to get over to her place and get her over here. Tell her Tucker's in some trouble. I'll try to get close while you're gone and see if I can do some reconnaissance." 
“Some what?" Rooter asked.

"Just go get her, damnit!"

So Rooter took off and Bags steeled himself for his own encounter with Stubbs.

Jenny Dieter sat on the back porch with a worn Swiss Army knife, slicing slivers of wood off a knotted twig and whittling it down. For each stroke, she had to strain hard to get a cut in, since her father had passed on after he had given her the knife but before he had taught her to sharpen it. Her stepfather wrote textbooks about angles and calculations for a living, and he didn't have much use for knives or sharp things in his line of work. When he moved to the farm, Jenny wished that he had never visited their country church and met her mother, but all in all, he turned out mostly all right. He left Jenny alone to do what she pleased and at least talked to her nice most of the time.

As she worked a knot on the twig, Jenny realized that she kept working Tucker over and over in her mind the same way. She would think of his oversized body and take her mental knife to the parts she wanted off, like his goofy haircut, the bad tooth he had in front, and the slight slump in his shoulders. Even with all that, though, he kept working his way into her mind. That both irritated her and intrigued her. Tucker had the same determined but slow eyes her father had. She could respect that.

What she could not respect was the way he constantly ignored her. He spent all his days troublemaking with Rooter and Bags, and Jenny couldn't understand much why a boy would want to do that when he could have her. This also made her think of her father. She had a memory of when the bright daylight sifted through the windows in the TV room and cast these long soft rays onto a maroon and black floral patterned couch. It 
looked heavenly, or it might just have been dusty, but all this light filled the whole room. Jenny saw her father sitting in a faded orange recliner, and her mother sat across his lap. Her parents kissed briefly, no tongue. Jenny's mother whispered something into his ear. He gazed into her eyes for a brief moment before lowering his head against her breasts. He moved his head from side-to-side, pressing his face deep into the fabric of her shirt. He pulled away, and whispered something back. Jenny noticed that her mother's shirt was damp in small tiny spots, but she didn't know why until she saw the wetness on her father's face. He tried to whisper something else, but he never got past a word or two before his body sagged, and he pushed his forehead back against the body of his wife. It was at this moment that Jenny was discovered leaning against the door frame, wide-eyed and confused.

Jenny's mother always claimed that there was no way she could have remembered something like that. She was way too young, and it was way too long ago. Jenny's father died less than two years later, and she had few other memories of him. She remembered when he gave her the knife, but she didn't even remember what he said. She remembered his face had the texture of Play-Doh at his funeral. She recalled asking why he didn't move any more. She remembered that no one really answered her.

Jenny also knew that the same shirt her mother had worn in the memory-shewasn't-supposed-to-have was one that her father had bought at a county fair. It was a simple cotton t-shirt, but she wore it often. It lay folded in half, hanging over the bottom of the bed for two years. A week after Jenny's future stepfather visited their church, the shirt disappeared forever. 
To complicate matters, for Jenny at least, almost every time she saw Tucker, she thought of that shirt. She longed to know why the t-shirt haunted her so much. Somehow, Tucker was wrapped up in all this, she figured, but she couldn't quite understand how. So she often set to whittling, hoping it would, some way or another, help her mind work it out.

As for the other boys, Jenny didn't care much for them. Rooter just did whatever anyone told him, and Bags was never straightforward. He always had some plan or scheme in the works. Out of the four boys that lived within miles, Tucker would always be the best, she thought. The fourth was the Johnson's crippled boy, and he never left the house anyhow.

Yes, Tucker and his lumbering kindness found Jenny's sharp but cautious attention somewhere along the way. And now that the summer was almost over and school would gather them all back up from the countryside, her time was running out. Girls would surround him again in August, but what could she do? As she pondered whether to just scrape the knot in the stick clean off, she saw the frantic figure of a running Rooter coming up the gravel drive.

Bags shimmied up along the side of the house where the rose bush grew and marveled at the tufts of gorilla hair sprouting off all the thorns. The bushes were completely mangled, but at least it gave him easier access to the house. He looked in the window and saw the damnedest thing. The gorilla suit, clearly damp and heavy, was laid out along the mantel above the fireplace, drying slowly. Bags looked for blood on the suit, but it was mostly dark in there. Tucker was nowhere to be seen. Stubbs entered the 
room and Bags ducked below the windowsill. When Bags gathered the courage to look up over again, Stubbs had his back to him. Stubbs put an old iron pot, big as a head or two heads, up on the cooking stove and took some coals from the hot fireplace to start a fire underneath. A whirlwind of muffled cussing caught Bags' ears as a terrible feeling washed over him. I hope Tucker is not dinner. The possibility that Stubbs, crazy as a loon, might have thought Tucker was in fact a real gorilla and tried to skin him was terrifying, but he had to wait. If Tucker was such an easy catch, there was no way he could face Stubbs alone. He needed a distraction, but he really wanted Jenny Dieter to get there and talk Stubbs down before Tucker was eaten up.

When Jenny arrived with Rooter at a stand of trees just east of the Stubbs house, the sun had almost set. In the twilight, Bags noticed she was wearing a tank top the same color as her blonde hair. When she smiled, the big gap in her front teeth opened up, and when Bags looked away, he noticed she wasn't wearing a bra. Her shorts were cut-off jeans, and he saw the goose bumps pricking up in the cooling air. "This had better be good," she said. "I was about to make out with a boy better looking than any of you before Rooter interrupted me for whatever this emergency is."

“I didn't see nobody there," said Rooter.

"Shut up, Rooter," Jenny replied. "He was on his way. Anyway, what am I exactly here for?"

"Well," began Bags, "it is like this. We need you to go inside and get Tucker. Simple, see? I'm surprised Root didn't tell you." Rooter frowned and kicked at dirt and pine needles. 
"He tried, but it made no sense. Something about Stubbs and gorilla or you and a gorilla. I'm not sure, but I also ain't sure I want to help you."

“Then why'd you come, anyway. This is dangerous, so if you aren't all-in with us, then you ain't no use," Rooter replied. He knew that Dirty Jenny Dieter was a bit sweet on Tucker and would help out for that alone.

"I'm in. I'm in," she said, and flashed her teeth at him. "As long as I don't get hurt, or don't get hurt more than the hurt I do."

“Alright," began Bags, "Here's the deal. Tucker's inside with Stubbs, at least I think. I never saw him in there, but Stubbs took him in earlier, and no one's left yet. What we need is for you to go up there, knock on the door, and get Tucker out."

"That don't make no sense," Dieter said, a hand on her hip and one stuck in her back pocket. "You could do that."

"Yeah, but Stubbs hates on us, and you know that. He don't hate you. You're a girl. He'd never put a hand on you, so you should go on up there and knock. Besides, everybody knows you'd like Tucker to be sweet on you, and you ain't gonna' get a better chance. Tucker needs you."

Dieter looked past the boys and up to the house, where the windows flickered with firelight. The farmhouse looked settled in for the night, and she still didn't quite figure they were telling her everything. "Something ain’t right. You haven't told me all of it. What did you all do to get Tucker in there?"

“Damnit!” snapped Bags. "We played a joke on Stubbs, but we don’t have time for all that now. We're afraid Stubbs might hurt him, ranting, and raving as he has of late, but we know he won't hurt you. Go'on up there and rescue your boy!" 
"He ain’t my boy," she said, "yet. But why should I care to get you two out of trouble." Her eyebrows furrowed, and she look back at the house.

"Look," said Bags. He pulled out a patch of the gorilla hair. "I found this after Stubbs took him in. Could be Tucker's. We can't call the police or nothing because we'd get whipped good for messing with Stubbs."

Dieter left the boys and approached the house. Timidly, she lifted her hand up to the door, looked back at the boys hiding in the brush, and then knocked loudly three times. She heard a low murmur from the other side of the door. The voice maintained a steady, even pace. She knocked again, more loudly. The voice stopped. Dieter blinked at the sharp click of a hasp, and the door swung open to reveal Old Stubbs grinning like a corpse. His jowls drooped like icing, but his eyes radiated a sharp brightness and a strange elation. "What can I do for you, little dear?" he asked.

"I c-c-came to see how you were doing," began Dieter. She shifted her weight from one foot to the other. The thin rail of her body nearly disappeared in the flush of warm light from the doorway.

"Well, now," began Stubbs, "It is clearly a day for visiting. You're the second that's come around to see me, though a fair might prettier than the last, I'd say. Come in if you like. We were just starting dinner."

Dieter entered the house, and the whole place smelled like meat and onions fried in a skillet. Tucker sat the kitchen table, and on the table, two plates of cubed steak steamed on opposite ends of the periwinkle tablecloth. Tucker's arms were in his lap, underneath the table, and Dieter couldn't see where his hands were. She wondered if 
they were tied up down there, as he hadn't taken a bit of anything on the plate yet.

Stubbs stepped past her and dragged another chair to the side of the table. He sat back in his own spot. "Have a seat there, young lady," he said. Dieter noticed his voice was soft and buoyant, certainly not what she had expected from the raving madman Stubbs had become as of late.

She sat down tenderly in the chair and looked over at Tucker. His face, particularly his forehead, was traced with small, bloody scratches. They looked as if they had been cleaned and dried. "What are you gentlemen doing?" she asked.

"We are having a bit of dinner and conversation," replied Stubbs. He took a drink from a bottle of bourbon on the table near him. "Drink?" he asked. He waved the bottle dangerously in her direction.

"No thanks," she said. Dieter tried her best to keep a neutral expression on her face. She wanted to help Tucker, and he looked tired and scared enough and possibly violent.

Stubbs tried to reply, but the words came out quiet and mumbled. Now closer to the table, Dieter looked at the plates of food and frowned deeply at the steaks. They were gristly, undercooked, and horribly unappetizing. She plotted her next move. Tucker looked exhausted, scared, and frozen. She didn't know what Stubbs had said to him, but Tucker barely had the courage to make eye contact with her, much less remove himself from the table. She thought of grabbing him and running, but Stubbs had a number of guns, two of which, a 14 gauge shotgun and a .22 rifle, leaned in the corner beside the fridge. The gorilla suit had probably already spooked him, so she didn't want to take any 
chances with sudden moves. She wondered what the best way to get them both out would be.

"So what have you two been doing," she asked.

"Weeeelll," began Stubbs, "we been talking about good and evil and the nature of life and being boys and so on, so on." He tried to take another drink of bourbon, but missed part of his mouth. The leavings soaked and spread into his red flannel shirt collar. "Don't mind that," he said. "It's been a while since I had company over for dinner, and it has been nice for us to have a, whatever you call it, a chat."

Tucker stared directly at the table, as if he were counting each wrinkle in the tablecloth. Dieter kicked him under the table, but he still sat unresponsive.

"Wooooooooo buddy!" Stubbs hollered with his head tilted toward the ceiling. "What a talk we have had, boy howdy!"

Dieter frowned and started to worry a bit. She'd seen a lot of drunk men in her life, and this Stubbs was no different than most. She could tell he'd already had way too much to get violent and wondered if he'd even make it through dinner. What worried her was the undercurrent of what his mind was doing. His wife's death had changed him into the holler's halfwit, and that meant that even drunk beyond coordination he could still be a bit squirrelly.

"I tell you what," said Dieter, “Tucker don't look like he has much more talk in him, now does he? Why don't you send him on home and I'll stick around and have dinner with you. Tucker ain't hungry noway. My momma tried to cook for him before and get him over, but he don't know good food when he smells it." 
Stubbs pounded his fist on the table. Tucker, startled, looked up and glanced nervously at Dieter, then Stubbs. He went back to staring at the table. "I," began Stubbs, "that'd be alright. You seem like a nice enough young lady."

"Ok, then, I'll see Tucker off, then." Dieter stood up but did not move from the table. Stubbs reeled and didn't stay focused as she pushed the breath sharply through the gap in her teeth and hissed at Tucker. "Here's your chance fool, get on out of here." Tucker stood slowly and painfully. His eyes left the table and he gave Dieter a sad, weak smile. He opened his mouth as if to speak, but nothing came out, and he simply turned and left. Dieter had no idea what happened to him, exactly, as neither Rooter or Bags were much use with details. She figured that later she could find out about all of it, but now she had to find a way to get herself safely out of the situation.

Dieter sat back down where Tucker had been, not only to face Stubbs and predict any craziness, but also to get a bit farther away from him. She was about to make some comment about dinner and getting started when Stubbs let out a low, pitiful moan. Dieter felt it in the floor, the chair, her ears, her whole body. The horrible sound, to her, felt like all the regrets she had ever formed being thrust out into one, solid breath. Her spirits sank and she considered that she may be in more danger than she thought at first. Then Stubbs lolled his head around a bit before starting to speak.

"Young lady," he began with startling clarity. "I don't know if you know what that boy did today, but it's no matter anyhow. You are about the prettiest thing I've seen in this house since Betty died. I loved her dearly and had dinner with her every night. We talked about everything we could think of, and she was the best company on the whole Earth. I miss her a great deal.” And with that, Dieter began to listen intently as 
the drunken Stubbs began to tell her the whole story of his life with his late wife Betty and all their hopes and dreams.

Stubbs spent a great deal of time storytelling over the dinner table, he on one end and the young teenage Jenny Dieter on the other. Jenny learned of the way Stubbs proposed to Betty, the first time from the seat of the tractor when she was bringing him lemonade on a hot summer day, and how she rejected him because she felt he had a bad attitude and didn't think often enough of others. Stubbs told her how he spent weeks and months trying to mold himself to what Betty envisioned for him, but the short of it was that the way he felt most complete and humble happened to be when she was with him.

Stubbs watched Betty carefully and she did the kindest acts for people who were sick or needed help. He saw her serve up her last ham to a family newly moved to the area. He saw her make gooseberry pies for the churchwomen on Mother's Day. Gradually, he tried to model the way she lived her life. He never cared much for pies, but he started offering a helping hand to his neighbors in tobacco season. He lent out his bailer to help with hay on other farms.

Betty knew that it was hard to change anyone completely, and even Stubbs, now long lonely, had realized that when she agreed to marry him it probably wasn't because he was really all that different. What he had shown her was that he was willing to even become another man to prove he loved her, and that was enough to make her love the man he really was. This tipped the scales in his favor, and then, to the shock of everyone who knew them back then, Betty proposed to Stubbs. 
"I accepted, of course," he told Dieter. "She was the most fantastic woman I have ever met and would have been an even better man than I was, or am." Stubbs sighed heavily and drooped his head. "She's been gone for so long," he whimpered.

Dieter looked at his plate, full of neglected food, and then at hers. During the conversation, she had chopped everything in smaller bits and rearranged them to look like she was eating more, but now she simply lowered her fork and examined the pitiful man in front of her. Is this what the boys were afraid of? she wondered, this sad, sad man. She marveled at the strength of his love and the weakness of his mind and body and wondered if such things were in store for her. How could she love Tucker or anyone if this is what it does to people? She felt confused. She hated Stubbs for being weird and hateful and kidnapping Tucker. She pitied and wanted better things for him because of love and Betty and kisses under trees and all those things. As her mind flew in circles, she suddenly realized that Stubbs was snoring.

He sat, chin to chest, fast asleep in the chair. It even sounded as if he were still half-sobbing into his shirt. Dieter pushed her chair back ever-so-slowly and slinked out the front door. In the moonlight, she could make out the faint outlines of the hiding boys. She waved at the boys and then made a motion with her hand to shush them. Along the side of the house, she saw rose bush, now somehow recovered and hot all over with blossoms. The beautiful flowers seemed even brighter now in darkness than they had in the daylight. Tucker's, for some reason deep inside her, she recognized Tucker immediately, but the other two were just confused shadows. Dieter gathered a bundle of roses from the bush, using her long nails to clip the branches between the thorns. 
She returned to the inside of the house and the dinner table and the bereaved and sleeping Stubbs. In his bourbon bottle, now mostly empty, she arranged several of the red roses. They burst out from the top in a bright display of hope and joy. She put her hands on her hips and smiled at her work. She leaned over the upright sleeping Stubbs, smelled the sharp hook of liquor on his breath, and pushed her lips together softly to kiss his forehead. She sighed heavily and left him to his sleep.

The next day, the boys peppered Tucker with questions about what Old Stubbs had done, but he refused to even speak about it. He simply told them he had no wish to ever go back there, that he had seen enough. Dieter, likewise, didn't share anything, and Rooter, and especially Bags, tried everything under the sun to get them to tell it all. They figured it must be some kind of fantastic story.

At the center of it all, though, Rooter and Bags were as ignorant as anybody could be. Tucker felt a warm, soft lump in his belly every time he thought of Dieter coming to his rescue, and Dieter began to think much more often of true love and the hope that it might bring her in life. From that day forward, even Stubbs stopped his yard rants and wandering.

So, then, for Bags and for Rooter and for most of the rest of Peyton's Lick, the whole plot with the gorilla suit, the arrival of Dirty Jenny Dieter, and the final escape, lived on as a local legend of girl done good and man reformed. But for Jenny, the most important part of the story happened a week after all the exciting stuff took place. She, under the cover of twilight, kissed Tucker for the first time and gave him the most important gift of all, a simple cotton extra-large t-shirt. 


\section{PART TWO}

As Homer finished up his tale of a man reformed through the power of love and tenderness, the other men in the store quickly realized that Helen Hayes was entirely bored out of her mind. She had her hair pulled back into a scraggly ponytail tied by an old blue rubber band. Having been trapped indoors by the rains, she sat in the center of the glossy, wooden floor with a pile of corn kernels splayed out before her. She had begun arranging them into stick figures and animals, and she was making a wide-bellied fish with a penny for an eye when Ray Workman asked her if she liked any stories.

"I like the ones that mommy tells me," she said, not looking up from her art.

"What are those stories like?” asked Ray.

“They are like," she began. She stopped to think for a moment, looking up from her corn. The dried yellow kernels formed a scattered pile around the outline of the fish. She began to arrange rows of kernels into waves beneath her fish when she suddenly turned her hands into paddles and scooped them all back up into a single pile. "They are like stories from books!" she exclaimed.

“Are the people in books like the people you know around here?" asked Ray.

"Not always," she replied. "Not really. Sometimes I see things like here, like tractors and fields with grass growing in them." 
"Well," Ray began in a soft voice, "Sometimes the best stories you can hear, and the ones that are the most magical, are the ones that are about real people. I have a story about your great-grandmother that you might like to hear. Do you like horses?"

"I like horses," she said. "Daddy used to have one. It was brown. Horses are always brown. They have scratchy tongues. It ate oats off my hand."

“Did you know your great-grandmother had a very special horse?" Ray asked. "No," she said. "I bet it was a brown horse, though."

"Yes," Ray began, "It was a brown horse, but it was much more special than just an brown horse. That horse was her best friend in the whole world. Would you like me to tell you about it?"

"Only if the horse is brown and it likes oats," she proposed.

"Well, it is both," Ray answered. "Come over here, and I'll tell you and all the fellas here about it."

Helen hopped up and took two steps toward the loafing tables before looking down with a sad and dejected face. Ray saw her glance at a rack of Moonpies, but she said nothing, instead swaying gently in front of the men.

"Go head," Ray said. Homer chuckled and shook his head. "You can get you a Moonpie snack. Pick one out, and come over, here and sit while you eat it."

A maniacal giggle erupted out of her, and she danced over to carefully select a chocolate pie from the rack. She skipped back to the table and sat cross-legged on the floor in front of the men. "Ok, dear," Ray began. "Let's hear about this horse." Ray began and Homer, Julian, and the Bishops turned to listen intently. Hoss feigned disinterest, but he still had his head turned to where he could hear Ray's every word. 


\section{RAY WORKMAN'S ANIMAL TALE: \\ SHIFTY THE CLEVER FOAL}

Once upon a time, and this time was long before any of us were around, Helen, your great grandmother Ida was a little girl just like you. Well, she was a bit older than you, just a tad older than your brother Hoss. She had two brothers, one eighteen years old, and the other sixteen. Both were old enough to almost be men, but your great grandmother was younger, and still in some ways a little girl. All three lived on a farm here in the Levy, but not the one you live on now, with their father, Roger. Their mother wasn't with them anymore because she had gone to live with the Lord, and the sad day came when her father left to live with the Lord, too.

Their father wasn't a wealthy man. Though he tried his best, the years then were hard and dry, but they did make enough to eat good food most days. When he left this Earth, the siblings agreed to decide it amongst themselves. Because the older boys felt that Ida could find a good family to marry into, they decided they needed the largest shares. The oldest took the farm and croplands. The middle took the forty head of cattle. Ida was left with taking the yearling family horse, Shifty.

She said to herself, "My brothers will easily be able to make a living by working together! But as for me, what am I to do with a young horse that hasn't yet learned to work? It can carry me around, but that's about it."

Shifty the horse, who had been listening to her but pretending not to hear, said in a calm and very serious voice, "Do not despair, my master, for I am a very clever horse. 
All I need are some new shoes and some saddlebags, and you will then see how very smart and useful I am!”

Though Ida would never believe anything a horse told her to be true, most especially a horse named Shifty, she figured she had little to lose at this point. She did know that the horse could be clever if it wanted. When she was a younger girl, the horse had carried her back and forth to the Levy Store without her ever knowing the way; Shifty knew it and safely walked her to and fro. He had also once escaped the barn only to be found pulling carrots from the family garden in the morning dew. He had pulled and eaten through two of the rows before they managed to scare him off. So Ida, though still saddened by the loss of her father, did not despair. She held out some small hope that Shifty could help make her way in life and be a success in her own right, even if she did not have the advantages of her brothers.

So Ida searched through the shed before she took Shifty from the farm to make her way in the world and found the perfect set of iron shoes. They fit snug to Shifty's feet and even had a small metal lip in the front, on the bottom, to help Shifty gain traction on slippery surfaces. Then she took a set of saddlebags from the barn and draped them over Shifty behind his saddle. Once Shifty had all that he had asked for, he whinnied and guffawed loudly before trotting off down the gravel driveway and down through the Levy valley.

Shifty knew of a special area along Bunker Hill Road where wild apple trees grew in a cluster behind an old tenant shed. The trees had been planted long ago and then left to the wild animals. Just as the rickety old house began to decay and crumble, the orchard lost the grooming of life as well. Apples fell and rotted, and the seeds grew up 
into scraggly, crowded clumps of trees. Despite this, the disorganized little orchard produced some of the tastiest Washington apples anywhere in the Levy. Shifty quickly set to work gingerly picking each apple from the tree and placing it in the saddlebags. Soon enough, he had two large sackfulls, enough for at least five pies! Even better, he had resisted temptation and only eaten about a dozen apples while he was picking them.

Proudly sporting his swollen saddlebags full of fruit, Shifty traipsed off to North Middleton where he found the director of the farmer's market, who also happened to be the mayor of the small town. Shifty whinnied and reared up, slinging the saddlebags off his hindquarters and directly onto the registration table of the farmer's market. He said, "My owner, Farmer Hayes of the Stonewall Farm, sends you her best wishes. Her crops grow in such abundance that she has sent you this gift, for your market and your town. Please accept these apples."

The mayor opened the flap on the saddlebags and pulled out a bright, red delicious apple. "These apples are marvelous! Tell your owner that I thank her greatly for the gift. These certainly won't go to waste."

On another occasion, Shifty found a patch of blackberries filled with thorns and briars. The clearing that surrounded it was filled with small robins, so Shifty made a deal with them. They fluttered about and picked the blackberry vines clean until they filled Shifty's saddlebags to the brim with delicious, ripe fruit. In exchange, Shifty led them to the waste-water run-off from the Hayes farm. The pipe emptied into an open, grass area and stayed damp and stocked full of plump juicy earthworms all year long. 
Shifty took the berries to the mayor and director of the farmer's market and once again said, "These berries are from my owner, Farmer Hayes of the Stonewall Farm. She wishes you to share in the abundance of her land, so she sends this gift to you."

The mayor was astonished at the quality and ripeness of the berries. Each one looked pristine and plump and delicious. "These look as if they have been barely touched!" he exclaimed. "I see not a single bruise on them. Tell you owner I thank her greatly for sharing the fruits of her land.”

Shifty did this until late in the farmer's market summer season. He couldn't remember exactly, but he must have brought dozens of gifts of luscious fruit. Then it came time for the mayor to travel and visit each farm in the Levy to secure contracts for next year's farmers' market. His handsome young son also accompanied him, as he did each year. Shifty knew of this yearly pattern, and when he saw the mayor's horse and wagon coming down the road, he ran and told his owner, Ida, to get into the pool formed by Johnson's Crick and have a nice swim.

Ida, who had not yet seen reason to doubt her faithful horse companion, did think it was a nice day for a swim. She stripped down to her undergarments and slipped into the pool for a refreshing swim. The water was only slightly muddy and cool on a humid fall day.

While she was swimming, she heard Shifty begin to call out at the top of his voice, "Help! Help! Farmer Hayes of Stonewall Farm is drowning in the creek pool!" As soon as the mayor heard this piercing cry, he recognized the name of the famer who had sent him so many lovely gifts over the summer, and he immediately set his son into action to rescue Ida Hayes. The young man jumped into the pool and began to drag 
her out. While the son was rescuing Ida, Shifty stood next to the mayor and lamented the fact that someone, dirty thieves probably, had thought to pull one over on Ida or get a peek of her swimming and stolen her clothes, even though he'd cried out loud for them to stop and tried to chase them down. Shifty, clever and always plotting, had simply hidden the clothes under a rock near the spring that fed the pool.

The mayor immediately fetched his finest overcoat from the wagon and placed it over Ida's shoulders. His son, at first unswayed by Ida's beauty, suddenly noticed the sharp and delicate curves of her features and the pleasing way she carried her body. His father's coat added an air of familiarity and closeness to her, and once she turned her eyes to him, he was drawn in and fell madly in love with her.

The mayor insisted she get on the wagon with him and his son, so that they might carry her home to the safety of her farm at Stonewall. Ida felt a brief tinge of panic at the realization that she owned no property at all, but Shifty had taken her this far. His comforting gaze met her with a wink, and he sped off towards Stonewall Farm.

As he travelled, he further worked his plan. He saw some hired hands working in a bottom field cutting hay. Before he sped on, he shouted to them, "Good folk, if you do not tell the mayor of North Middletown that this field belongs to Farmer Hayes of Stonewall Farm, then you'll never find work in the Levy again."

The mayor, who saw the hands working in the field, did not hesitate to ask them who they worked for so that he might see if their employer was interested in a contract at the farmers' market for the next year.

“We work for Famer Hayes of Stonewall Farm!" they all shouted in unison, as life as a tenant worker was hard and unpredictable and Shifty's threat had scared them. 
"You have a fine bottom field here that looks productive. It must help you feed many livestock. And your workers appear very dedicated," said the mayor, turning to Ida.

Ida, who was now beginning to catch wind of Shifty's plan, answered, "Yes, as you see, mayor, that field grows alfalfa as thick as any and offers up at least one more cutting per year than any of the others."

Shifty, who was still far ahead of the mayor's wagon, came across another bottom field where hired hands were loading cut tobacco on sticks onto the back of a wagon for hanging. He said to them, "Good folk, if you see the mayor pass and inquire about this field, you are to say that this harvest belongs to Farmer Hayes of Stonewall Farm. If you do not, you will never work tobacco fields again."

The mayor, who passed by the field later, opened his eyes wide and the heavy bundles of tobacco, larger than any he'd seen. "Who owns this miraculous field?" he inquired of the workers.

"It belongs to Farmer Hayes of Stonewall Farm," they chanted. The mayor complimented Ida again on her green thumb and well-tasked laborers.

This same pattern continued on as the mayor travelled all through the Levy. He was amazed at the scope and quality of the land that Ida, Famer Hayes of Stonewall Farm, managed through her farm. He had never seen such produce on a single farm.

Shifty finally reached a grand farmhouse deep within the Levy. He had taken great pains to listen to rumors and stories and find out everything about the place. It stood three-stories tall and offered more room for raising a family and storing canned goods than he had seen anywhere else in the Levy. Next to the farmhouse, fields of 
livestock spread out in squares. One field had pigs. Another had chickens. A third had alpacas. In a fourth, thoroughbred horses raced along the fencerow, kicking up great clouds of dust. This must be the wealthiest farm in all the Levy, thought Shifty. In fact, most of the tenants the mayor had seen on his way through the Levy had been hired by the owner of this house. A magnificent stone and stainless steel sign arched over the gate, saying "Stonewall Farm" in glorious cursive script. The owner, known as Farmer Cecil the Hungry for his great appetite and greed, was the wealthiest farmer in all the land. He was the only farmer in the entire Levy who had enough wealth to own and race legendary thoroughbred horses, and he even had so many that he could barely find enough trainers and groomers to care for them all.

Shifty clopped up to the farmhouse and asked if he could see Cecil, for he would not want to pass through the Levy without stopping to pay his respect and see the finest horses in the land. Cecil, finishing off the fourth chicken of his lunchtime meal, licked his fingers and greeted Shifty with noticeable disinterest.

"I've been told," began Shifty, "that you have the finest horses in the Levy or even the whole county. I've heard that you can outrace anyone with almost any horse you pick off your property."

"This is true," said Cecil. "I take great pride in owning the fastest horses. But you, you don't look like much. I doubt you could outrun one of my alpacas!"

"I imagine you may be right," began Shifty, "But how could I return to my owner without seeing one of your fine beasts in action? I propose a race between you on your fastest horse and myself." 
Cecil laughed heartily and scraps of chicken meat and skin fell from his beard to the ground. He skipped over to the horse enclosure, hopped the fence, and mounted the closest horse, no saddle at all. He clipped his heels into the horses flank, and it leapt over the fence and sped past Shifty, who tried to keep up, but it was no use. Shifty tired quickly and watched as Cecil sped to the end of his drive and back in a cloud of dust.

Shifty felt a pang of sadness as he watched the scene unfold before him. He had never been a fast horse, and he had always felt a bit insecure about it. Now Cecil had shown him proof that'd he'd never be one of the most valuable horses in the land. But then, he had another clever idea.

Once Cecil had stopped showing off, he reigned in the horse and glared at Shifty. "Not the kind of farm you belong on, eh slowpoke?" Cecil teased.

Shifty shook his mane and said, "well, you certainly have the fastest horses, but it is important for horses to jump as well. I saw you jump the fence earlier, but that isn't very impressive. I know a better test of jumping, and I'm sure to beat you."

Cecil took the challenge immediately and followed Shifty to a small field in a corner of the Levy. In the center was a deep ravine lined by shrubs and bushes. "That is a deep ravine," began Shifty, "and I'm the only horse I know who's ever been able to jump it." That said, Shifty carefully picked a line toward the ravine and jumped it, careful to cross at one of the narrower points of the ditch.

Cecil, in a moment of arrogance, selected one of widest parts of the ravine and raced his thoroughbred directly at it. The thoroughbred foamed and groaned at the pace, heading at breakneck speed toward the jump. A second before he was to leap, the thoroughbred recognized the danger, discovering that the ravine fed into a great sinkhole 
at the widest part. The thoroughbred stopped short, heaving the unsaddled Cecil up and over his mane and screaming down into the sinkhole. As Cecil hit the bottom, the ground shifted and swallowed him right up!

Meanwhile, the mayor, his son, and Ida had finally arrived at the gates to Stonewall Farm. The mayor marveled at the stone entrance and complimented Ida on the excellent upkeep of her farm. As they entered the drive, Shifty returned to accompany the party up to the house, at which the mayor's mouth dropped open to reveal how astonished he was at the splendor of the house and animals surrounding it. Shifty lowered a leg and bowed his head. He said, "Mayor, I present to you Stonewall Farm, home of the greatest and most abundant farmer in the land, Ida Hayes!"

"Truly, Ida, you are a magnificent farmer. I have not seen such a great steward of the land in all my years. May we see the inside of your home as well?"

Ida offered up the crook of her arm to the mayor's young son, and he took it to escort her into the farmhouse. Once inside, they shared glasses of strawberry wine, hard apple cider, and tarts made from berries of each and every type that could be grown in the Levy.

After several hours of wonderful companionship, the mayor drunkenly exclaimed that he could only dream that his son would find a woman such as Ida and make her his daughter-in-law. His son, who was already madly enchanted with Ida from the first moment he saw her, jumped at the chance and offered his hand in marriage to the young Ida Hayes.

She blushed and graciously accepted, now knowing that her way in the world would be set and secure. She had even surpassed her brothers in wealth and land, and her 
marriage would make her one of the most important women in all the Levy. She and mayor's son were married in the North Middletown courthouse on the very next Monday. As for Shifty, for his cleverness he earned oats, apples, and carrots every day. He had new shoes every three weeks for the remainder of his life, which was long and joyous and more than most horses could ever dream. 


\section{PART THREE}

Helen giggled madly after Ray finished his story. "Horses wearing shoes is silly!" she exclaimed. The Bishops both got up to clunk an Ale-8 out of the machine.

"Hush it, stupid," hissed Hoss. "You know what horse shoes are. Don’t act like you don't. And there ain't no way that's a true story. Horses can't talk."

"Yes they can!" pronounced Helen. "Horses are super smart." Hoss coiled his finger up and flicked his sister hard on the knee. "Ouch!" she screamed, and started to cry a little. She took her hand swiped it across the floor where she had been playing with the corn kernels by arranging them in funny shapes. "Hossy, you should just swim home. If not, I'll tell Mommy that you picked on me again.”

“Ok kids," Julian interrupted. The other adults were content to watch the children behave as they do, but Julian knew they were all trapped together in the store for the time being, and he didn't want to deal with fighting and crying children. "Have you ever seen dogs sniff each others' butts?"

Both children snickered at the word "butts" and shook their head yes. "Hossy is a butt sniffer, too, so he must be part dog!' Helen erupted in laughter, proud of her poke at Hoss until he flicked her hard on the other knee.

“Ok, now stop messin' with each other and listen, and I'll tell you why they do that," Julian said. "I bet you two didn't know that some dogs can talk though." 
“That's dumb," growled Hoss. "Dogs eat rotten groundhogs and roll around in the creek. They don't talk, or at least I never heard one."

But Helen did not seem so convinced. Her eyes welled up, and she said, "Why won't my doggy talk to me then?"

"He may yet," soothed Julian. "The dog in my story is the best friend you could ever have, maybe even better than a horse."

Shirley and Russel sat back down with their open sodas and put their feet up to listen attentively. Ray Workman began to clean up and wash some of the dishes for the day, but he was still in range to hear the story. In the corner, Homer had fallen asleep with his head and beard buried in his chest and his legs on the seat of another chair. Julian felt a bit unsettled. He was one of the group who had been farther outside the Levy than most. He had grown up on a Levy farm, had worked in the fields with his family, had gone away to college to study agricultural science, and had then returned to try his hand at the trade his parents and grandparents worked. His time outside the Levy in a city of fifteen thousand changed some of his patterns. He occasionally felt ashamed at the way his voice would correct words as they came out of his mouth. His mind struggled with dropping out of the accent and flow of the other men at the store, all of whom had grown up and lived their entire lives at the Levy save some of the years they went to war. He didn't have much trouble fitting in most of the time, but every now and then he would let an uncommon, or what the men around him called educated, word slip from his lips. They mostly used it as a means of teasing and tugging at him, but for Julian it was a reminder that he had left and returned. 
Leaving was one of the cardinal sins of a child born to the Levy. Parents watched their little ones grow up hoping they would find their place among the people and the land that connected them. Each family watched in sadness as child after child grew to a teenager and dreamed of nothing more than getting away from a place that offered little more than chicken chasing, drink, fast driving, and shooting for fun and craziness.

Those who left for college or jobs in the city often never returned. Those who did only visited for short periods, not staying long enough to get recaptured by the routine of farm life, the cutting of tobacco, topping, driving cattle from field to field, cutting hay, or curing leaves. These processes took time and hard labor and offered little in the way of conversation until the task was done. In fact, much of the solidarity of people in the Levy came from the work itself. In some ways, they saw it as a moment of work for survival, and anyone who labored through the trials of work for subsistence already earned some sort of kinship.

No one questioned Julian's desire and ability to work hard. He had a taken over a family farm that had fallen into disrepair while he was away. His aging father had neither the money nor the physical stature to do everything. Other farmers in the Levy helped when they could, but their own land needed tending first to ensure their livelihood. In just a couple of seasons, he managed to mend the fences enough to keep livestock safe. He took down rusted gates and put up barbed-wire gaps until he could earn enough to replace them completely. He had, with the help of the Bishops, laid out two full fields of tobacco in the hopes he could sell the rest under the table to farmers who had not met their quotas for the year. 
Surely he had earned the respect of those at the Levy, and they held no hard feelings against him. Julian's worries came from within himself, igniting a fear that he may have betrayed his kind. He'd heard plenty of rumors as a kid about others who had moved out and away in this very store, and the words were rarely kind about those who didn't tend to at least some of their kin who remained. He justified to himself by trying to apply the knowledge he gained in college to his daily life in the field. He tried to share new techniques with his fellow farmers. Still, whenever anyone was skeptical about a new machine or a new method for pulling plants, Julian noticed the heat rising up his neck and the dislocation of being from the outside or at least tainted by it.

This, in part, was why Julian was excited to tell his story, but he knew he was not as good a storyteller as the other men. Their confinement and the fellowship that grew out of it in the store filled him with a wonderful feeling of being home, close to that after a long absence. Even though he had been back and farming for years, this felt exciting to him. Perhaps it was his age. He was old enough that he wanted to seek out traditional comforts and friendship in place of setting out to discover the newness of the world. Few other men his age stuck with the traditional small farming methods.

The story he had in mind centered on a legendary man in the Levy. Julian clearly had more schooling than the rest and read lots of stories himself, but he wasn't sure if most of those were proper for children. So he steeled himself and tried to tell his story like the other men, while still making it his own. "This is a true story, kids," he began. "It is a serious story in a lot of ways, but I think you'll like the way it turns out in the end." 
"What kind of things are in the story?" asked Helen. "Are there fairies or anything? I like those."

“There's no silly fairies," replied Hoss. "Stop being such a little girl," he sneered.

"But I am a little girl," she said. She stuck out her bottom lip.

"Both girls and boys can listen to this one," said Julian, "But you can tell me to stop if you don't like the story." And so Julian began his story. He tried to tell it in a way to entertain the men and the kids. In particular, he knew that the other men in the store would know the man he talked about in the story, and the older of them, Ray and Homer, would have known of Luke. Ray had seen him many a day, and for Homer, Luke was family. 


\section{JULIAN BOWLES' MAGICAL TALE OF VICTORY: PLAYING THE OPOSSUM HARMONICA}

Once upon a time, here in the very hills we sit now, there lived a boy a bit older than you, Hoss. Well, he was at that point where boys and men are the same thing, a place you'll know before too long. You'll recognize that time, but not until it has already passed you. What you will notice, is that you have an uncontrollable desire to make an imprint on the world, as many young men do. That's what this boy wanted to do. Most folks called him Lou, and he always formally introduced himself as Luke, son of Farmer Johns. His full name would have garnered him a bit of attention, though he would have been hard pressed to tell you whether it brought him more shame or respect. With the family name Johns, his devout mother, then 42 and still rumored to be Presbyterian before she married into the Levy, felt he was a gift from the Lord himself with an intervention on the side from Jesus. She loved the New Testament, so she named him Matthew Mark Luke Johns, cursing him with a four part name while at the same time forbidding any good Christian to mock the boy for its pretention to holiness.

As a young child, Luke hid under the wings of his mother most days. He rarely went out into the fields with his father and older brother, Samuel. He pulled tobacco seedlings for replanting on days when his mother helped out, but otherwise, he kept to her skirt and played or pretended to help her with the house chores. He kept to his mother more than most young boys, and before long he stood out as the odd child.

Luke, as most boys do, quickly grew to manhood, and his father and mother had many a quiet conversation after bedtime about what to do with their young son. His 
father wanted him to join his brother in the field and help to ensure a robust tobacco crop for the year. The mother wanted the same, as the money would bring security in other ways, but try as she might, the boy just could not leave. He was a terrible disappointment to his parents, and his father began to wonder if he'd ever be of any use at all.

Both parents thought the boy might be ill, since every time he was startled, he simply passed out, then and there. The problem escalated gradually. At first, he simply fainted when the preacher would get too angry and shout about the dangers of hellfire and damnation. Then his illness progressed to unexpected thunder claps, birds crashing into the clear windows of the house, and once he even lost consciousness when Samuel snuck across the room and passed gas beside his head at midnight. Passing out in the dining room might give him a cracked noggin or a bruise or two, but if he collapsed on the tractor or around the livestock, Luke could have been seriously injured or worse. $\mathrm{He}$ would have to work his way around his fears, or end up an old beggar, scraping together a living as a tenant farmer at best.

The town doctor had seen and heard all this before, and he wrote out a prescription that would supposedly make Luke better. The drug was meant to grant him some wakefulness, and thousands of people used it. Luke, however, didn't see much progress. He certainly could wake up in the morning a bit easier. He felt more alert throughout the day. Even at night, just before bedtime, he would struggle to go to sleep. Unfortunately for Luke, the doctor's cure did little to help with Luke's reaction to surprise or fear.

Sure enough, the weather in the spring caused him more trouble than usual. Just as the Farmers' Almanac had predicted, the spring was violent and tumultuous. Several 
tornadoes passed nearby in late February and early March, one strong enough to kill forty head of cattle across the Levy, though none thankfully at the Johns farm. Staying inside, Luke passed through most of the storms with ease, but one evening Luke, Samuel, and their father were fixing a fence around the field in the bottom when a fast storm cell moved in and clapped a great roar of thunder. Luke, who had been holding the barbed wire to the post for his father to secure it, stiffened like a corpse for an instant before slumping, under all the weight of his body, face first into the fence.

When he woke, his mother hovered over him, gently touching each of the small sores across his face and neck with a cloth soaked in alcohol. Samuel and his father had carried the boy up the hill from the bottom, cussing the whole time. His father declared his dissatisfaction with his second, younger son and wondering aloud if he could ever make a life as a farmer so close to the unpredictability of nature and animals. For his part, Luke remained thankfully oblivious of most of his father's rant, but then one thing his father said when Luke awoke was more hurtful than any surprise. "Lou, you'll never amount to anything on this farm. I am ashamed to call you a Johns, and I don't imagine you're fit for much other than work in the house with your mother. In the morning, we will send you to town to register for school in the city where you can learn a soft skill that will keep you out of danger. You can go your own way after that, and never come back here unless you've fixed yourself from fear." Luke understood the words, and promptly fainted.

His last night in the house, Luke despaired and slept little at all. He was not so much worried about being sent away to study, but rather he felt a dark hole in his heart from his father's disappointment. So in the wee hours of the morning, he decided to set 
forth from the farm and explore the world until he could learn to face danger and fear without a flinch. With a lightly packed bag of clothes and food over his shoulders and enough dryer lint to start a dozen fires, Luke had walked to the Levy store by sunrise and hitchhiked halfway to the city by noon. His last ride had been a farmer's wife returning from the grocery. With no other options, he set out on foot again toward the city, hopeful he could find his way and lose his fear.

Somewhere down a gravel road into a holler that he figured would be a shortcut to Montgomery, Luke decided he was lost and needed a place to rest before the sun set. He soon came upon a small trailer home parked near the edge of the road. The trailer had been used to temporarily house migrants during last year's harvest but was now abandoned. Not wanting to be rude to the farmer who owned the land, Luke settled himself in outside the trailer near a ring of stones that had been used as a fire pit. He sparked his own small fire and stretched out on a blanket he'd carried with him. He took out his Hohner harmonica and played a quiet lullaby to himself before trying to sleep.

Luke tossed and turned most of the night, but he finally fell into a deep sleep just before morning. He awoke to being shaken, and when he opened his eyes he saw a crinkled old twisted up face that was yelling something at him. Luke, immediately, passed out.

When he woke up the second time, the crinkled face was sitting in the doorway of the trailer home on the steps. The man did not move or speak, and Luke slowly sat upright, not taking his eyes away from the figure. "I am sorry, sir," Luke said. "This must be your house. I did not mean to disrespect you. I just wanted a place to rest for a while. I can be on my way." 
"You can stay," the man said. "But why are you traveling through here and surprising folks?"

Luke began to tell the man of his quest and his hopes to return one day and make his father proud. The old man understood, as he once had a father, and he told Luke that he was a farmer, wise from years and years of experience, but that he had no sons left to help him on his farm. He lost his last son early in the spring when he was swept into a rushing creek and drowned. The old man and his son had planted a fine crop of tobacco in two fields just before the drowning, so the old farmer had one more year of tobacco to get up and dry before selling. Then, maybe, he could relax and enjoy being old and get back a bit closer to the Lord. His only problem was the condition of his barn. Most of it was sound, but high in the loft, two beams had split and weakened. The old man was worried they would ruin his tobacco if they fell.

The young man decided to assist the famer as much as he could, for he knew what it was like to feel helpless. However, Luke vowed to himself to only stay for as short a time as possible, since he wanted to continue on his journey to discover bravery and include it in his life, hopefully along with his father once again.

The next morning the farmer and the young man met to fix the beams. Dew had formed heavily on the grass and rooftops. The two men, at opposite threads of life, dragged the new beams to the barn and lifted them with ropes and pulleys up high into the rafters. Luke, with a rope wrapped around his waist, something the old farmer insisted on, climbed higher and higher until he reached the two split beams near the apex of the barn's roof. They were highest where tobacco hung, and the air this far up felt hot 
and humid in the summer day. The barn vents were not open, and he immediately began to sweat profusely. The rope felt tight around his gut, the knot pressed tightly against him. He knew the old saying, to never look down, but he suddenly felt lightheaded. He wondered briefly if it was the heat. He looked down to shout at the farmer for a drink of some kind when he noticed how very far below the ground seemed, and without warning he suddenly passed out.

When he came to, the old man was leaning over him, and Luke saw his crinkled leathery face much closer than he would have liked. He also saw a vision of the most beautiful creature his eyes had witnessed. In his weakened state, he considered at first that she might be a guardian angel, either his or the farmer's. Her hair cast a brilliant light over him, and she softly told him that all would be just fine, that his father would take good care of him and that she would help.

Apparently, Luke, when he looked at the great distance between himself and the ground, fainted and tumbled right out of the barn rafters. Luckily, he had missed hitting his head on any of the beams on his way down. Instead, one leg had almost stopped him before his ankle gave way beneath him. The ankle did not break, but Luke would be unable to walk easily for quite some time, and the rope knot bruised him deeply under his ribcage when it caught his fall.

The farmer and Luke struck a deal that seemed fair to them both. Since Luke injured himself while in the farmer's employ, even though it was because of his own trespassing, the farmer felt a need to offer him assistance. However, because Luke was still mostly a stranger and had not yet proven himself, the farmer offered him a work arrangement more suited to Luke's new mobility. He was to stay in an old, abandoned 
tenant farmhouse on the property and restore it to living conditions as best as he was able. He was to start working on the house immediately, and as he recovered, he would work on the more difficult tasks. First, he needed to spend the night in the house to take note of its condition and needs.

Shortly after the famer left Luke to consider his work, the boy saw a slight figure leave the farmhouse and travel up the gravel drive to the tenant shack. The figure moved with deliberate caution, as if at any moment it might be observed. As the figure approached, he realized it was a young woman, and she introduced herself as the daughter of the farmer.

"I did not know the farmer had any children," said Luke. He had considered earlier that the farmer's childless nature might have caused him to be kinder to strangers, but now he wondered if there were some other reason behind it.

"I am his only one," said the shy woman. She was only a year or two older than Luke, and he immediately decided her to be the most beautiful creature he had ever seen. "I find it lonely here on the farm," she began. "My mother died when I was a little girl of five, so I have been raised to help my father here on the farm. I dream of other places far away, but I do so love my father and my life here. I fear if I do not leave I will forever be alone after my father passes.”

"I am sure you will not be alone," replied Luke. "Someone as beautiful as you must have many admirers."

"There are no admirers here save the cattle and crickets," she said forlornly. "That is not true," Luke replied, "because one stands before you!" 
With that the two began to speak intimately with one another, and they spent nearly the whole afternoon talking about love and life and work. Luke told her of his condition and his quest, and she wept in admiration of his determination and at the loss of his own father, for she knew the loss of a parent. The farmer's daughter, whom Luke came to know as Sasha, told him of life on the farm, the lonely nights she spent reading to her father, and her weekly trips to a Sunday school class full of old men and women. There were so few children in the holler, and as soon as the older ones matured, they disappeared and left forever. She had only once been in love with a young boy, but her father did not care for the young man and drove him off. She had been forbidden from talking to other boys, so this was a rare moment in her life.

The two of them found much in common, but the greatest of them was their great pain of isolation. In that one small afternoon, the two young companions fell hopelessly in love with one another, and they secretly resolved to help one another with their goals in whatever ways possible. Furthermore, they agreed to marry once Luke was well again and had repaired the house, for she felt that the two of them would lead an exciting life together. Eventually, Sasha had to pull herself away and return to the farmhouse to cook dinner for her father and their guest. Before she left, Sasha leaned in close to kiss Luke and seal their agreement. As soon as their lips met, he fainted and slept right through dinner.

On the first night in the old abandoned tenant house, Luke saw clouds through the roof and prayed that it would not rain on him during the night. Thankfully the clouds soon wore away, and the stars began to shine brightly. In this weather, however, the 
night became cool. The wooden boards of the house, swollen from the day's heat, shrunk inward and groaned, popping in the quiet night air. Luke was unable to sleep. As the ground cooled, the house settled slightly with the new weight inside and snapped loudly in the early hours of the morning. Luke sat up with a start and felt the house shake slightly. He imagined it an earthquake and suddenly feared for his life. In his mind, he saw the house tumbling before him into a pile of sticks as he promptly lost consciousness.

When they came to look for him in the bright morning light, they found him in the bed sleeping so soundly they could hardly wake him. They felt he must have been brave to sleep so soundly in such a dangerous house. He explained to them what he remembered of the night before he passed out, and they laughed as they explained that the old house was simply that: old. Weather changes caused noises to erupt all the time, and it was just many of the unsettling things about staying in the house. The whole structure was full of holes and cracks, and plenty of wildlife was drawn to it. The old farmer suggested that what Luke heard could have been a beam settling on the foundation as it weathered, or it could have been any number of small animals crawling out of the attic. Either way, the farmer assured him that despite all the deterioration, the roof was sound and would not fall. He could continue to sleep there but not in the house. His daughter frowned as her father explained that Luke could not stay in the main farmhouse, even if it would be safer. "My daughter is precious to me," he said. "I cannot let her leave this farm; nor can I let young wanderers such as you near her."

With that the young man thanked the Lord that he still had some form of shelter, and he prayed for a speedy recovery so he could fix the house, repay the farmer for his hospitality, and continue on his quest, hopefully now stealing away with Sasha as well. 
On the second night, Luke was nearly asleep when he heard the sound of soft footsteps on the front porch of the house. Thinking it was the farmer come to him with some need or emergency in the middle of the night, Luke rose, dressed himself, and went to see. He saw a young boy sitting on the porch in a pair or threadbare denim overalls. The boy motioned to him to come and sit beside him on the steps. Luke followed instructions. "Who are you?" Luke asked.

"My name is Billy Bowles," the young boy said. "I used to live around here, but I moved on a while back."

"What are you doing out here late at night, here on the old man's farm?" Luke asked. He looked the boy up and down for anything that stood out, but he looked like most other farm boys, slightly dirty, hair slightly long over the ears, and a face and arms that had seen a lot of sun.

"It ain't that late," the boy replied, "But I come out here to this porch a lot because it. . . well, I have a lot of memories of this place."

"This house?" said Luke. "Did your family used to farm here as tenants? It must have been a while ago, "cause this place is worn down."

"Something like that," the boy replied. "I spent a lot of time near this place, at least."

Luke and the boy talked into the long hours of the morning, but never did the boy reveal his past. The boy learned a great deal about where Luke grew up, what his parents were like, how he ended up here. All in all, the plan seemed like a sound one to the boy, but he warned Luke not to spend too much time at the farm or else he might lose his way. 
The boy said it with such a fierceness to his eyes that Luke felt a lump rise in his throat, but he couldn't quite interpret the boy's meaning. Before dawn, the young boy stood up without a fuss, brushed off his pants seat and bid goodbye to Luke before walking off into the holler, opposite the direction to the house.

Luke had only been asleep an hour or two before sunrise brought Sasha bearing a plate of toast, two slices of bacon, and a tomato slice. When he told Sasha about the visitor last night, she asked a number of strange and detailed questions. She wanted to know if his hair laid this way or that, how he held his hands when he talked, and what the nature of his walk was like. As Luke began to explain and answer all her questions, she grew paler and paler. As he neared the end of his story and told Sasha what the boy had told him about the farm, she broke into tears and told Luke the whole story.

Several years ago, the lad came to the farm with his tenant parents. While Sasha and the boy worked together in the fields, they came to know each other well. Her parents and the farmer quickly noticed that the children would sneak off from the day's labors to romance one another and craft a plan to run to Montgomery where there would be all the food they could eat and hundreds of other young people just like them. They planned a whole life together in the way that young lovers do. No one had ever loved him in spite of his condition. In fact, Sasha rarely even mentioned it, even if it was an inconvenience. She had no fear that he would be unable to protect her, and so she loved him anyway. She had faith in him, something he had never felt. She believed that he would one day overcome his fear, and so she loved him all the more for it.

Her father discovered the passionate love between the Sasha and the young boy after he found their stash of provisions for the road. They had been stuffing anything 
they could scrounge behind the potatoes in the cellar, and the farmer was furious at his daughter's betrayal. Two days later, the boy died under mysterious circumstances. He was breaking up the ice in the pond at the farmer's request when he slipped on the muddy, icy banks and fell and drowned. The old farmer was the only witness, and by the time he had retrieved a branch to try and pull the boy out, it was too late. When Luke's brain connected all the dots and he realized he'd been talking to a ghost into the wee hours of the morning, he once again passed out, quick as you please.

Luke did not wake again until late afternoon. He felt great anger with himself for his great weakness. He could not even comfort the young girl he had fallen in love with without his body overcoming him and giving way to the fear. Luke lamented his predicament and decided that he should simply move on. He wouldn't be useful to Sasha in his current condition. The darkness overcame him and seeped into his very soul. He felt despair once again, the same feeling that he felt when confronted by his father's dismissal. He vowed to leave in the morning and rid both the farmer and the daughter of his troubled soul, even if it meant breaking his arrangement with the farmer. That small amount of dishonesty would surely be better than a lifetime of troublesome fear.

Luke wrapped himself up in his blankets and prepared for his last night of sleep in the tenant house that he had never completely fixed. He hadn't yet resolved how far he could walk or move with his wounded ankle and bruised ribs, but he intended to travel as far away toward Montgomery as he could.

Just after midnight, Luke awoke to the sounds of loud hissing outside the house that grew louder and louder, as if a pack of snakes were crawling up the porch and underneath the doors. He pulled the covers up over his head and willed himself to pay 
attention, to keep his eyes, open. He saw a pair of bright yellow glowing eyes in the moonlight, then another and another. They were set close together and low to the ground. Several of them began to approach the bed, and Luke felt his blood giving way. One stepped into the light, and Luke saw it to be an opossum.

Opossums haven't always been such comical creatures. Their fierce nature still resides within them. If an opossum encounters a cat or a dog, it will hiss like a firecracker until the fight erupts or the invader runs away. Their impressive teeth and defensive stench have always been enough to drive away all but the most curious and foolhardy. Even skunks would not have dared cross an opossum's path. Being surrounded by a seething pack of them in the middle of the night would be absolutely terrifying. Luke didn't have time to wonder whether they were connected to the spirit of the boy, the sounds the house made that first night, or the dark change in Luke's soul; instead, he thought of Sasha and how she wanted to run away with him. Luke's blood calmed ever so slightly, and he looked for a way out.

Any unusual noise might drive them away, so Luke grasped for his harmonica and put it to his lips. He played "When the Roll Is Called Up Yonder" with all his lungs, and the opossums froze, transfixed at the sound. They all relaxed and fell under Luke's spell. The night fell quiet again, briefly, when he paused his playing. Suddenly, he heard a chorus of screeching down the holler. Looking out the window, Luke saw hundreds of opossums heading toward the farmhouse. A great opossum invasion was underway, triggered either by the balance of love and despair tilting too far in one direction or by the whims of mother nature herself. Either way, Luke had already pacified the opossums in 
his domain and leapt out the window. He ran hard and fast down the gravel path to the farmhouse, the yard obscured by a writhing mass of fur and naked tails.

As he ran up behind the passel of opossum, he saw they had split into two groups, one by the main door to the farmhouse, and the other by the mud room entrance. Luke positioned himself in the center of the yard, just under a pair of apple trees and played his harmonica brightly and cleanly. The music that wailed out of the instrument drew illusions of loss and pain, of a father's disappointment and the suffering of a son's exile. The boy played so sweetly the tree branches hung low, and every opossum, of all ages, turned to him in wonder. They were all affected, each and every last one. The talent that opossums have, far above all others, is to see into a man's soul. Making their way through the night as they have as long as anyone can remember, they suffer greatly. Many die on the roads. Some die from predators. All of the them face the dangers of the darkness, and only those equipped or cursed with such experience can see into the center of a person and tell good from bad. The mourning of the Luke's song matched so closely the blackness of the night that they all drew closer to him. The mass of opossum grew closer and closer, tumbling over one another and scrambling atop like a pile of large grotesque rats. They had clearly turned their attention away from the farmhouse, but the farmer and his daughter saw Luke in a moment of imminent danger.

The opossums would soon overtake him, and Luke could see this. He felt his eyes rolling gently into his head and his breath leaving him, so he thought of his love for Sasha. His eyes met hers; she was now safe to run from the angry passel. The heat flushed his face and desperation dried his mouth. He knew it to be his last moments, so he switched songs to a beautiful love song for his darling Sasha. If he were to lose 
consciousness now, be consumed by the horde and never see her again, at least his last moments could be sweetly drawn out in his love for her.

Luke's song of love was so sweet and delicate that the passel paused to absorb his wondrous sound. No one can say exactly what changed inside of those small creatures, but the universe granted Luke a gift in that moment. Or, perhaps, Luke earned it himself. As he fought his own worst instincts to succumb to the crisis at hand, the burden suddenly broke free. All of the opossums ceased their movement and stared at him, transfixed.

A loud shotgun peal broke the silence and startled both Luke and Sasha. Remarkably, Luke stayed upright and alert while most definitely in love. The opossums, however, for the first time anyone had ever seen, all promptly passed right out on their backs and stayed motionless. In the silence of the night, Luke made his way over to Sasha on tiptoes, and swept her up in his arms. Their eyes met, and he kissed her deeply. As soon as their kiss broke, the entire passel of opossums awoke and scattered into the night.

The farmer was so amazed at the young man's poise and rescue that he granted the two permission right then and there to marry. For their part, Luke and Sasha loved each other dearly but could not leave the old man. Luke no longer needed to go to Montgomery anyway, so they settled right there. Luke refinished the tenant house, and the happy couple grew into a large family over time.

As for the opossums, they were forever changed. From there on out, they mimicked the behavior of their idol and hissed loudly at those who do not make sweet sounds. And that is how playing opossum came to be, just by playing a little thing like a 
harmonica. You probably won't believe me, but I tell you straight. Next time you see an opossum, go play a harmonica in its face, and you'll see what happens. 


\section{PART FOUR}

Julian's story delighted the children, even if Helen didn't fully understand what

the boy had been through. Hoss did though, and he was quiet as he searched his soul and paused at the moments of his life when he was afraid. He shortly realized that he looked a bit ashamed, so he jumped up and started running circles around the store to burn off energy and hide his own secrets from the men in the store, particularly Helen.

Meanwhile, Shirley and Russel stepped to the porch to see how the rain was coming. Clouds roiled along the horizon, and they passed into a much deeper and darker gray as the sun set somewhere high above them. The pace of the rain had slowed while they were telling stories, but the water still flowed swift and muddy across the roads and the bridge that led back into the hollers. "Looks like we'll be up in here all night, at least until that water pulls back," said Shirley.

"We best get comfortable," said Russel. "It won't be the first chair I've slept in, and it won't be the first breakfast I've eaten on account of the Workmans."

They broke the news to the other men, who nodded solemnly, and to the children who were immediately worried that they would get in trouble for not being home at dark. Ray took care of that part by calling over to the house and asking Louella to call and speak with their mother. She then brought over a few blankets and pillows for the children to wrap up in. Shirley had a certain tenderness for the children, and he wanted 
to put them at ease. He decided he could tell them a story that his and Russel's mother used to tell them when they were little boys. "Alright you two, gather over here and make yourselves comfortable. I'll tell you a story our momma used to read us when we was little. It can be a little scary, but it's mostly just a funny story. We didn't have money to buy a lot of candy and moonpies when we was growing up. Some years all we had was what we could grow and what momma could can before winter. In times like that, you dream all winter about eating a fresh, ripe strawberry or even a fat, red tomato. You eat what you have, and while you have eggs every morning from the hens, you can't make a good pie or nothing from eggs."

“Is this the snipe huntin' story?" asked Russel.

"Yes, it is," responded Shirley.

"What's snipe hunting?" asked Hoss. He had never heard of hunting snipes, and he imagined he should learn to hunt almost anything.

"Well, listen to this and you'll figure it out," said Shirley. "But I don't guess you'll be wantin' to go snipe hunting anytime soon."

And with that, the men settled into their chairs, Julian up against the wall on the floor, and the children wrapped up in square-patterned quilts. Russel pulled his cap down over his face because he'd heard the story a million times. Ray Workman lit a few candles and then apologized for having to trip the electric breaker for the store. The water was dangerously close to the porch at this point, and when the story began, he kept an eye out the door to watch for the rising water.

The children made themselves comfortable sitting in on the floor, several pillows piled up around them and three handmade quilts, one serving as a covering for the floor 
and each child with their own blanket to wrap up tight in. "Ok you two, I'll try and tell this as close to the way our momma' did as I can, so listen up."

With that, Shirley tried his hardest to remember the parts of the story from his mother used to tell him. He had loved the rhyming language of the old witch story so much, but he wanted to make it sound important like the stories from the other men. The snipe hunting was his own invention, and he was proud of that part. He gathered up his memories and his best words, and set to work telling the story. 


\section{SHIRLEY BISHOP'S TALE OF MAGIC PIES AND WITCHES: HANK AND GINGER GO SNIPE HUNTING}

Deep in the rolling hills spreading out from the Appalachians, a poor new farmer and his wife left their office jobs in the city to move into a small farmhouse atop a hill. They had two children, a boy named Hank and a girl named Ginger. They had brought all the food and money they had when they moved to the farm, but after the first winter, supplies were already running low. The earth had produced for the inexperienced farmer but not well. The first year's crop of tobacco had grown puny and dried small, so the farmer and his wife had enough to buy a few staples weekly, like bread and milk, but not much else. The rest of their money had gone into mortgage payments on the land and to have a heifer slaughtered to keep meat in the freezer for the year.

And so the children were always fed, but the variety of abundant food was absent. Hank and Ginger, who heard and saw the children of their neighbors feasting on treats and the sweets of the hot July sun, jams and cakes and watermelons, longed for a sugary treat to coat the length of their tongues. They complained often and loudly to their father and mother, who quickly grew tired of their complaints. One day the father said, "You two are lucky you have food at all, since we must grow it to survive." This made the children complain even louder and hardened his resolve to make them appreciate the joy in life that comes from hard work and stewardship.

Late one evening, after the children were in bed, the mother and father complained about the daily nagging they endured from their children. What the children did not see was that their parents suffered just as much, if not more. The father and 
mother both knew that it would be several seasons before the farm would be fully productive. They would need to limit treats until they could afford them without danger of starvation. "What will become of us?" the farmer asked. "How can we live a life without moments of happiness to quell the bitter taste of hard work?"

"I have an idea," said his wife. "The children are strong and will survive anyway. Their youth can give them patience. We, though, are older and have fewer years, and fewer joys, left to us. When I go to town for groceries this week, I will buy us a watermelon, and we will eat it all ourselves!"

"That seems very cruel," said the farmer. "We should share it with them or not have it at all."

"Do not feel guilty," she said. "For the land to respond well to you, there must be joy in your heart. Without some of the sweetness of life, how can you find joy? The children will survive and not know the difference, and you'll be rejuvenated."

The farmer did indeed love a good watermelon more than any other treat, but his guilt worked on him. Would there not be enough for all of us? What if the children discovered us? Yet his wife nagged, every day, up until she left for the grocery that week. Before she left, the farmer said, "Wife, buy the things that we need, and if money remains, buy our watermelon. But, it must be a good price. Pay no more than four dollars for it, or else we will have to neglect something else."

She agreed and returned from the grocery with a small melon she had found in a manager's special bin. It was small but round and bright green. It had been flattened completely on one side as it grew. She had paid only three dollars for it. She quickly hid it in the deep freezer to cool while the children played down by the creek. 
The melon was clearly too small for the four of them, so the farmer began to feel a little less guilty about deceiving his children. He imagined he could smell the sweet flesh of the cooling melon in the freezer even when he was out in the yard. After all the groceries were put away, his wife approached him. "Husband, we must find a way to have the children away from the house, so we can eat our melon."

The farmer, however, began to have second thoughts and wondered if he should simply give the delicious fruit to his children. His wife saw the doubt on his face and knew that he was wavering. "I will get them out of the house," she said, "and we will eat our lovely watermelon while they are gone.” The farmer agreed because he knew he could not sway her.

The mother called Hank and Ginger to her and said, "Children, I know that we do not have many treats to eat and little to give you beyond the most basic foods. And I know children, I know the great cravings you have for sweets and tarts. If you can find me what I need to make a snipe pie, I will cook one up for you right away!"

Now, the children did not know what snipes were or what snipe pie was. They thought, since they had only recently moved to the country, that it must be some new great thing that people in the country would eat. "Momma, we will bring you all the snipes we can find if you will tell us what they are and where they are," said Hank.

"Snipes are rare and hard to catch," said their mother. "You will have to be patient and clever to catch one, but they are so delicious that you will hardly believe that they came from anywhere but the Lord himself!” The children's eyes widened. Their mother gave Hank a burlap sack and a baseball cap. She gave Ginger a whistle. Then she gave them their instructions. They were to go to the tobacco field farthest from the 
house, since snipes like to live as far away from people as possible. They were to wander deep into the rows of tobacco, now tall as a man. Hank was to hold the sack open and wait for the snipes to run in while Ginger, blowing the whistle, would call them closer. "Snipes are drawn to the sound of a whistle," their mother told them, "but be very patient because snipes are timid."

During the heat of the early afternoon, when the watermelon would taste the most wonderful, the wife asked the farmer to lead the children out to the tobacco field at the edge of the property. The children were never allowed to go there alone because it was so far. The children were playing marbles when the farmer interrupted, and he seemed so out-of-sorts that Hank simply gathered all the marbles up and shoved them in his pockets to avoid making his father angry.

Once they had arrived at the field, the farmer told the children, "Come back to the house quickly after you have done what your mother asked of you. The fields can be dangerous at night, and the coyotes will find you."

As their father turned and walked back to the farm house, Hank's head filled with the imagined pleasures of eating snipe pie. He wondered if they tasted more like strawberries or apples. "Sister, follow me and stay close. It will be easy to get lost in all this tobacco." And Hank was right, for the Burley was already four feet tall from an unseasonably wet summer. Ginger stayed close behind him. Hank knew that the field was long and wide and that they could easily lose their way. He suddenly remembered the marbles in his pocket and decided to use them to mark their path back to the edge of the field. Every few feet he dropped one onto the soil between the rows. Even though 
the leaves of tobacco were broad and created much shade, enough sunlight filtered through to make the tiny marbles glint cleanly and brightly along the path.

Once they had wandered far enough through the stalks for Hank to drop his last marble, they set about collecting snipes. Ginger began with short, crisp whistles, but no snipes came running. Afraid to wander far from her brother and become lost in the field, she stayed close. She tried whistling lullabies, sparrow and robin calls, and even cattle calls, but no snipes. This took quite a lot of time, and the sun began to set. The children began to be afraid.

Meanwhile, at the farmhouse, the farmer's wife fetched the watermelon from the freezer and brought it and a large knife from the kitchen. The farmer and wife sat at a weathered, red picnic table while he split the small melon cleanly in two with a sharp blow from the knife. The melon cleaved cleanly, the full ripeness of its juices dripping down on the table and through the cracks between planks. "What a delicious looking melon!" his wife exclaimed.

They each took half, and his wife greedily cut chunks of dripping melon from the rind with a butter knife. Pink juice slid from her chin, and she barely paused long enough to fully taste the flesh. The farmer seemed less enthusiastic now. He ate a piece of melon, but it felt grainy and gritty in his mouth. He wondered if the melon had begun to turn, but his wife did not seem to notice. As he thought of his children out in the fields, he added salt to the flesh of the melon to make it more edible. This worked for a bit, but the melon did not end up as wonderful as he anticipated. Instead his half tasted bitter and sweet, leaving him unsatisfied and feeling guilty for tricking his children. 
As the sun set several hours later, the farmer and his wife became concerned, as their children had not yet returned from the tobacco fields. The farmer was just about to set out and look for them when they heard a faint whistling across the holler. Sure enough, Hank had used his marbles glinting in the twilight to bring the children back home.

Reunited with their parents, the children wailed that they had found no snipes, and Ginger cried many tears. In her imagination, she had been tasting the sweet and delicious snipe pie all day long, and now she would never have one! The farmer was worried about his children when they were gone, and he was overjoyed to see them back home.

"Never fear, children," the wife said. "There will be more snipe hunting soon enough. Give them a few days to come back, and you shall try again!" The children went to bed and had fitful dreams of sweet cakes, jellies, and pies.

Several days passed and the farmer's wife made another trip into to town for groceries. This time the watermelons were not cheap, so she picked out a large musk melon with deep furrows and quickly hurried home.

Once again, she sent the farmer with the children out into the fields to snipe hunt. This time, too, he felt guilty as the first time. In for a penny, in for a pound, he figured, so because he had agreed to the plan to first time, he went along with his wife the second time.

The children, for their part, were as eager as ever. The summer had been so long and so hot that they longed for a sweet treat of any kind. This time, the children had been floating sticks down the creek and watching them race, so the only thing that Hank had 
with him were a few saltines as a snack. He crumbled them up in small chunks and used them to mark a path through the tobacco rows. Hank and Ginger hunted snipes for hours, and finally the sun began to set. Ginger became worried they might not find their way back this time, and Hank said, "Don't worry, sister, we will wait until the moon rises and we will be able to see the white spots of crackers against the dark earth."

But when the sun went down, the children couldn't find a single cracker crumb. The squirrels and birds had eaten some, but the rest were hidden from the moonlight under the tobacco leaves. The children were lost, and Ginger began to cry.

Meanwhile, the farmer and his wife dipped huge spoonfuls of melon from the rind. The musk melon was truly delicious, and the sweet juices ran down their chins as they ate. They heard the distant whistle for a long time out in the fields, but toward dusk, the whistling stopped, but had not come any closer. The farmer began to worry they had made a huge mistake and wanted to set out across the farm to look for the children. His wife stopped him, warning him that coddling the children would spoil them. She wanted to let them find their own way back and convinced the farmer she was right.

Back in the fields, Hank noticed a change in the wind as the land began to cool in the night. He detected a faint hint of strawberries. "Ginger!" he exclaimed, "Do you smell that? Even if we don't make our way home tonight, maybe we can at least find something delicious to eat!" And they set off, following their noses, in the direction of cooking strawberries.

The children came out from the rows of tobacco to unfamiliar territory. Across a small rise and through a white clapboard fence, they saw a small farm house with light streaming from the kitchen. They knew there were other farm houses in the countryside, 
but they had never seen another one near their own. As the children quietly approached, they found the source of the beautiful and sweet smells.

Along a pair of open window ledges sat four pies, cooling in the air and drifting a breeze of strawberry, blackberry, persimmon, and apple. Hank, crouched on a small stump beneath the window, knew that he smelled more inside. From where he crouched, he could not see inside the house, but his nose told him that there were cakes, jams, jellies, melons, and more pies through that window. Even more, his gut knew, and it growled and hissed under the open windows. Ginger tilted her arm over her head and daintily tried to pinch a piece of crust from the strawberry pie. Hank leaned up and took a big whiff of the blackberry pie. Suddenly, they heard a voice form inside:

"Nibble, nibble, is it a fly?

Who's that nibbling on my pies?"

The children replied:

"The wind so mild,

The heavenly child."

They each began to take pieces of the crust from each pie. Hansel was about to lift the whole apple pie when suddenly the porch door opened and out stepped an old woman. "Good Lord, children! What are you all doing out here so late? Come on inside where it is safe, and we will get you back home by morning."

The woman led the children inside and fed them every joy imaginable. They ate fried biscuits, country ham, fresh sausage, angel food cake, pickled pears, and a slice of each pie. They were so stuffed that they nearly fainted at the table, but the woman led 
them to the attic where she had prepared two soft beds. The children laid down like they were in heaven and fell fast asleep.

The old woman only pretended to be friendly. She was really a wicked witch who used to live in the city and had moved here to avoid competition from other witches. All witches love to eat little children and puppies, and the old woman was no different. She knew that children wandered all over in the countryside, and when she could catch one, she always had the biggest feast of the year. Ginger looked a bit scrawny, but Hank had potential. So she planned to fatten him up and make a roast while Ginger would help her make the meals. "They will make tasty morsels!" cackled the witch.

At sunrise, the witch grabbed the sleepyheaded Hank and dragged him out to a shed behind the house. She barred the door and felt no pity in her heart for his screams for help. She shook Ginger awake and told her. "I've locked your brother out in the corn shed for I plan to eat him. But first I want to fatten him up. Get out of bed and hurry up to get the eggs and make some for your brother. Once he's fat enough, I'll eat him."

Ginger cried and cried, but the witch had a hard heart from all that she had seen in the city and ignored every tear. Ginger had to do what the witch said, and she hoped to somehow save her brother. Each day she prepared eggs, biscuits, gravy, cornbread, ham, and beans for her brother. Each night, she was given the scraps left over, barely enough to survive. At dawn each morning, the witch would go to the corn shed and ask Hank to stick his pinky finger through the crack in the door. She would squeeze Hank's finger to see if he had fattened up. Hank cleverly stuck out a squirrel bone every day, and the witch wondered why Hank never gained any weight. She had been feeding him enough for two grown men! 
After four weeks, the witch simply couldn't wait any longer to eat those delicious children, so she commanded Ginger to light the wood stove and fetch some water in the boiling pot on top of it. "I don't care whether Hank is still scrawny or not. Once you get the stove ready, I will slaughter him and cook him!”

“Oooooh," wailed Ginger. "If only we had not wanted something so sweet to eat, we would not become sweets ourselves. Being eaten by wild coyotes would have been better, for we would have at least died together.

"Spare me your whining," the witch said, "You will be cooked for dinner tomorrow, so you can share your brother's fate. Now get the wood for the stove before I decide to cook you first!"

Ginger ran outside the door and went past the woodpile to the corn shed. She quickly lifted the crossbar and let him out. "The witch plans to cook us and eat us," she said. "Go get a bucket from the shed and hide behind the outhouse. When you hear me come looking for you, shout for your life into the bucket." Hank did exactly as she asked.

When Ginger returned to the witch without Hank, the witch became furious. "He wanted out to go to the bathroom," Ginger replied. "You wouldn't want him to go in your broth would you?" The witch grunted and pushed her aside. The witch left the house with Ginger following and stomped loudly to the door. "Come out Hank!" Ginger cried. "The nice old woman is ready for us to help her make lunch."

When Hank heard his cue, he started yelling, "Help! Help! Someone rescue me!" Thinking that he had fallen into the toilet and not wanting to lose a plump roast, even if she had to wash it first, the witch swung open the door and leaned over the wooden hole. 
"Go get me a rope," she shouted at Ginger. Hank yelled louder as the witch leaned closer to the hole to try and see him. Instead of running for the rope, Ginger saw her opportunity. She gave the witch a huge shove on her behind, and the witch tumbled helplessly through the hole. She made a loud squishy thud at the bottom and then died from her injuries.

"We are safe now, brother," Ginger cried with joy. Hank came out from behind the outhouse with his bucket. They had nothing to fear from the witch now, so they returned to her house. Hank filled his bucket with candies and jar of sweet jams and jellies. Ginger filled her apron with delicious fruits and a country ham, and both children fled the house and turned toward where they thought home should be.

They walked for what seemed like hours before they arrived at an unfamiliar small pond. Beside it, in the shade of a chestnut tree, rested a large red dog with long curly hair. The dog stretched out and yawned.

"We are terribly lost," said Ginger. She called out to the dog:

“Help us, help us, big red dog

Hank and Ginger are so far from home.

There's no path, not cow or gravel,

Help us, help get us home."

The dog stood up slowly and yawned again. He walked over to let Ginger get on, but not Hank, since he had been eating all the witches good food and had become a bit heavy. With Ginger on his back and Hank by his side, the dog took them across the hollow and up to the next ridge where he waited for Ginger to get off his back. He laid down to sleep under the shade of a honeysuckle bush, but the children looked down over 
the other side of the ridge and began to recognize trees and rocks. They walked a little farther, and they soon saw the farmhouse in the distance. They ran and ran while Ginger blew her whistle the whole way.

The farmer heard the whistle in the distance and wept with joy, for he thought that his children were lost because of his own greed. He had not had a single good thing happen to him while his children were gone. His tobacco had yellowed and at least half his crop had been flooded out. His wife had died. He ran to embrace the children when they returned, and the children presented all their lovely food they had gathered. They prepared and ate the most delicious food of their lives, and the father never again desired fine foods over his family. They all lived together in perfect happiness, even after the sweets ran out.

My fairy tale is done. See the squirrel run. Whoever catches it, can make a pair of socks out of it. 


\section{PART FIVE}

"So what did you learn from that, young man?" asked Shirley when he was finished with his story.

"I learned that I'm not sure if snipe huntin' is a good idea," Hoss replied. His sister lay curled up and asleep on the hard floor, on a quilt doubled up beneath her, and another that Hoss had wrapped her in to keep her warm.

"Well, I'd say it's a good thing to avoid hunting something that you don't know what it is," offered Russel Bishop. His long face twisted up into a chuckle.

Julian's stomach rose and fell as he napped quietly leaned up against the wall. Ray Workman stayed more or less alert, but every few minutes during the last story, he rose to check the level of the water outside and make sure no one was in danger. The rain had, in fact, stopped completely by this point. When everyone was quiet, the room was full of soft sounds like the deep, heavy breathing of Julian resting; the faint hiss and sizzle of the lit candles; and the gentle lapping of the water against the wheels and hubcaps of the trucks outside. The moon remained obscured behind the clouds, so the only light streamed away from the candles and out into the country night around the store. Through the back door of the store, light from Louella Workman's kitchen and back porch diffused out across the raised path from the house to the store, revealing one of the few areas of raised but soggy ground, upon which rested the house, the foundation 
of the store, one end of the bridge crossing the creek at the Levy, and the Workman's tomato garden.

Inside the house, Louella had given up on sleep for the night. With her husband away from their warm bed, she stirred and tossed until she rose to sleepily make and cut biscuit dough for the early morning to come. She left the porch door open so the screen door would let her husband's voice filter through the night air if he or anyone at the store, especially the little ones, needed anything from her in the night. She had wanted to bring the children into the home for the night, but her husband told her before sunset that they didn't want to come in and wanted to stay out in the store. It was excitement for them, she supposed, and they always had the house to retreat to if the store was overtaken with water.

However, throughout all the floods, the families had survived at the Levy, none had fully breached the store, and none had ever truly threatened the house. As if they were blessed by the delicate hand of the Lord, they could always watch the waters rise and fall without worry that they were in God's care. Louella peered out her screen door and over the misty waters draining and surpassing the Levy, and she imagined all of it to be one of the Lord's greatest places on earth. She had lived here all her life, and she wanted the last moments of her life to be at the Levy. So many had been taken to hospitals in the city and never returned for their final moments. She and Ray spoke often of this, the life force of those leaving being sucked right out of them once their feet are off the land. Though dark outside, she saw the long and rippled fields of fescue, the pair of willows standing guard over the Lyon driveway, the small country church hidden two miles up the holler, and the locust trees holding firm on the boundaries of plowed fields. 
She could join them in the store, she figured, but the peace and fullness of this place, her kitchen and her mother's kitchen, sustained the part of her soul that perhaps even Ray could not understand. Love him as she did, he was tied to the people of this place and in the words and stories they told one another. She understood and felt that certainly, but the wide spaces and the dirt beneath them were the parts of life in the Levy that consummated her and fed her through all the years. Each morning while she made breakfast and scanned the landscape warming up to the dawn, she felt the ropes of sleep fall off of her, and she knew she never needed coffee or strong drink to wake her. The smell of insects and grass and even manure were enough to wake any soul that springs up from this land. So she stayed inside in these wee hours of the morning, alone and contemplative, full of the promises of morning just as the horizon, the low clouds graying for the impending rise and her own hair, gray and delicate down the nape of her neck.

Inside the store, the hours had become so long that those who remained awake, Shirley, Ray, Russel, and Hoss, struggled through fatigue to remain the last one standing. The men fought of sleep in a sort of strange responsibility, a desire to keep everyone safe and entertained. Hoss stayed awake out of sheer will to show he was one of the men and belonged among them of his own accord. The decades of life allowed Homer to slip peacefully into a sound sleep sitting in his chair, every bit as oblivious to the world as the young Helen.

Russel, yet to tell a story because almost all he knew were pranks and jokes not suitable for youngsters, saw the opportunity to take the young boy under his own guidance and winked at him to come nearer. "Son, I'm gonna' tell you a story about a young man not too much older than you from around the Levy. He had a run-in with 
misfortune and was sent out into the world to help out his momma. Since you might find yourself in such a way soon, I'll try and help you. You may think being only thirteen don't mean much, but that's old enough that you'll be called upon to be a man a fair bit more than you might expect." He took a serious look to his face.

"Yessir," responded Hoss. He figured he was pretty much already a man, as he had already kissed two girls and things had started happening to him down below. Yet he was always taught to respect the older men around him, and he did the same here. All these men had lived near the Levy longer than him, and even though Hoss thought he could run circles around them in most any area, he sat quietly to listen to Russel.

“This is not a story for your sister to hear, so I trust you won't repeat it to her later. I would also trust you don't tell your momma." Russel moved in closer to avoid waking Helen, and Shirley looked on with interest to see which of his brother's story could possibly be clean enough and even a lesson for a young boy. Either way, Hoss was already working in the fields and would be man enough soon. "You ain't been to the city by yourself yet," began Russel, "but when you do, there'll be a lot of sights that are new to you, and so here's at least one you can watch out for."

With that, Russel Bishop began a story that he confessed to only be partially true, but both Bishops knew it to be true as of only a few years ago. The family had since left the Levy, but the farm remained with much of the rusted out machinery and now untended fruit trees that remained. Russel's face, longer and thinner than his brother's, cast sharp shadows in the candlelight. His countenance sent a shiver through Hoss, and the boy looked on at him, rapt and ready to learn. 


\section{RUSSEL BISHOP'S WARNING TALE:}

\section{BIG RED CAP}

Not so long ago there lived a young man who suffered greatly at the death of his father. The young man, who became known as Red Cap for the old, dusty Marlboro hat he always wore, was loved by all those who lived in Saltlick. They found him a strong, lean young lad, willing to help out neighbors with the simplest request. When anyone needed a hand, Red Cap was there to chop wood, repair broken trailer pins and hitches, rescreen doors and windows, and set or pull or house tobacco. The cap itself was a remnant from the life of his father. Once when the young man was a young boy, he fell off the back of a tobacco wagon as it bounced up a gravel path to the barn. The boy cried and cried, even though he had only been scraped, until his father took the Marlboro cap from his own head and gave it to his son.

One day the young man's mother reminded him that the annual farm machinery show was going to be held in a nearby city. She told him very clearly, "I need you to take your father's tractor to the city and sell it so that we can keep food on our table for the year. Be careful and don't waste all the money while you're in town." She also explained to him the dangers of the city, in particular the fact that out-of-towners are preyed upon, for money or otherwise, when they spend too much time there. The young man had dreams of becoming a farmer himself, so at first he was quite disappointed that his mother would ask him to sell the tractor. But, he thought, his father's smaller, red utility tractor, a tiny International, would still do well on the farm, and the money from 
the sale of the bigger tractor would help keep him and his mother fed while he practiced what he'd learned about farming from his father.

Red Cap's father had never asked him to attend the show. His father often went, nearly every fall, but Red Cap typically stayed home with his friends and got into mischief in Saltlick or played out in the field with the family dog. Red Cap had been as far as Burford, twenty miles away and populated with a single stoplight, but he had never been farther. The world beyond seemed mysterious and dangerous, even though he could read about most everything about it from the World Book.

Now, to become the man of the house after his father had passed on, Red Cap needed to go out into the world and do as his mother asked. Red Cap loaded the main tractor into a large box trailer and headed out to the highway and the city beyond.

Once Red Cap reached Louisville, he found it much more disorienting than he expected. He saw a forest of buildings and light poles and signs covered with advertisements. He marveled as he followed the signs for the Annual Farm Machinery Show that led him through sweeping and sloped highway interchanges and along aboveground bridges that loomed over the cityscape. Saltlick had none of these. His home had more grass and trees and dung in an acre than he figured could be found throughout the entire city.

The closer to the highway exit he drew, the taller the buildings grew. Eventually he saw them so packed in that it made him think of neat rows of towering tobacco ready to harvest. This thought actually comforted him. It felt like something familiar in a wilderness of dark, strange things. 
Near the fairgrounds, Red Cap took an exit and pulled his truck and load into a grand parking lot. In a sea of trucks and trailers and tractors, he put his palm up to shield his eyes and scanned across the lot. He saw no clear signs to direct him and had no idea where to go next. Did he check in somewhere? Did he wait for someone to approach?

As he was pondering his next path, an attractive young woman stepped out from behind a row of John Deere machines and handed him a small flyer. He glanced briefly enough to only notice a young woman dressed in a bright red cloak on the flyer.

"Hi, honey," the young woman said. She held a stack of the small flyers, all the same. She wore a fitted pair of denim jeans, cowboy boots, and a yellow tank top.

"Good evening," said Red Cap. He glanced away from her hands to her face and back quickly. He felt a bit ashamed at talking to her, though he wasn't quite sure why. “Do you work for the Machinery Show?” he muttered.

"No," she said. "I work at JT's, six blocks north on Crittendon." She pointed at the flyer in Red Cap's hand, touching her finger to it and softly brushing his thumb as she drew it back. He noticed she had an inviting smile, understanding and alluring. "You should come see me."

"Well, I'm talking to you right now," he said, proud at his cleverness.

"You can see more of me there," she hinted. "Not too much more on account of the city lawyers and council and so forth but more than what you see here."

"Well, I'm not sure," Red Cap stammered. He looked her up and down again and realized he didn't know many women like this from Saltlick. She was fairly smaller than he was used to, and she looked at him differently, like she was hungry and excited that he was around. Women, mainly, and some girls from Saltlick usually invited him to dinner 
or to stop by the house and talk later. None had ever hinted that he might see more of them or what that meant. Red Cap wasn't sure what JT's was and why it was further into the city. 'I'm not from Louisville, so I don't know the area much, and I'm here to sell this tractor anyway." He gestured at the trailer behind him.

"Honey,” she began again, “it ain't far, and surely you'd rather look at something other than tractors all night." She reached for his hands and turned over the flyer in it. Pointing at the back, she said, "Look there and you'll see easy directions to get down there." She hugged him, a little awkwardly, and walked on down the lot.

Within the hour, Red Cap sold the tractor, as it was a rare model of that size. The payment, all cash, he tucked deep down in his boot-sock, safe and sound. He considered wandering around and looking at some of the other equipment, but he felt tired and homesick already. He planned to leave quickly when he encountered the young woman in the parking lot again. He noticed this time, from behind, that she had longer hair than he expected, mostly brunette with some blond streaks throughout. She waved at him as she positioned the last of her flyers under the wiper on a nearby Ford pickup.

"Are you coming to see me later?" she asked.

"Maybe," he said, "are you done here?"

"I'm done," she said. "Going to JT's here in just a few. I would offer you a ride, but we aren't allowed."

"Ah, I'd have a hard time explaining that story at home anyway," he said. "Not many people like you where I'm from." She smiled. "What is your name anyway?" he asked. "So I know who to ask for at the place." 
"I go by Candy," she said. "But I'm not always sweet to people. I just like it when the farmers come to town."

"Why is that?"

"Let's just say they make it worth my while for the whole year," she answered. It was clear that she didn't want to explain because she quickly asked again if Red Cap would be visiting her club.

"I might," he answered. "I probably could." This seemed affirmation enough, as she hopped excitedly and asked him when he might arrive. He told her was going to head that way immediately, but that he felt like he'd rather walk to get a better sense of what the city was like. Yes, he planned to walk the six blocks, but he figured that was pretty easy compared to getting cattle where you wanted them to go all day and working in corn or soybeans or tobacco. With that, she jumped into her a small sedan and squealed off, flyers all gone, toward the downtown skyscrapers.

Red Cap's walk was more amazing than he ever expected. Though he had heard, read, or seen pictures of the many types of people in large cities, he had never seen them up close. The sidewalks were full of mysteries. A man pushing a baby carriage filled with soda cans, a woman with a white and tattered wig whispering to everyone who passed, a three-legged dog being led by a one-legged man on a motorized wheelchair, dozens of shirtless black boys walking in small groups, a police officer on a horse, and even three teenage girls zipping by on a single, tiny scooter. It was a wilderness of unfamiliar people and things. Feeling disoriented, Red Cap remembered the small flyer in his pocket and knew the directions would lead him if necessary. However, he needed 
no such help. Soon he saw for himself the great, glowing sign marking the entrance to JT's.

He went in. It was darker than Red Cap expected. The lights gave only a muted, bluish glow. A young, nightie-clad woman quickly approached him.

"Hi, honey, you want to get a drink?" she asked.

“I'm looking for someone," Red Cap answered.

"Well, sweetie, you're in the right place. There are lots of someones here." And she was right. Red Cap looked past her and saw dozens of men and a few women gripping bills tightly and finding curious ways to give them to women who were dancing on the stages. He remembered the money from the tractor sale and felt the folded pile deep in his boot and damp with sweat against his ankle.

“I’m looking for Candy,” Red Cap replied.

"She's over by the bar," the woman said. She turned to leave, and Red Cap realized that she was wearing a small rabbit tail.

Puzzling over this, Red Cap made his way to the bar where he had been sent. Candy was there, sure enough. She spoke with another man beside her. She had her back to Red Cap, and he noticed that she, along with a rather revealing gray outfit, sported a tail of some sort. It looked wolfish.

As he looked around the establishment, Red Cap slowly understood the reason for the tails. The club was themed, to a degree, around hunting. The walls were the dark cedar of a men's lodge. The upper areas were adorned with the trophy heads of hunted beasts. The ceiling displayed fake greenery, made up to look like the overhang of a canopy of trees. For Red Cap, who had only read and heard about places of this caliber, 
the scene was jarring. Yet he could quickly see how the atmosphere excited and invigorated the men, who then freely gave their money. In turn, the women, who freely accepted bills tucked into intimate places, including just beneath their tails, were invigorated by the exchange of money.

What struck Red Cap suddenly is that his father never mentioned such places. Surely such knowledge would have helped Red Cap in the long run, as so many of the farmers he recognized from the show had ended up here.

Unsure of how to act in such a strange space, Red Cap sat at the bar and nervously ordered a glass of water from a young female bartender who wore a brown bikini with what looked like a raccoon tail attached. A song with a consistent beat played in the background, making Red Cap think of the put-put-put of the cornmeal grinder at the county fair near Saltlick. Soon, Candy left the bar with the other man and disappeared into another part of the club. She left through a doorway framed by a skinned and stuffed water moccasin, and Red Cap turned back to his glass, which was now becoming slick with condensation.

While she was gone, several other women approached Red Cap and asked him for a drink, to drink with them, or to come somewhere and sit with them. Each time he refused and repeated that he was there to speak to Candy and that he would wait right there for her. Each woman, after he refused, slinked out into the open space of the room and weaved through and around and against all the other farmers wearing various caps of dozens of colors, and many, Red Cap saw, sat down beside some of the men or sat in their laps, giggling into their ears. 
Before long though, Candy returned from her doorway, now alone. She wore a different outfit, even more revealing than the tight gray shirt and bottom she wore before. This time it was a pink bikini with small red cherries all over. The tail was nowhere to be seen now. She grabbed him by the hand without a word and led him from the bar into a small room.

Red Cap felt disoriented by the room, as it had mirrors all along the walls and a long dark leather couch along a whole side. Candy sat him down and asked him how he was doing.

“Good,” Red Cap said, "though I've never really been in a place like this.”

"Are you having a good time?" she asked. She began removing her top.

"I think," Red Cap answered. Her top fell to the floor. He felt frozen, unsure of what to do next. Should he leave? Should he ask her about something, herself? "Did you go to the machinery show today, or were you just outside?" he finally asked.

"I never go in," she said. "I go down there to pass out flyers for this place."

"Well, it sure was nice to meet you down there today. This is the first time I've ever even been to the machinery show."

“Oh," she said. She glided toward him and straddled his lap. "I hope you're enjoying yourself."

“Do you not remember me from this afternoon?" Red Cap asked.

"Of course, honey," she said.

"You were wearing jeans and tank top," he said. "You changed when you got to work?"

"Yes," she answered. "I can't get very comfortable in here wearing that stuff." 
"Why is everyone wearing tails?" Red Cap wondered aloud.

"It is part of the way we work here, club's rules," she cooed, "part of our theme here at the club."

"Why is that?"

"Well, the better to entertain you with," she giggled. She began to rub her hips hard against him. Red Cap sensed himself growing uncomfortable. Candy's hip and the undulations of her body matched the pace of the song. Red Cap tried to think of the cornmeal grinder, but it was no use. When she removed her bottoms, he was surprised and confused to notice the tail still attached to her. He thought that surely it was glued on, wasn't it? His heart beat faster, and he felt both excited and worried. To his relief, or perhaps lack thereof, the song ended and Candy moved off of him and sat beside him on the couch.

"That's twenty," she said.

“Twenty what?" Red Cap asked.

“Twenty dollars. That's one dance. Later there'll be a two-for-one special and I can come back if you like," she said smiling. Her teeth, a bright white, unnerved Red Cap a bit.

"What makes you think I have money," he said.

"All the farmers have money when they come here. If you didn't want to spend, why did you even come in here? At least you're getting something good for it!" Candy retorted.

Red Cap, now realizing how people behaved here, finally began to understand. He wondered if his father had come here. He thought about his father's excitement every 
year before the show, and he considered that it might not just have been for farm machinery. "I have to go outside," he said quickly.

"The twenty first," Candy demanded. Red Cap thought of the fights his mother and father often had over money. He furiously stuck his hand in his boot and sock and wriggled out a bill. That his father's legacy to the family was a collection of well-worn land and machinery seemed bitterly cruel. He shoved the wadded money into her palm. Red Cap would have purchased feed or fertilizer with it; frustration made him want the money back, but Candy had already slipped away, behind some secret curtains. He stumbled out into the main room, still a bit disoriented. He saw the dozens of men in the club laughing and cackling and eagerly waving money in the air. Some drew out single bills from a large wad of cash, much like his own, and tucked one after another into bikini strings, bra straps, garters, and underneath the rabbit, raccoon, beaver, and wolf tails. Red Cap felt ashamed, as if everyone could see that he felt strange and weird and out-of-place, but at the same time he knew that all the men were clearly focused elsewhere. He realized, though, that he could escape while the others could not.

Another woman with a fake nose sporting whiskers approached him and inquired if he'd like to sit down for another drink. "May I go to the bathroom first?" he asked.

"Of course darlin'. You go and I'll be right here when you get back," the woman responded.

Red Cap sped towards the bathroom, beyond it, and out the door into the street. For a moment, panic struck him as he considered the possibility that others in the club had seen him withdraw money from his hiding spot. The money was vital to keep him and his mother in good shape while he became a true farmer. Finding himself out in the 
street, in the dark, Red Cap swiftly walked back the six blocks, trying to avoid making eye contact with anyone or anything. Before long, he found his truck, locked himself inside, and took a deep breath that brought in the smells of the dirty truck floor, speckled with earth and mud from his home in Saltlick. He felt great relief.

So Red Cap left JT's and Louisville and headed home to Saltlick and his mother and the still raw absence of his father. Red Cap knew, though, that he was not his father, and the journey to Louisville convinced him of such. However, he did so with a boot sock still strapped with cash, a small legacy from his father that would serve as riches enough while Red Cap made his own way in the world as a farmer and son. 


\section{PART SIX}

During the time Russel told his story, young Hoss faded and faded closer to sleep. Shirley, leaned back in a chair while resting his eyes rather than full-on sleeping, and watched through squinted eyes as his brother traced out the details of Red Cap's journey. The two men waded through life with a bond stronger than most any kinship, but it had cost them dearly. Neither man had married, and each day in the twilight hours they only had each other to look to for comfort. Now, as Russel added little flourishes of his hand for effect during his retelling, Shirley saw that Russel had a gentle touch with younger minds contrary to a man who had lived without children. Russel, in some ways, was a better storyteller than all of them, not because of the story he chose to tell, but because his delivery held an immediacy and potency of rarity. He had a certain reverence for a good story that Shirley knew from the soft words from their mother and her hard-worked hands as she tucked them in each night.

Hoss fought until the end of the story to stay alert, but he had lost at the very end and ended up curled up, back to back, with his sister on the floor. The other men awoke in gradual stages, as the light seeped through the heavy clouds and into the dark wood of the store's floor. Each in turn yawned to the weak sunlight, Homer first after many years of waking to feed the cattle and chickens. He stepped to the front door and out onto the porch where he leaned up against a support post and looked out over the Levy. 
The rains had moved on. The waters of the creek swiftly escaped under the bridge and out toward the west, driven by the unseen and swollen banks below the water's surface. The floodwaters were on the escape, and in a bit of time, they would let the men return to their lives.

Inside, the day began to proceed as normal. Louella brought in some fried biscuits from yesterday's supper and slices from a country ham. She sat with all the men on stools around the counter as they ate their breakfast in silence. The children slept soundly in the sunlight, a rare refuge of childhood available to country folk where the light of the day brings work. Each of the adults grew up in the same way; they awoke as young babes to the clinking of spatulas and frying of meat in skillets. The beautiful smells of thick, rich food reached into their often shared bedrooms, gently drawing them from slumber into the discussion of morning. Fathers and mothers and uncles and cousins and grandparents all joined around in a chorus of the living and the survivors to seek out another day as stewards of a lush and harsh countryside. They all overheard stern discussions of the latest local illness, emphasized by hushed words and glancing eyes when it was a mental illness or an unexpected pregnancy. When one of the Levy people would pass on, the conversations would continue much the same, but for months and years after the morning would be punctuated by a confession of sorrow, one relative or that proclaiming aloud that so-and-so would have been overjoyed to be eating this or that fruit during that time of the year. No soul every truly left the Levy, but the greatest sorrows were held tight and silent, like the absence of a young person lost to the larger world outside the Levy in the guise of school or work or even play. These disappearances felt by the host at every breakfast table served as the greatest pain of loss, 
as none there could know if the spirits of the lost would ever return to the Levy where years of life and toil and joys in small things had built up into faith in the Lord and maybe even more strongly, a faith in one another.

And so it was there in that damp morning that they all gathered and ate and felt the sting of fatigue and knowledge that a day of work lay ahead before any of their souls could rest. As they chuckled over the story they would tell loved ones once they returned home, about another night stuck at the Levy store, the waters outside fled the countryside, sucked up by still thirsty maples and oaks. The rest sped out into the tributaries and then into the Kentucky River. The River flowed past the rural and into the urban areas near Lexington where it was bound up in damns and controlled by man's engineering all the way down into the Ohio. As for decades people had followed the same course, trickling from the farmland and into the suburbs and cities, the water also journeyed.

The mud and silt scoured from the rich farmland spread out in fingers and rivulets across the paved and gravel roadways, and the driveways gradually opened up. One by one, the storytellers made their way back outside and to the tasks that lay before them on their own land. Shirley and Russel roused the children and loaded their four wheeler in to the back of the Bishop pickup, taking Hoss and Helen safely back home. Hoss would, in his years as a young man, choose to stay in the Levy and try to modernize the farm his family had left to him. Helen took an education as a schoolteacher and moved to where she was needed in Pikeville.

Homer Johnson ended up in a rather heated debate with Julian about a new pesticide available. He argued that the new stuff wasn't anything they'd needed to grow tobacco in years past, but he conceded that it might help a bit with worms over what 
they'd had. The two men agreed to wait and see how things'd turn out, and Homer sauntered out to his truck to leave. He took a quick glance back and smiled at the store that he'd been visiting all his years. He figured he would tease Ray on the next visit that the roof needed another coat of silver paint before the fall.

Louella returned to the house with the complaint that she'd better get to the chickens before they got to her. In truth, she loved to take care of all the animals. They all seemed to take such joy in being alive and in a quiet place that she felt a kinship with them. She knew of no other way of living, and the Levy was all she had known. Absent the restless heart that comes from routine and familiarity, even the ritual of shucking and dropping corn for the chickens filled her with such joy and love for her husband and life and all the living around her that she could not bear to think of a different time or place. She went on to the house humming "Amazing Grace" softly and firmly to the two ratty tomcats that followed her through the yard.

Ray set about cleaning a store that would never appear anything but dirty to the unfamiliar eye. The age and wear of use in the old boards and planks of the store showed to him a lineage of service and companionship with the people of the countryside. His busy work kept his mind off the age of his own body and the worry of what came next. Someday he would pass on from the physical realm of this place, and the wooden floors of the store would crack and splinter and rot in the weather as the old building awaited another man or woman dedicated more to people than the money they carried. But there was no time for that when the farmers would soon be in for a lunch of fried bologna sandwiches. 
Julian was the last at the store, and he said his see-you-laters to Ray before stepping onto the porch. He turned to look at the store and wondered where his life would take him. He still felt himself a young man, but it always seemed that the Levy was trapped in an older time. He took his time in leaving, as his wooden bridge over the creek would be one of the last spots to emerge from the waters. He watched the floodwaters carry the sticks and foam as it roiled past the Levy and considered that they would end up in the river and past the cities and finally into an ocean he had seen only once in his life. He briefly considered what it would be like to join all the earth and life swifted down the creek and out of the Levy, if when his time came they would burn his earthly body to ashes and spread it throughout the waters to make the same journey. In the end, though, he knew this was not the way of his people or those he shared life with here. They would be interred, as would he, deep within the fragrant dark earth beneath all their feet, and there his body would sleep out the rest of the days of the earth while his soul, vibrant and full of the life it drank up while working and breathing along the banks of these waters, would forever meet with others at mailboxes and hay fields. And then there would be the days that the creek waters, in the way waters of time, would flood them all into a small space filled only with one another and the things they saw and ate and worked and loved. He wondered who would visit them in this rarest space. Would it be only the animals and plants, returned as they do to cover the human world, or would there be human voices to fill the space as a new generation took over as stewards for the Levy? He tried to pass the thought from his mind, as his education had taught him the path that most of these places take. At any rate, the cattle needed to be driven from the 
back field, and washed out fences would need repair. With that, he left in his pickup and made his way slowly towards home. 


\section{REFERENCES}

“9349-1: Fairytale and Historic Minifigure Set.” Brickset.com. 2014. Web. 21 Oct. 2014. Asbjørnsen Peter Christen. Norske Folkeeventyr. Charleston, SC: Nabu Press, 2014. Print.

Anderson, Graham. Fairytale in the Ancient World. New York: Routledge, 2000. Print. Apulius. The Golden Ass. Trans. P.G. Walsh. Oxford: Oxford UP, 2008. Print.

Ashliman, D.L. “Charles Perrault's Mother Goose Tales.” University of Pittsburgh. 2013. Web. 18 Jan. 2014.

---. Folk and Fairy Tales: A Handbook. Westport, CT: Greenwood P, 2004. Print.

---. “The Pied Piper of Hameln.” Homepage. University of Pittsburgh, 17 Feb. 2010. Web. 8 Apr. 2014.

Avery, Tex. “Little Rural Riding Hood.” Metro-Goldwyn-Mayer, 1949. Film.

Bacchilega, Cristina. Fairy Tales Transformed?: Twenty-First-Century Adaptations \& the Politics of Wonder. Detroit: Wayne State UP, 2013. Print.

Basile, Giambattista. The Tales of Tales, or Entertainment for Little Ones. Tr. Nancy L. Canepa. Detroit: Wayne State UP, 2007. Print.

Baudrillard, Jean. Simulations. New York: Semiolext, 1903. Print.

Beauty and the Beast. Perf. Ron Perlman and Linda Hamilton. Prod. Witt/Thomas

Productions. CBS, 1987-1990. Television.

Bell, David Christopher. "4 Bizarrely Specific Rules Fairy Tale Adaptations All Follow.” 
Cracked.com. 16 Nov. 2013. Web. 10 Jan. 2014.

Berry, Wendell. "The Peace of Wild Things.” Gratefulness.com. N.d. Web. 13 April 2014.

Bettelheim, Bruno. The Uses of Enchantment: The Meaning and Importance of Fairy Tales. New York: Vintage Books, 1989. Print.

Boccaccio, Giovanni. The Decameron. Trans. Wayne A. Rebhorn. New York: Norton, 2012. Print.

Bottigheimer, Ruth B. Fairy Tales: A New History. Albany, NY: State U of NY P, 2009. Print.

Canepa, Nancy. "Straparola, Giovanni Francesco (c. 1480-1558)." The Greenwood Encyclopedia of Folktales and Fairy Tale. Ed. Donald Haase. Westport, CT: Greenwood P, 2008. Print. 926-927.

Carey, Benedict. “Do You Believe in Magic?” The New York Times. 23 Jan. 2007. Web. 1 Jan 2014.

Chase, Richard. Grandfather Tales. Illus. Berkeley Williams Jr. Boston: Houghton Mifflin, 1948. Print.

Chaucer, Geoffrey. The Canterbury Tales. Trans. Nevill Coghill. New York: Penguin, 2003. Print.

Chiriac, Jean. "Psychoanalysis and Fairy-Tales." Freudfile. 2010. Web. 31 Jan. 2011.

Darnton, Robert. The Great Cat Massacre and Other Episodes in French Cultural History. New York: Random House, 1985. Print.

Davenport, Tom and Gary Carden. From the Brothers Grimm: A Contemporary Retelling of American Folktales and Classic Stories. Fort Atkinson, WI: Highsnoth, 1992. 
Print.

Davenport, Tom. Davenport Films \& From the Brothers Grimm. n.d. Web. 20 July 2014.

Davidson, Hilda Ellis and Anna Chaudhri, eds. A Companion to the Fairy Tale.

Cambridge: D. S. Brewer, 2003. Print.

Davidson, Hilda Ellis. "Helpers and Adversaries in Fairy Tales." Davidson and Chaudhri, A Companion to the Fairy Tale. 99-122.

Delarue, Paul. “The Story of Grandmother.” Trans. Maria Tatar. Tatar, The Classic Fairy Tales 10-11.

“Design with Life Vinyl: Life Itself Is a Most Wonderful Fairytale.” Amazon.com. 2014. Web. 20 Oct. 2014 .

Dieckmann, Hans. Twice Told Tales-The Psychological Use of Fairy Tales. Trans. Boris Matthews. Wilmette, IL: Chiron Publications, 1986. Print.

Disney, Walt. Beauty and the Beast: Diamond Edition. Walt Disney Studios, 2010. DVD. ---, dir. “Little Red Riding Hood.” YouTube. YouTube, 1 Sept. 2012. Web. 15 June 2013. ---. Snow White and the Seven Dwarves. Dir. William Cottrell. Disney, 1937. Film.

Dragon, Al. Avalanche and Gorilla Jim: Appalachian Trail Adventures and Other Tales. New York: Morgan James Publishing, 2012. Print.

Dundes, Alan, ed. Little Red Riding Hood: A Casebook. Madison, WI: The U of Wisconsin P, 1989. Print.

Edgerton, Franklin. The Panchatantra Reconstructed: Volumes I and II. New Haven Connecticut: American Oriental Series, 1924. Print.

Eliade, Mircea. Myth and Reality. Trans. Willard R. Trask. Long Grove, IL: Waveland P, Inc, 1998. Print. 
"Fairy Tale F1." Johnny's Selected Seeds. Johnny's Selected Seeds, 2014. Web. 17 Oct. 2014.

Fairy Tale Brownies: A Taste of Pure Enchantment. Fairytale Brownies, 2014. Web. 20 Oct. 2014.

Fairy Tales. Fairytaleshaircare.com. 2013. Web. 18 Oct. 2014.

"Fairy Tales." Search. Amazon.com. 2014. Web. 21 Oct. 2014.

"Fairy Tales Told Children Blamed for Later Ills." The Science News-Letter. 31.830 (1937): 153. Print.

Faris, Wendy. Ordinary Enchantments: Magical Realism and the Remystification Narrative. Nashville: Vanderbilt UP, 2004. Print.

Felson, Richard B. and George Gmelch. Current Anthropology 20.3 (1979): 587-589. JSTOR. Web. 16 Nov. 2014.

Frazer, James George. The Golden Bough. Ed. Robert Fraser. Oxford: Oxford UP, 2009. Print.

Giroux, Henry A. "Animating Youth: The Disneyfication of Children's Culture.” A Socialist Review 24.3 (1995): 23-29. Print.

Griffin, Peggy Ann. Talking Treasures, Illus. Darrell Pulliman. Chicago: Scribes, 1995. Print.

Grimm, Jacob and Wilhelm Grimm. "Little Red Cap.” Trans. Maria Tatar. Tatar, The Classic Fairy Tales 13-16.

---. “Snow White.” The Classic Fairy Tales. Ed. Maria Tatar. New York: Norton, 1999. Print. 83-9. 
---. "The Boy Who Went Forth to Learn What Fear Was." The Complete Fairy Tales of the Brothers Grimm. Trans. Jack Zipes. New York: Bantam, 1987. 11-18. Print.

---. "Why Dogs Sniff One Another." The Complete Fairy Tales of the Brothers Grimm. Trans. Jack Zipes. New York: Bantam, 1987. 174. Print.

Haase, Donald. "Yours, Mine, or Ours?" The Classic Fairy Tales. Ed. Maria Tatar. New York: Norton, 1999. 353-63. Print.

Hanlon, Tina L. Appalachian Folktale Collections. Ferrum College. 30 Sept. 2013. Web. 25 June 2014.

Hansel \& Gretel: Witch Hunters. Dir. Tommy Wirkola. Perf. Jeremy Renner, Gemma Arterton, and Peter Stormare. Paramount, 2013. Film.

Heuscher, Julius E. "Mythologic and Fairy Tale Themes in Psychotherapy.” American Journal of Psychotherapy 21.3 (1967): 655-65. Print.

Jacobs, Joseph. English Fairy Tales. 1 Feb. 2005. Kindle file.

Jones, Loyal and Billy Edd Wheeler. More Laughter in Appalachia: Southern Mountain Humor. Little Rock, AR: August House, Inc., 1995. Print.

Jones, Steven Swann. The Fairy Tale: The Magic Mirror of the Imagination. New York: Routledge, 2002. Print.

Junod, Tom. “The Falling Man.” Esquire. Hearst, 8 Sept. 2009. Web. 18 Mar. 2014.

Kast, Verona. Through Emotions to Maturity. Trans. Douglas Whitcher. New York: Fromm International Publishing, 1993. Print.

Lang, Andrew. The Arabian Nights Entertainments. Project Gutenburg. 1 May 1994. Kindle file.

---. The Red Fairy Book. London: Hesperus Press Limited, 2013. Print. 
Leary, Catherine. Personal Interview. 31 July 2012.

LeGuin, Ursula. "Why Are Americans Afraid of Dragons?" The Language of the Night: Essays on Fantasy and Science Fiction. Ed. Susan Woods. Penjee, NJ: Putnam, 1979. Print. 39-45.

Lüthi, Max. The European Folktale: Form and Nature. Trans. John D. Niles. Bloomington: IUP, 1982. Print.

Maupin, Dan. Personal Interview. 25 March, 2010.

McCarthy, Cormac. Child of God. New York: Vintage International, 1993. Print.

Mieder, Wolfgang. The Pied Piper: A Handbook. Westport, CT: Greenwood Publishing Group, 2007. Print.

Mushko, Becky. Little Meg Reddingoode: An Appalachian Red Riding Hood. PeevishPen, 23 Aug. 2014. Kindle edition.

de Navarre, Marguerite. The Heptameron. New York: Penguin Classics, 1984. Print.

Owen, James. "Snakes in Ireland: Blame Ice Age, Not St. Patrick." National Geographic News. 28 Oct. 2010. Web. 5 Apr. 2014.

Perrault, Charles. The Complete Fairy Tales in Verse and Prose. Trans. Stanley Applebaum. Mineola, NY: Dover, 2002. Print.

---. "Little Red Riding Hood." Trans. Maria Tatar. Tatar, The Classic Fairy Tales 11-13.

---. "Puss in Boots." The Fairy Tales of Charles Perrault. Trans. Nicoletta Simborowski. New York: Clarion, 1993. 45-53. Print.

Puss in Boots. Dir. Chris Miller. Dreamworks Animation, 2011. Film. Rafferty, Terrence. “The Better to Entertain You With, My Dear: 'Mirror, Mirror,' 'Grimm' and Hollywood Love for Fairy Tales.” The New York Times. 21 Mar. 
2012. Web. 10 Jan. 2014.

Richardson, Samuel. Pamela. Eds. Thomas Keymer and Alice Wakely. Oxford: Oxford UP, 2008. Print.

Sanders, Melissa, Tricia Cisney, and Brett Cullen. "Snipe Hunting.” Ozark History. 2002. Web. 11 November 2014.

Schraff, Marilyn Thornton. Appalachian Childhood: Memories of Growing Up In Rural Southern Ohio During the Mid 20th Century. Cleveland: Schraff, 2010. Print.

Sendak, Maurice. Where the Wild Things Are. New York: Harper Collins, 2012. Print.

Shavit, Zohar. “The Concept of Childhood and Children's Folktales: Test Case—_Little Red Riding Hood.'” The Classic Fairy Tales. Ed. Maria Tatar. New York: Norton, 1999. 317-331. Print.

Shelby, Anne. The Adventures of Molly Whuppie and Other Appalachian Folktales. Illus. Paula McArdle. Chapel Hill: U of NC P, 2007. Print.

“Snipe Hunt.” Urban Dictionary. 20 January 2005. Web. 11 November 2014.

“Some Don'ts for Farmers.” Mt. Sterling Advocate 10 Feb. 1904: 4. Kentuckiana Digital Library. Web. 22 May 2012.

“Store Keeps Plum Location.” Lexington Herald-Leader 1 Sept. 1997: C14+. Print.

Straparola, Giovanni Francesco. The Merry Nights of Straparola. Amsterdam: Fredonia Books, 2004. Print.

Stasz, Bird B., Jessica Milch, and James Simpson. "The Enchanted Forest: The Use of Fairy Tales in an Inmate Writing Workshop.” Adult Basic Education 1.3 (1991): 131-7. Print.

Suess, Dr. The Cat in the Hat. New York: Random House, 1985. Print. 
Sutherland, Natalie. "The Fiction in Autobiography: Fantasy, Narrative, and the Discovery of Truth.” Perilous Adventures. 2010. Web. 16 Nov. 2014.

Take 5 Productions and CBS Television Studios, prods. Beauty and the Beast. The CW. 2012. Television.

Tatar, Maria. Off with their Heads!:Fairy Tales and the Culture of Childhood. Princeton, NJ: Princeton UP, 1992. Print.

---, ed. The Classic Fairy Tales. New York: Norton, 1999. Print.

---. "Introduction: Little Red Riding Hood.” Tatar, The Classic Fairy Tales 3-10.

---. "Introduction: Beauty and the Beast." Tatar, The Classic Fairy Tales 50-53.

Troy, Anne. “Appalachia in Children's and Adolescents' Fiction.” Language Arts 54.1 (1977): 55-58, 90. Print.

Todorov, Tzvetan. The Fantastic. Trans. Richard Howard. Ithaca, NY: Cornell UP, 1975. Print.

Tolkien J.R.R. The Hobbit; or, There and Back Again. Boston: Houghton Mifflin Harcourt, 2012. Print.

---. “On Fairy Stories.” The Rivendell Community. 15 Aug. 2014. Web. 16 Nov. 2014. United States Census Bureau. "Greenville (City), South Carolina." State \& County QuickFacts. United States Department of Commerce, 27 June 2013. Web. 12 Aug. 2013.

Uther, Hans-Jörg. “Fairy Tales as a Forerunner of European Children's Literature: CrossBorder Fairy Tale Materials and Fairy Tale Motifs." Narodna umjetnost: hrvatski časopis za etnologiju i folkloristiku 38.1 (2001): 121-132. Print.

---. The Types of International Folktales: A Classification and Bibliography. Helsinki: 
Academia Scientiarum Fennica, 2004. Print.

Warner, Marina. “Mother Goose Tales: Female Fiction, Female Fact?” Folklore 101.1 (1990): 3-25. Print.

Wax, Murray and Rosalie Wax. "The Notion of Magic." Current Anthropology 4.5 (1963): 495-518. JSTOR. Web. 16 Nov. 2014.

Windling, Terri. "Beauty and the Beast.” The Endicott Studio. 2007. Web. 28 March 2014

Winters, Clyde Ahmad. "The Therapeutic Use of the Essay in Corrections." Journal of Correctional Education 44.2 (1993): 58-60. JSTOR. Web. 16 Nov. 2014.

Woolley, Jacqueline D. “Thinking about Fantasy: Are Children Fundamentally Different Thinkers and Believers from Adults?” Child Development 68.6 (1997): 991-1011. JSTOR. Web. 14 Oct. 2014.

Yeats, W.B. Fairy \& Folk Tales of Ireland. New York: Touchstone, 1998. Print. Zipes, Jack. "Breaking the Disney Spell.” Tatar, The Classic Fairy Tales 332-52.

---. Breaking the Magic Spell: Radical Theories of Folk \& Fairy Tales. Lexington, KY: The U of Kentucky P, 2002. Print.

---. Fairy Tales and the Art of Subversion. New York: Routledge, 1983. Print. ---. The Golden Age of Fairy Tales: From the Brothers Grimm to Andrew Lang. Indianapolis. Hackett Publishing Company, Inc., 2013. Print. ---, trans. The Complete Fairy Tales of the Brothers Grimm. New York: Bantam, 2002. Print. 


\section{APPENDIX A: PHOTOGRAPHS OF LEVY AND SURROUNDING AREAS}

This selection offers photographs of many of the locations described in the dissertation that were used as material for settings and characters. While the collection is fiction, many of the details have real-life counterparts.

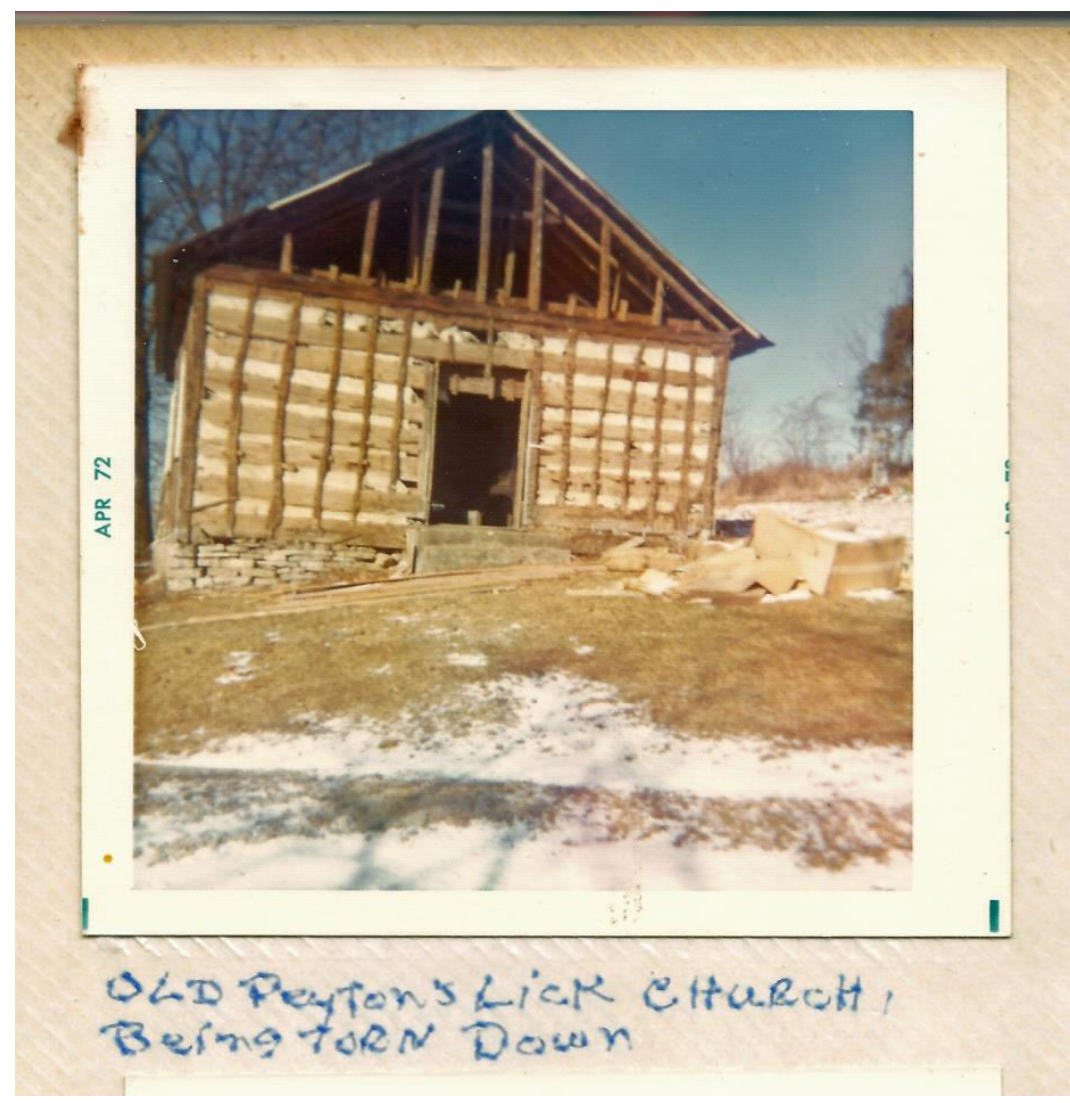

Fig. 1. Old Peyton's Lick Church Building Being Torn Down, personal photograph by Julian Wilson, April 1972. A new building was constructed on site in 1960, and this structure remained standing for several years. This church is near the site of the stories in the collection, even though many of the details are fictionalized. The church population is still currently active. 


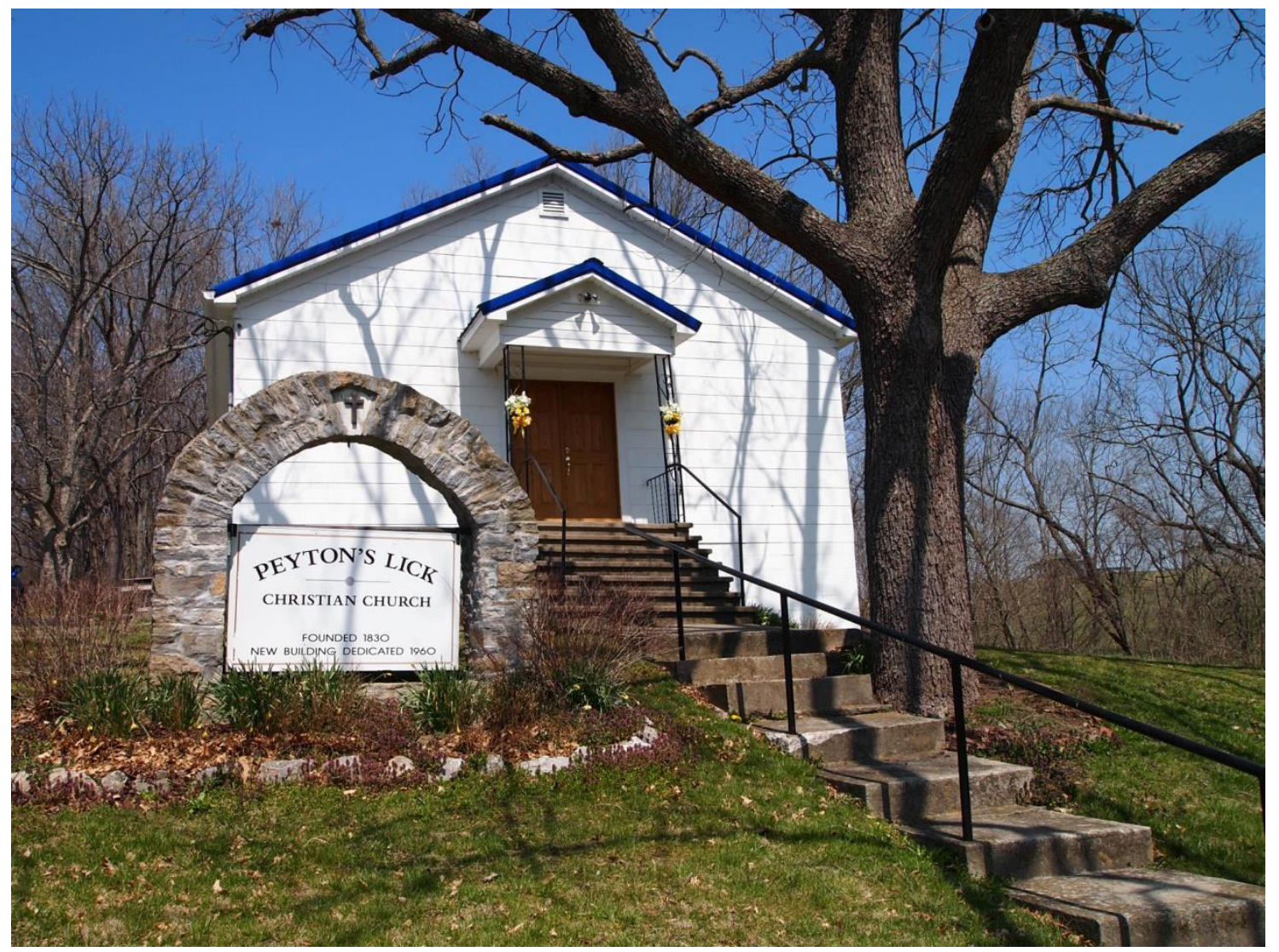

Fig. 2. Peyton's Lick Christian Church, personal photograph by Catherine Leary, 6 April 2013. This is the current structure. Indoor restrooms were installed in the late 1980's. 


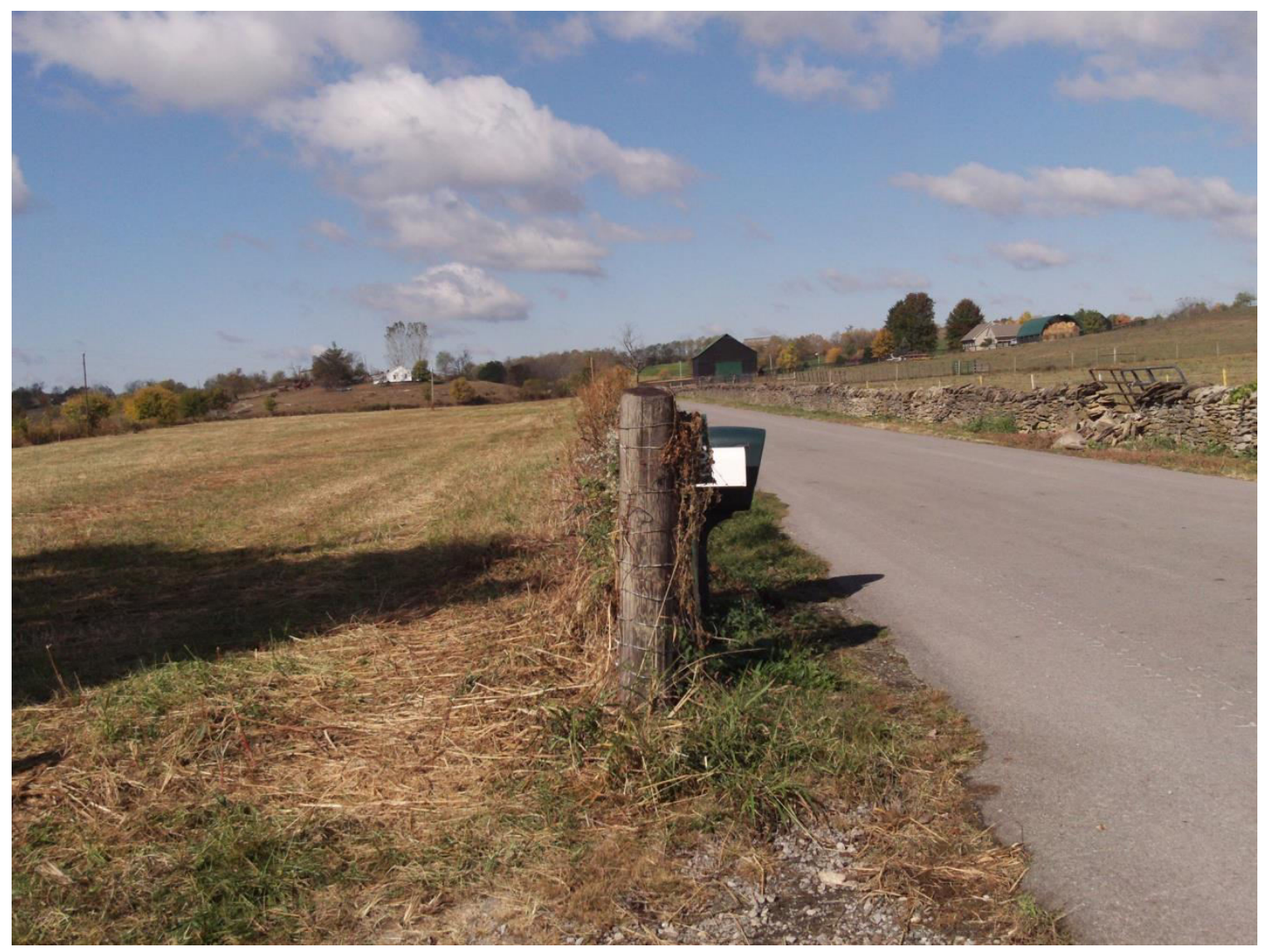

Fig. 3. Picture along Levy Road, personal photograph by Catherine Leary, 14 Oct. 2010. This area is along Levy Road, one of the sources for the collection. This road is several yards from Boone Creek to the left of this image. Normally, it is the only route to and from the homes along this route. Even though the address at these locations now list them as part of Paris, Kentucky, the nearest town is North Middletown. The nearest commercial building is the Levy Store. 


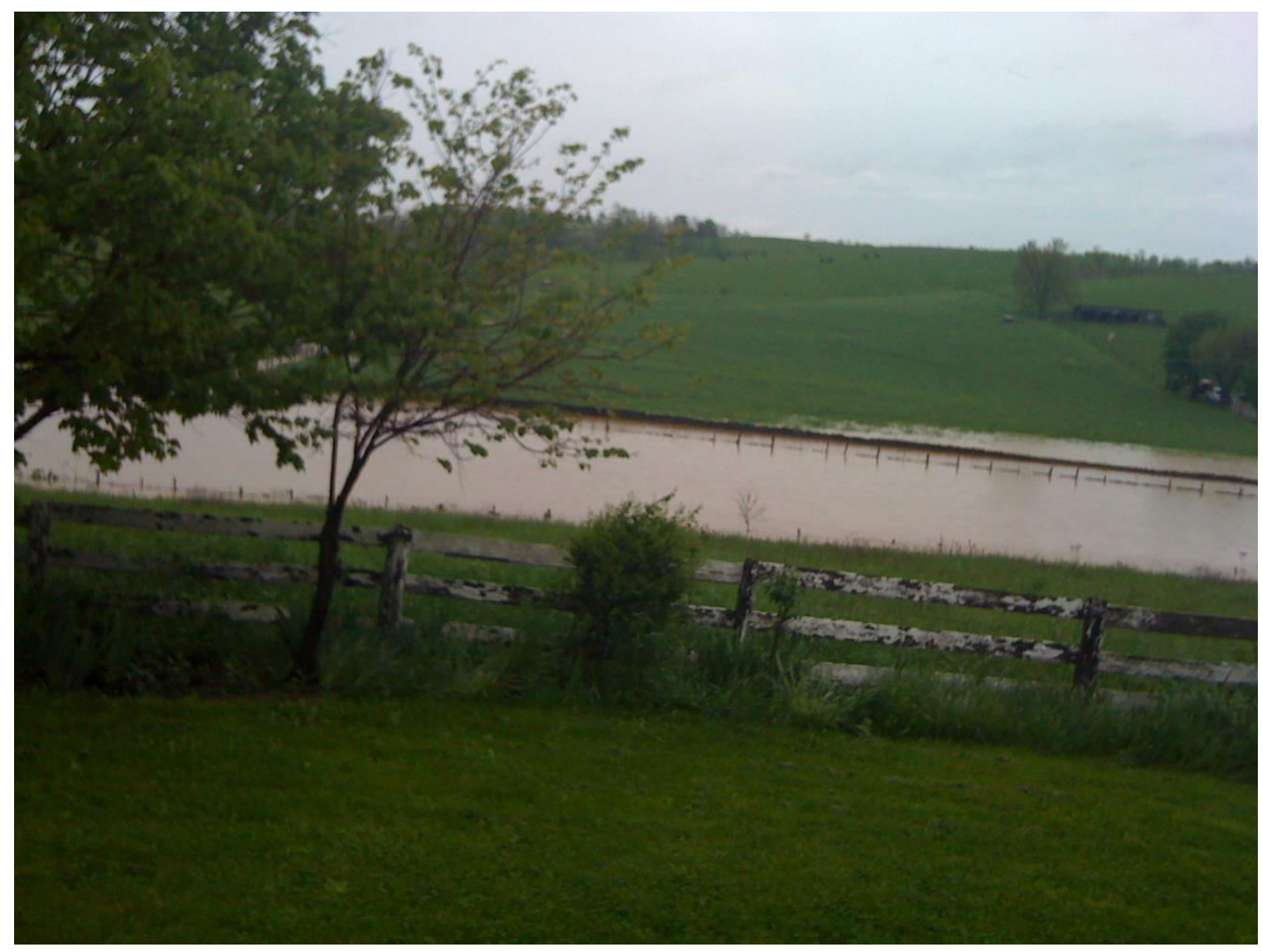

Fig. 4. High Creek Waters Near the Levy, personal photograph by Catherine Leary, 2 May 2010. This is the same road in Fig. 3 after heavy rains. The route becomes impassable, and residents must wait for the waters to recede before they can leave their homes. These floods usually happen on a yearly basis, with some years more severe than others. 


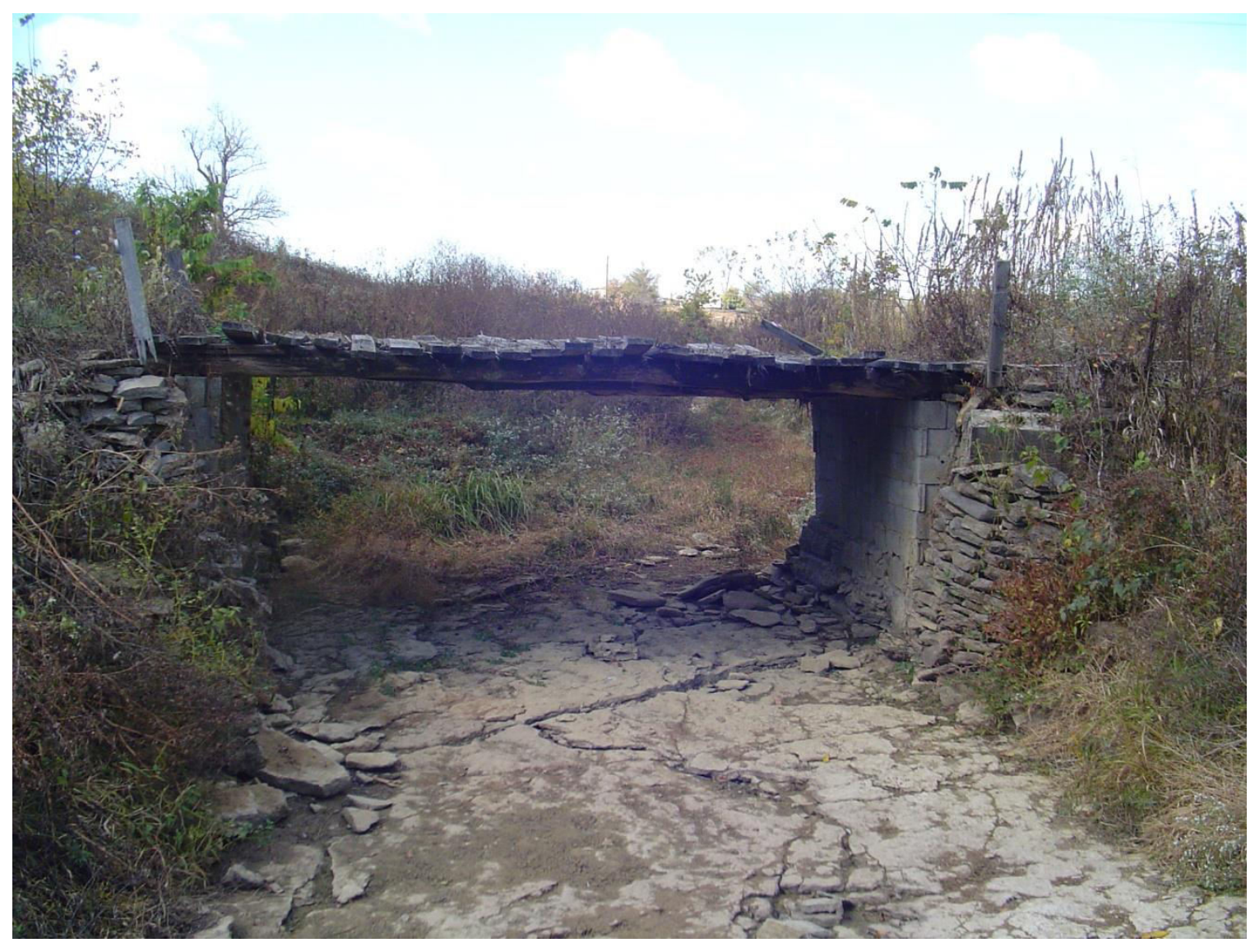

Fig. 5. Dry Boone Creek and Bridge, personal photograph by Catherine Leary, 14 Oct. 2010. This is the creek in Fig. 4 during the drier fall months. The bridge was in use until about 2005, but it had been in use for at least fifty years. A new concrete bridge stands just behind this location. 


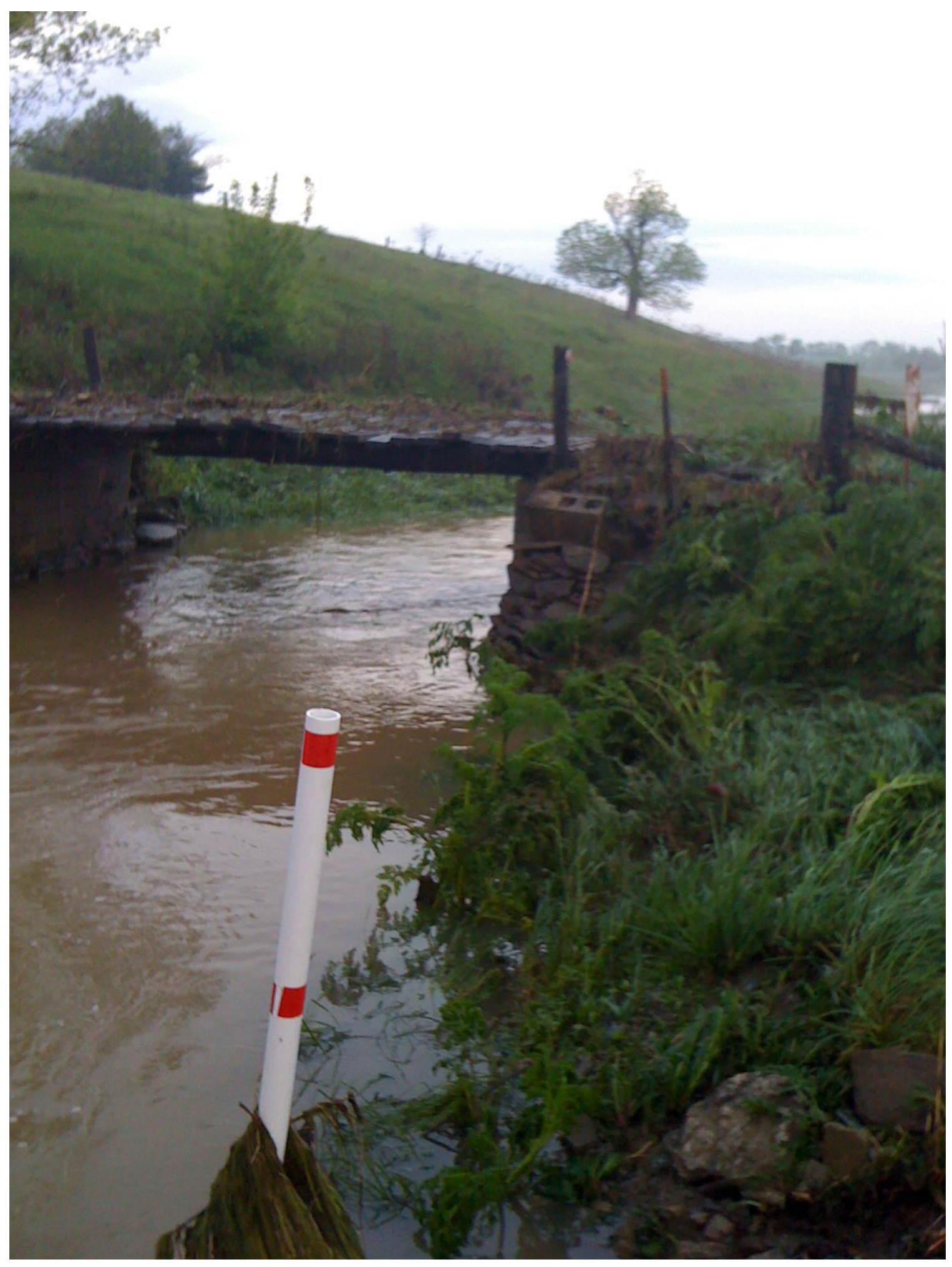

Fig. 6. Bridge Over Boone Creek after Flood, personal photograph by Catherine Leary, 3 May 2010. This is the creek and bridge from Fig. 5 the day after flood waters have receded. Debris from the rushing waters remains trapped in the slates on the bridge. 


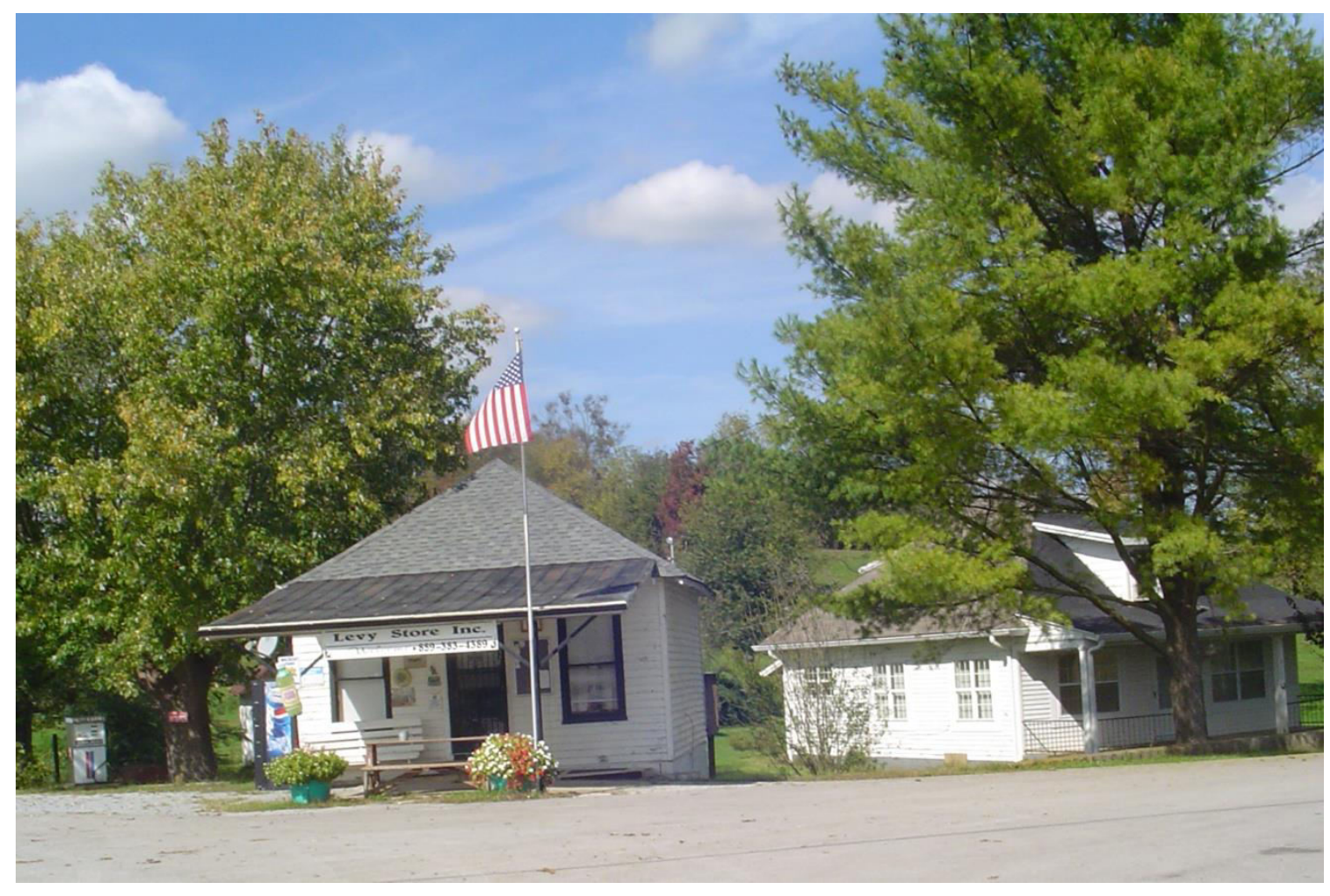

Fig. 7. Levy Store, personal photograph by Catherine Leary, 11 Oct. 2009. This is the store that serves as a model for the store in the collection. Boone Creek runs just behind the photographers location in this image. The store, while near Peyton's Lick, is in a location simply referred to as the Levy or Plum. The store is now closed. 


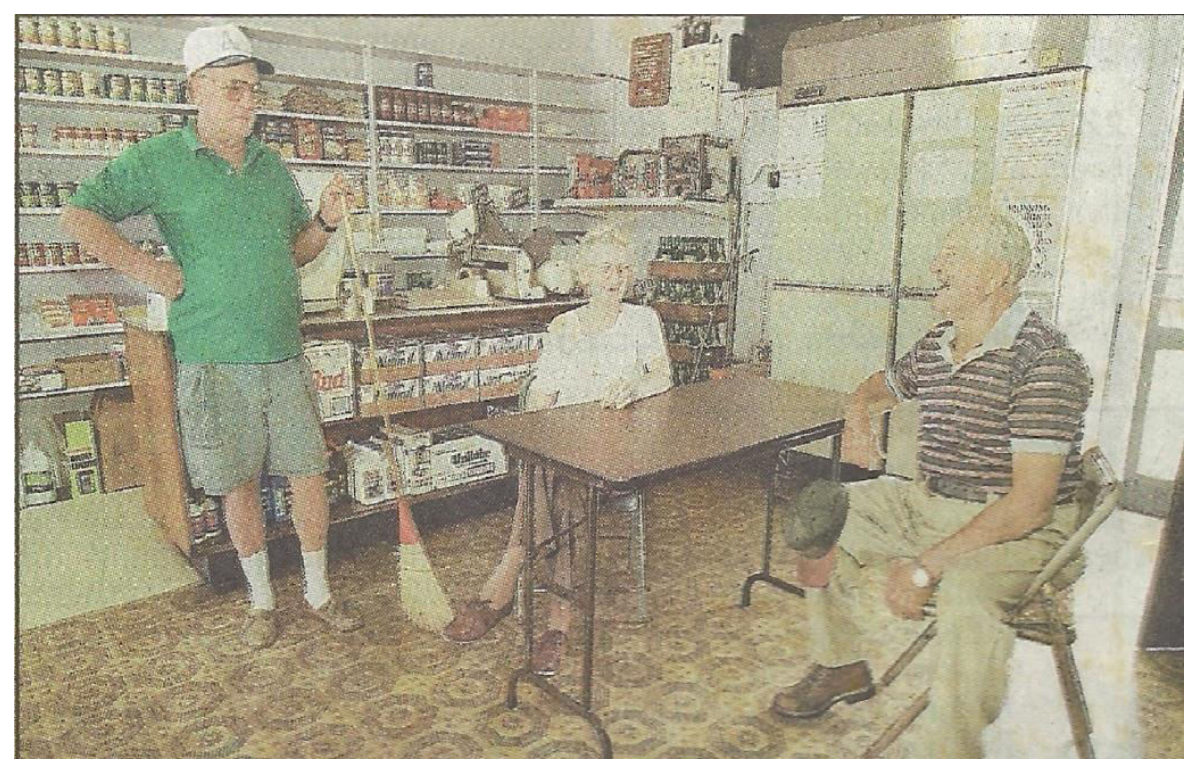

Fig. 8. Interior of the Levy Store, photograph by Zoya Tereshkova, "Store Keeps Plum Location" in Lexington Herald-Leader (1 Sept. 1997). This is a photograph of new store operator (as of 1997) Wilburn Dale (standing) and the previous owners, Ray and Lou Ellen Workman, on which the characters from the frame tale are loosely based. 


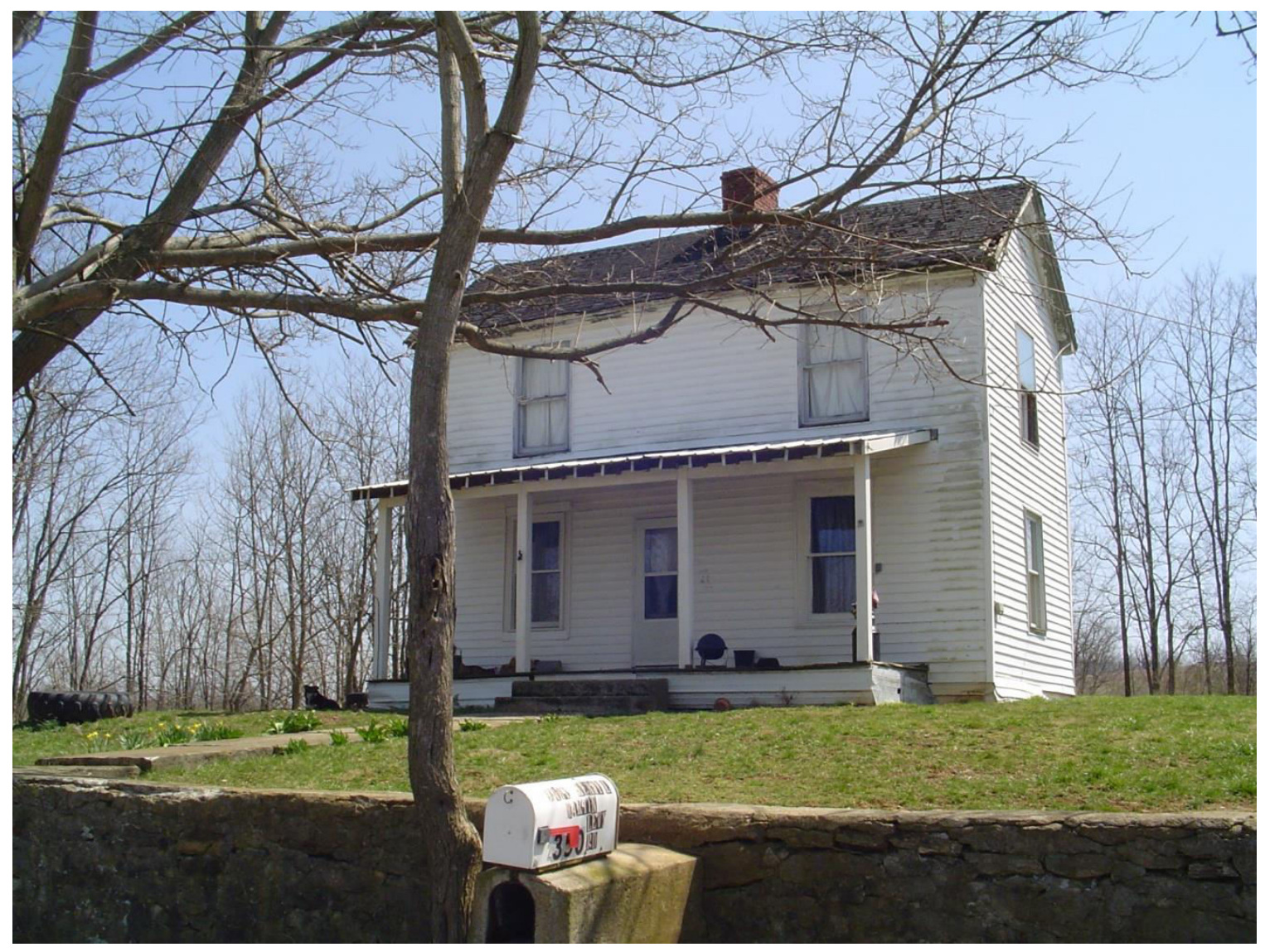

Fig. 9. Sargent House at the Levy, personal photograph by Catherine Leary, 6 April 2013. This image is one of the houses near the Levy and is used as a partial model for the Workmans' home in the collection. 


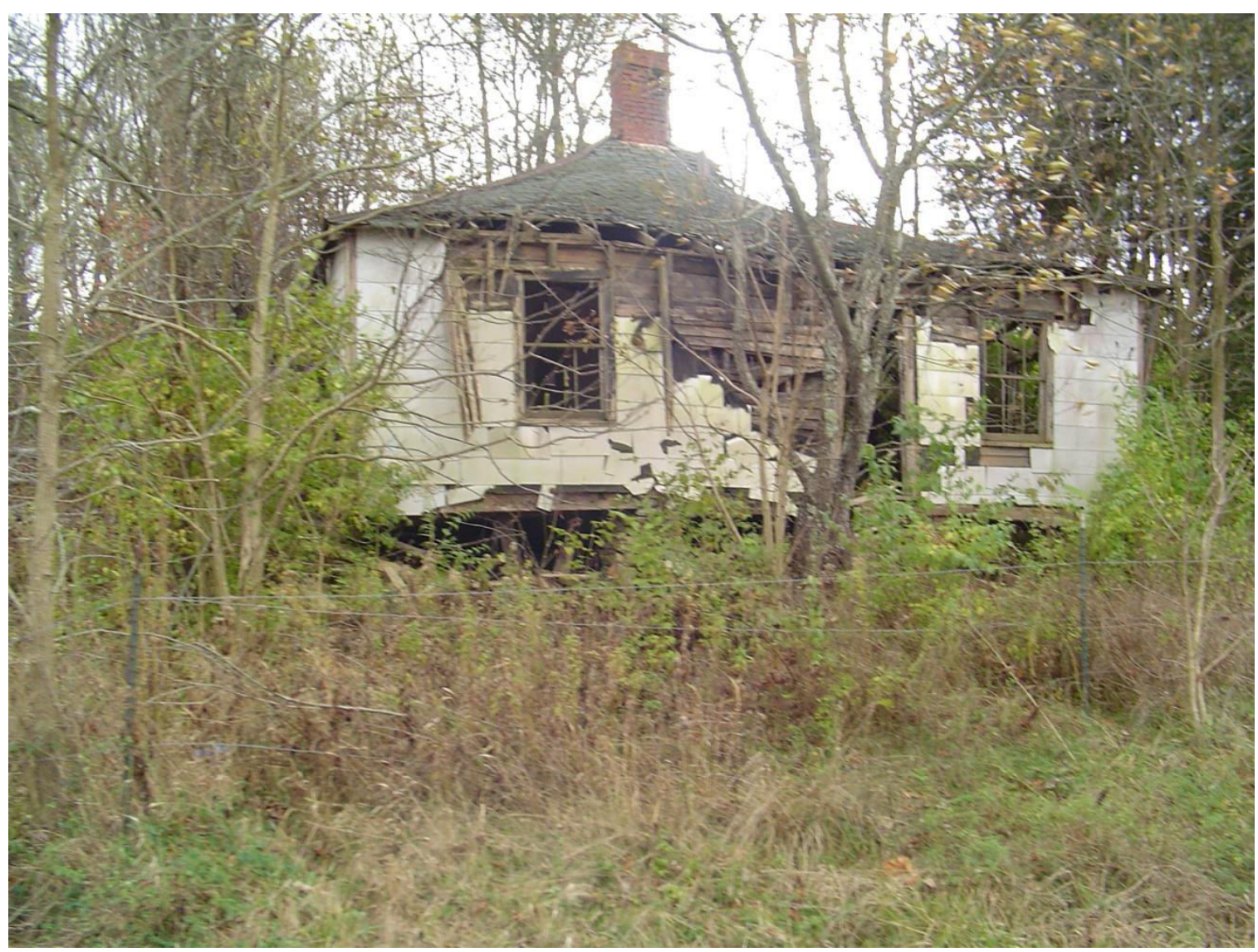

Fig. 10. Hedges Schoolhouse at the Levy, personal photograph by Catherine Leary, 28 Oct. 2010. Though not specifically addressed in the collection, this is the old schoolhouse from the early part of the twentieth-century near the Levy. By the 1950's, students were being sent by bus to more populated areas for school. 


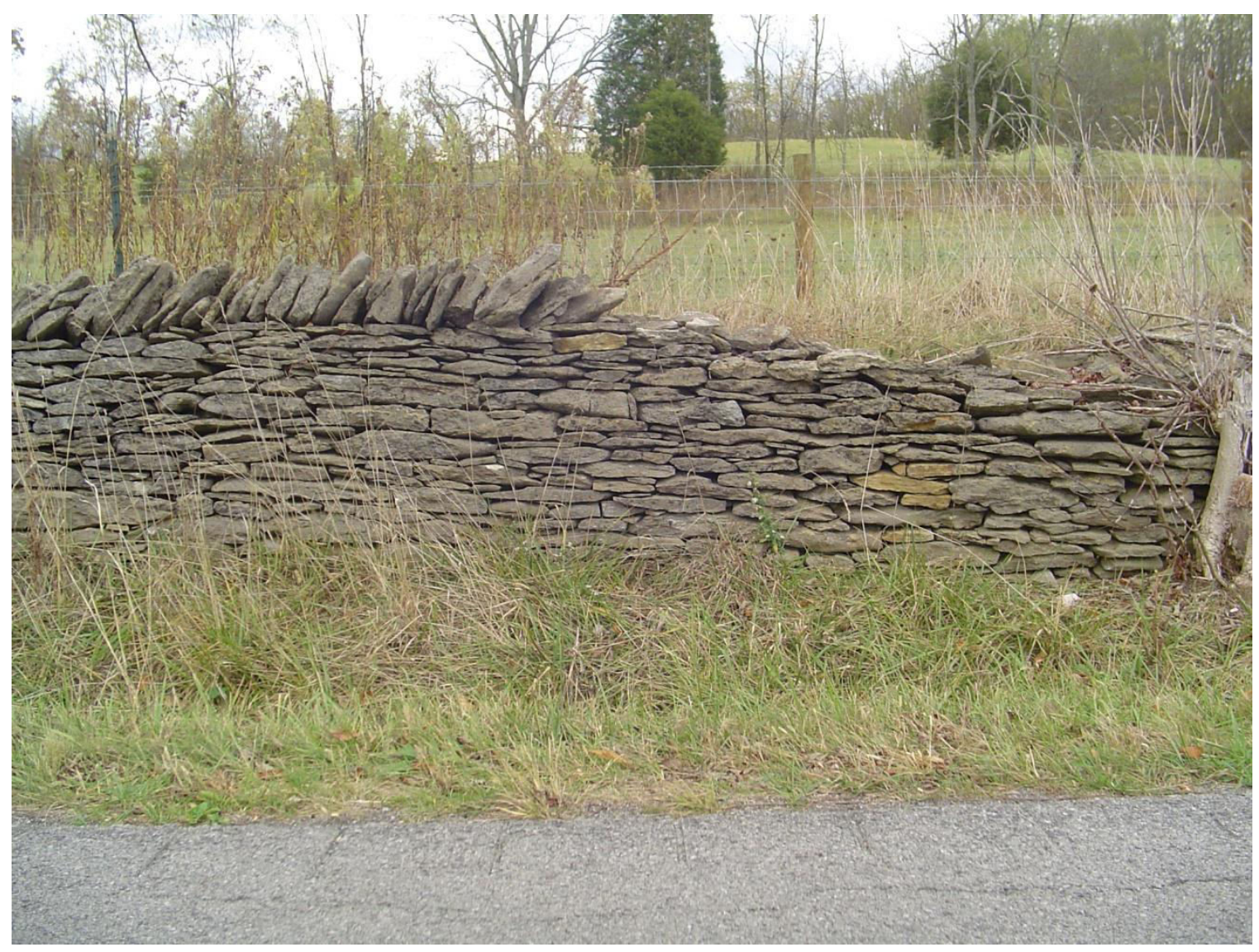

Fig. 11. Rock Fence at the Levy, personal photograph by Catherine Leary, 28 Oct. 2008. This is one of two types of fences common to the area. These rock fences were used to designate property lines and boundaries, while wire fences, as seen in the background, are used to control livestock and wildlife. New rock fences are rarely built now by local residents who now favor more modern building materials, and the one above is like many, in a partial state of collapse. 


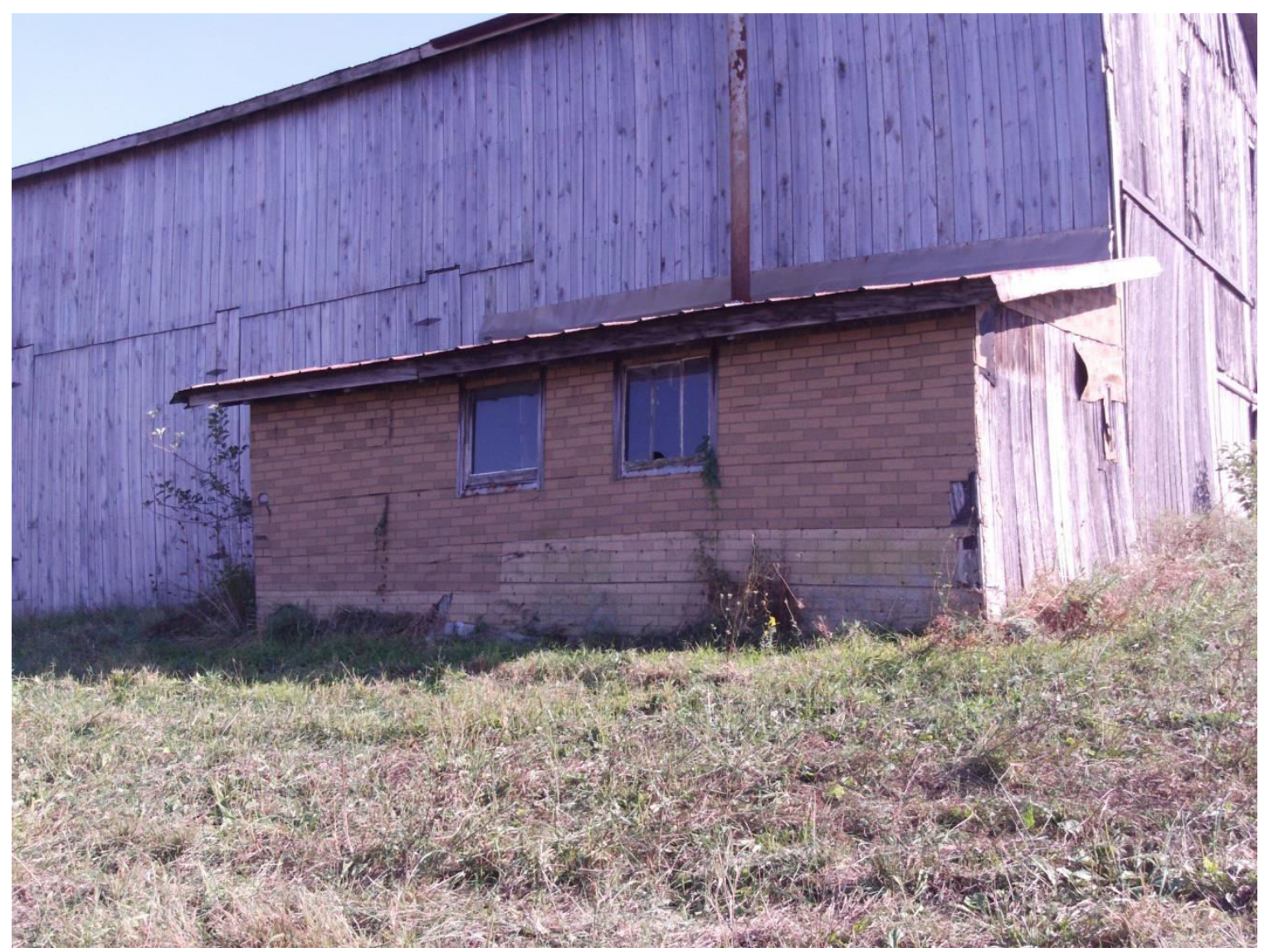

Fig. 12. Tobacco Barn with Stripping Room, personal photograph by Catherine Leary, 30 Sept. 2010. A typical barn in the Levy area built in the early twentieth-century. The larger building holds drying tobacco on large rails, and the smaller side-building is used as a room to strip dried leaves from plants and pack them in bales for delivery to market. Stripping is usually done in the colder months, so the exhaust pipe leads to a small iron stove inside the building. 


\section{APPENDIX B: BIBLIOGRAPHY OF FILMS AND TELEVISION SERIES WITH MAGICAL CONTENT ${ }^{66}$}

Arjun: The Warrior Prince. Dir. Arnab Chaudhuri. Walt Disney Pictures, 2012. Film.

Beastly. Dir. Daniel Barnz. Roadshow, 2011. Film.

Beauty and the Beast. Perf. Ron Perlman and Linda Hamilton. Prod. Witt/Thomas

Productions. CBS, 1987-1990. Television.

Beauty and the Beast. Dir. Siegmund Lubin. Lubin Manufacturing Company, 1903. Film.

Bridge to Terabithia. Dir. Gabor Csupo. Walden Media, 2007. Film.

Clash of the Titans. Dir. Louis Leterrier. Warner Bros., 2010. Film.

Disney, Walt. Beauty and the Beast: Diamond Edition. Walt Disney Studios, 2010. DVD.

Frozen. Dir. Chris Buck and Jennifer Lee. Walt Disney Studios, 2013. Film.

Grimm. Perfs. Russell Hornsby, Bitsie Tulloch, and David Giuntoli. Universal

Television, 2011-2014. Television.

Grimm's Snow White. Dir. Rachel Goldenberg. The Asylum, 2012. Film.

Hansel \& Gretel Get Baked. Dir. Duane Journey. Uptik Entertainment, 2013. Film.

Hansel \& Gretel: Warriors of Witchcraft. Dir. David DeCoteau. Rapid Heart Pictures, 2013. Film.

Hansel \& Gretel: Witch Hunters. Dir. Tommy Wirkola. 2013. Film.

\footnotetext{
${ }^{66}$ Films and television series are recently released, some from as early as 2001, but most from 2008 and after. Story types include fantasy, myth, legends, and fairy tales, with a heavy emphasis here on fairy tale variants.
} 
Ivan the Incredible. Dir. Michael Hegner. Crone Film Produktion A/S, 2012. Film. Jack the Giant Killer. Dir. Mark Atkins. Perfs. Jamie Atkins and Robert Boyle. The Asylum, 2013. Film.

Jack the Giant Slayer. Dir. Bryan Singer. New Line Cinema, 2013. Film.

Jeremy Fink and the Meaning of Life. Dir. Tamar Halpern. Fink Films, 2011. Film.

Life of Pi. Dir. Ang Lee. Fox 2000 Pictures, 2012. Film.

Merlin. Perfs. John Hurt, Colin Morgan, and Bradley James. Shine and BBC Wales, 2008-2014. Television.

Mirror Mirror. Dir. Tarsem Singh Dhandwar. Perfs. Lily Collins and Julie Roberts. Relativity Media, 2012. Film.

Monsters, Inc. Dirs. Pete Docter, David Silverman, and Lee Unkrich. Walt Disney Pictures, 2001. Film.

Monsters University. Dir. Dan Scanlon. Walt Disney Pictures, 2013. Film.

Neverland. Perfs. Keira Knightly, Charlotte Atkinson, and Anna Friel. SyFy, 2011. Television.

Once Upon a Time. Perfs. Ginnifer Goodwin, Jennifer Morrison, and Lana Parilla. ABC Studios, 2011-2014. Television.

Phoebe in Wonderland. Dir. Daniel Barnz. Silverwood Films, 2008. Film. Puss in Boots. Dir. Chris Miller. Dreamworks Animation, 2011. Film.

Red Riding Hood. Dir. Catherine Hardwicke. Warner Bros., 2011. Film. Season of the Witch. Dir. Dominic Sena. Atlas Entertainment, 2011. Film. Shrek 2. Dirs. Andrew Adamson, Kelly Asbury, and Conrad Vernon. Dreamworks, 2004. Film. 
Shrek the Musical. Dirs. Michael John Warren and Jason Moore. Dreamworks Animation, 2013. Film.

Shrek the Third. Dirs. Chris Miller and Raman Hui. Dreamworks Animation, 2007. Film. Snow Queen. Dirs. Vlad Barbe and Maksim Sveshnikov. Wizart Animation, 2012. Film. Snow White and the Huntsman 2. By David Koepp. Universal Pictures, 2015. Film.

Snow White and the Huntsman. Dir. Rupert Sanders. Universal Pictures, 2012. Film.

Take 5 Productions and CBS Television Studios, prods. Beauty and the Beast. The CW. 2012. Television.

Tales of the Night. Dir. Michel Ocelot. Nord-Ouest Productions, 2011. Film.

The Avengers. Dir. Joss Whedon. Marvel Studios, 2012. Film.

The Chronicles of Narnia: Prince Caspian. Dir. Andrew Adamson. Walt Disney Pictures, 2008. Film.

The Chronicles of Narnia: The Voyage of the Dawn Treader. Dir. Michael Apted. Fox 2000 Pictures, 2010. Film.

The Extraordinary Adventures of Adèle Blanc-Sec. Dir. Luc Besson. EuropaCorp, 2010. Film.

The Hobbit: An Unexpected Journey. Dir. Peter Jackson. New Line Cinema, 2012. Film. The Hobbit: Desolation of Smaug. Dir. Peter Jackson. New Line Cinema, 2013. Film. The Hobbit: There and Back Again. Dir. Peter Jackson. New Line Cinema, 2014. Film. The Tale of Despereaux. Dirs. Sam Fell and Robert Stevenhagen. Universal Pictures, 2008. Film.

Thor. Dir. Kenneth Branagh. Paramount Pictures, 2011. Film.

Thor: The Dark World. Dir. Alan Taylor. Marvel Studios, 2013. Film. 
Tinkerbell. Dir. Bradley Raymond. DisneyToon Studios, 2008. Film.

Wrath of the Titans. Dir. Jonathan Liebesman. Warner Bros., 2012. Film. 


\section{CURRICULUM VITAE}

NAME:

ADDRESS:

DOB:

\section{EDUCATION}

\& TRAINING:
James Leary

200 Inglewood Drive

Pittsburgh, PA 15228

Richmond, Kentucky - July 11, 1977

B.A., English

Eastern Kentucky University

1997-2001

B.A., Spanish

Eastern Kentucky University

1997-2001

M.A., English (Creative Writing)

University of Louisville

2003-2005

AWARDS:

Faculty Recognition Award

Jefferson Community and Technical College 2013

Sara-Jean McDowell Creative Writing Award University of Louisville 2004

College of Arts and Sciences High Distinction in Spanish Award Eastern Kentucky University

2001 and 2000 
Commonwealth Scholarship

Eastern Kentucky University

1998-2001

Presidential Scholarship

Eastern Kentucky University

1997-98

"Best Poem of the Year"

The Eagle's Flight, for "On Tiny Graves"

1996

Bausch and Lomb National Science Award Winner

1995

National Merit Scholarship Winner

1995

Kentucky Governor's Scholar

1994

PUBLICATIONS: WAG Anthology

"The Consequences of Beastly Behavior" Short Fiction

2013

Here and There

"Sometimes a Carved Fruit or Vegetable Isn't Enough"

Short Fiction

2008

Grab-a-Nickel

"Untitled" Poem

Spring/Summer 2002

The Chaffin Journal

"the moon rose and dipped over poseidon's oceans" Poem 2000

Aurora

"Missing You," "Dancing Gypsies," and "It's Quiet in the Factory" Poetry

1999 
The Eagle's Flight

"On Tiny Graves" (Poem)

1996

CONFERENCES Moderator, Identity through History, Community College

Humanities Association National Conference, Louisville, Kentucky, 2013.

Panelist, Short Fiction Workshop Leader, Second Annual Jefferson Community and Technical College Writers' Retreat, Louisville, Kentucky, 2013.

Moderator, Writing Center Roundtable, Community College Humanities Association Regional Conference, Louisville, Kentucky, 2012.

Panelist, "Fairy Tales in the Composition Classroom." Kentucky Association of Developmental Education Conference, Bowling Green, Kentucky, 2012.

Panelist, Short Fiction Workshop Leader, Jefferson Community and Technical College Writers' Retreat, Louisville, Kentucky 2012.

Panelist, Creative Writing Presentation, "Big Red Cap," Association of Humanities Academics Conference: The Phoenix Effect: Regeneration, Rebirth, \& Reformation, Louisville, Kentucky, 2012.

Panelist and Featured Reader, Creative Writing Presentation, Readings of Selected Poetry. Eastern Kentucky University Association of English Majors Annual Conference, Richmond, Kentucky, 2001.

Panelist, "A Dramatization of Selections from Kate Chopin's The Awakening." National Collegiate Honors Conference, Washington, D.C., 2000.

PROFESSIONAL SOCIETIES Community College Humanities Association 2011-2013

Kentucky Association of Developmental Education 2012-13 
Two Year College Association 2011-2013 